OHARA AUGUSTO

\title{
METABOLISMO DE XENOBIÓTICOS: FORMAÇÃO DE RADICAIS DE CARBONO E SUAS IMPLICAÇÕES TERAPÊUTICAS E TOXICOLÓGICAS
}

\footnotetext{
Tese de Livre Docência apresentada ao Departamento de Bioquímica do Instituto de Quimica da Universida de de são paulo.
} 
To M.D. Arsedo,

as an acknowledgment for the crazy love, as an excuse for the rational end. 
Agradeço:

A todos aqueles que me propriciaram condições de aprendizagem e crescimento, particularmente a:

Roséli P. Schnetzler

Oswaldo Augusto

Anna M. Augusto

Giuseppe Cilento

P.R. Ortiz de Montellano

Alex Quintanilha

Kent L. Kunze

Richard C. Zimler

Roberto Casadej de Baptista

Iracema Fagá

Beatriz R. Castellani

Shirley Schreier

Etelvino J.H. Bechara

Lester Packer

Ao apoio financeiro da Fundação de Amparo à Pesquisa do Estado de São Paulo (FAPESP), do Conselho Nacional de Desenvolvimento Cientifi co e Tecnológico (CNPq) e da Financiadora de Estudos e Projetos (FINEP). 
$\begin{array}{ll}\text { ABREVIATURAS } & 1\end{array}$

1. INTRODUÇÃO 2

1.1. Apresentação 2

1.2. Metabolismo de Xenobióticos: Visão Geral 3

1.3. Citocromo $\mathrm{P}_{450}$ : Propriedades e Mecanismo de Catálise 11

1.4. Deteção de Radicais Livres em Sistemas Biológicos: Método do Captador de Spin 22

2. MATERIAIS E METODOS 35

2.1: Materiais 35

2.2. Métodos 36

a. Microssomos Hepáticos 36

b. Dosagem da Proteina Microssomal 36

C. Estudos com Citocromo $\mathrm{P}_{450}$ "in vitro" 36

d. Análise de Metabólitos 37

e. Purificação e Caracterização do Aduto de $\begin{array}{ll}\text { Heme } & 39\end{array}$

f. Estudos de Ressonância Paramagnética Eletrônica 40

g. Purificação e Caracterização do Aduto $\begin{array}{ll}\text { Etil-POBN } & 41\end{array}$

h. Purificação e Caracterização do Aduto de POBN derivado da Fenelzina 42

3. RESULTAdOS E DISCUSSÃO 45

3.1. Efeito dos Captadores de Spin sobre o Me tabolismo Microssomal: Isolamento Bioló- 
lógico do Aduto Etil-POBN

a. Efeito dos Captadores de Spin Sobre o Metabolismo Microssomal

b. Ligação dos Captadores de Spin ao Citocro mo $\overline{\mathrm{P}}_{450}$

c. Isolamento e Propriedades Espectroscópicas do Aduto Radical Etil-PoBN

d. Conclusões

3.2. Formação de Radicais de Carbono Durante - Metabolismo da Fenelzina: Implicações Toxicológicas e Terapêuticas

a. Metabólitos da Fenelzina

b. Destruição do Citocromo $\mathrm{P}_{450}$ e sua Relação com a Formação de Metabólitos

c. Estrutura do Produto da Inatìvação do Citocromo $\mathrm{P}_{450}$ pela Fenelzina

d. Formação de Radicais Livres Durante o Metabolismo da Fenelzina

e. Identificação do Radical Aduto de POBN obtido a partir da Fenelzina

f. Implicações Terapêuticas e Toxicológicas

4. CONCLUSOEES GERAIS.

5. SUMARIo k caluno.

6. SUMMARY

7. REFERENCIAS BIBLIOGRAFICAS 
ABREVIATURAS

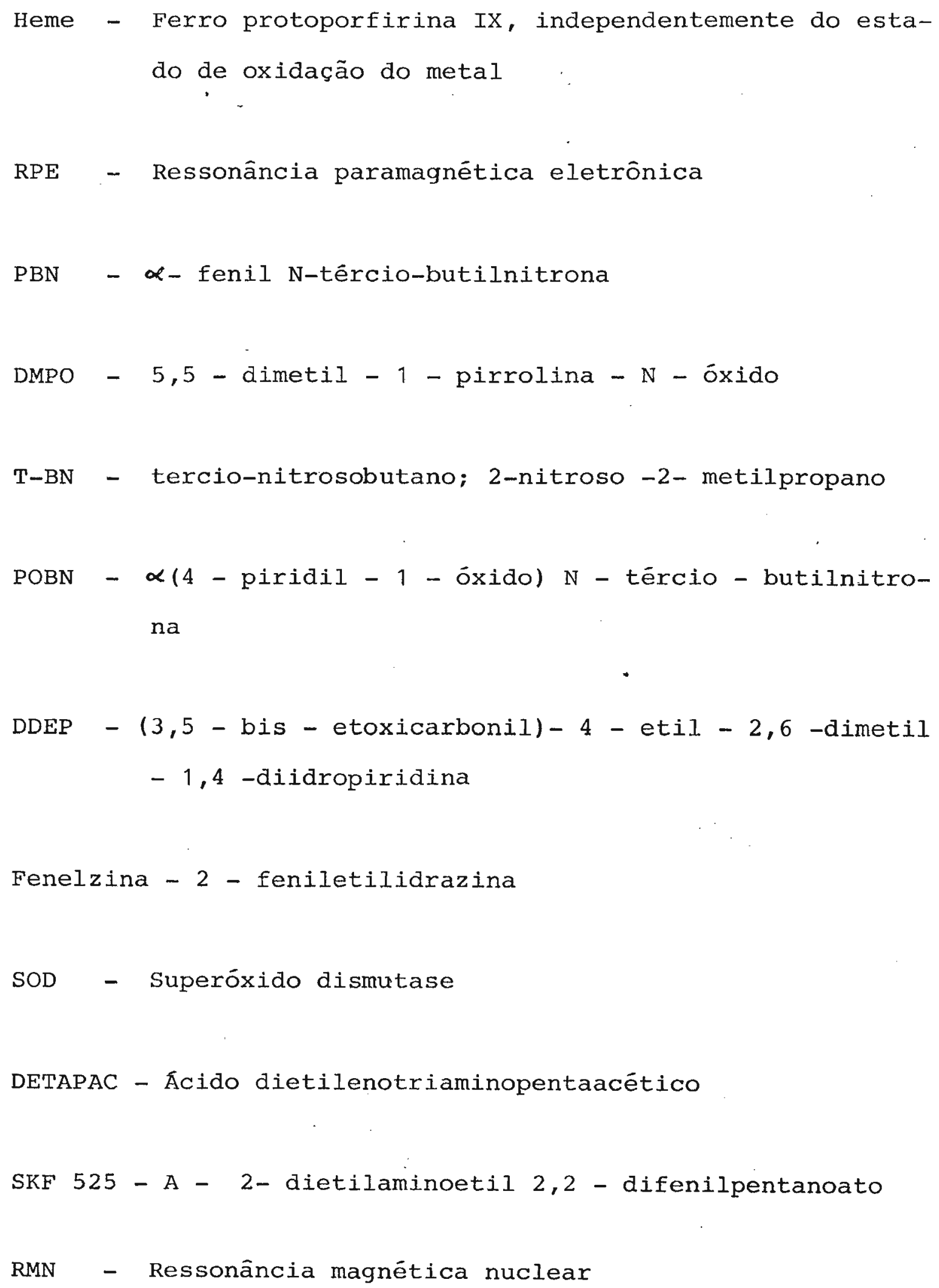




\section{INTRODUÇÃO}

\section{1. APRESENTAÇÃO}

Nos ültimos anos temos nos dedicado ao estudo da formação de intermediários reativos durante o metabolismo de xe nobióticos. Nosso maior interesse vem sendo a deteç̧ão de ra dicais livres centrados no carbono e o estabelecimento de seus mecanismos de interação com sistemas biológicos, pelo possível envolvimento dessas espécies nos efeitos terapêuticos e/ ou tóxicos associados aos xenobióticos.

A maioria dos estudos sobre as interações entre radicais livres e sistemas biológicos tem se concentrado nos aspectos benéficos e tóxicos dos radicais de oxigênio.Tal ten dência é facilmente explicável pelo papel central do oxigênio na vida dos organismos aeróbicos e pela demonstração inequívo ca da formação daqueles radicais em sistëmas biológicos.Já os radicais livres centrados no carbono tem sido de dificil detecção durante o metabolismo normal e, embora tenham sido su geridos hã muito tempo como intermediārios na degradação de xenobiōticos, só mais recentemente tem sido diretamente demons trados. Um fator importante para essa comprovação, tem sido a aplicação da técnica do captador de spin (spin trapping) em sistemas biológicos. Embora a técnica apresente os problemas comuns às abordagens experimentais indiretas, ela pode fornecer valiosas informações quando criteriosamente empregada e, complementada por outros dados.

Acreditamos que demos uma contribuição importante para o emprego judicioso dessa técnica em estudos do metą 
bolismo microssomal. Pudemos então, não só demonstrạ a formą ção de radicais de carbono durante o metabolismo de alguns xenobióticos, como, secundados por outras abordagens experimentais, identificá-los e estabelecer os seus mecanismos de interação com hemoproteinas. Nesta tese, pretendemos apresen tar essa nossa contribuição e uma de suas aplicações, inserin do-a no contexto geral dos processos biológicos de destoxicação e toxicação.

\subsection{METABOLISMO DE XENOBIOTICOS: VISÃO GERAL}

O termo xenobiótico vem sendo utilizado para se referir a qualquer composto químico, natural ou manufaturado, que seja exógeno ào metabolismo normal do organismo. Embora o termo tenha sido introduzido recentemente, pode-se concluir que o conhecimento dos efeitos das interações entre substâncias exógenas e sistemas biológicos remonta aos primórdios da civilização, logo que o homem toma contacto com toxinas natu rais de origem vegetal ou animal (1).

Apesar de sua longa história, o estudo da intera ção entre compostos químicos e sistemas biológicos continua importantíssimo na atualidade, quando a ênfase desloca-se das substâncias naturais para o incomensurável número de compostos sintetizados e utilizados pela sociedade industrial. São inúmeras as implicações sociais e econômicas da compreensão das bases moleculares dessas interações; somente ela poderá forne cer abordagens racionais para o desenvolvimento de remédios, herbicidas e inseticidas que sejam mais efetivos e especifi- 
cos em suas ações.

A busca da toxidez seletiva enfatiza a importância de estudos paralelos sobre os processos de destoxicação e toxicação, cujas diferenças entre as espécies seria convenien te explorar. 'Tambēm, numa mesma espécie, a relação existente entre a desintoxicação e a intoxicação é bastante estreita, como tão bem documentado para drogas que podem exercer efeitos terapêuticos ou efeitos tóxicos, dependendo da dosagem e outras variáveis $(2,3)$.

De fato, a interação entre os xenobióticos e os sistemas biológicos que os transformam é irônica. A ação do sistema de destoxicação é potencialmente um perigo para os organismos vivos. Sua função normal, protetora, pode ser sub vertida e o resultado pode ser o dano reversivel ou irreversí vel.

A maioria dos xenobióticos que atingem os tecidos são lipofilicos, uma propriedade que permite a sua pene tração através das regiões lipídicas das membranas e seu subsequente transporte nos fluidos biológicos por lipoproteínas. Uma vez no organismo, tais compostos podem permanecer inal terados, sofrer transformações espontāneas, ser enzimaticamen te metabolizados. Essas últimas transformações, catalisadas por enzimas relativamente não especificos, são as que mais frequentemente ocorrem, constituem o metabolismo dos xenobióticos e estão divididas em duas fases (1-3).

Durante a fase I, constituida principalmente pe las oxidações microssomais, um grupo polar é introduzido na molécula o que aumenta a solubilidade em água e transforma o 
xenobiótico num substrato mais adequado para as reações da fạ se II.

Essas são reações de conjugação, nas quais o xenobiótico ou um seu metabólito da fase I, contendo grupos funcionais como hidroxila, amino, carboxila, epóxido ou halogênio, liga-se covalentemente a aceptores endógenos. Desses, os mais importantes são a glutationa, o ácido uridina difosfa to glicurônico, a adenosina $3^{\prime}$ - fosfato - 5' - fosfossulfato e a acetil coenzima $A$, destacando-se a glutationa que está presente na maioria dos tecidos a uma concentração aproximada de $5 \mathrm{mM} \mathrm{(4).}$

Os produtos das reações na fase II são; em geral, mais polares, menos lipossolúveis, menos tóxicos e mais facil mente excretáveis pelo organismo via, principalmente, os sis temas urinário e biliar $(1-4)$.

Como descrita acima, essa séqû́ncia de reações é um mecanismo de destoxicação. Contudo, em determinadas condicões, esses processos que seriam protetores, convertem os xe nobiōticos em derivados mais tóxicos que eles próprios. Estão bem documentados na literatura casos em que os efeitos tóxicos, teratogênicos, necróticos, mutagênicos e carcinogênicos de certos compostos resultam da ativação metabólica de grupa mentos funcionais inócuos a intermediārios extremamente reati vos e lesivos (5).

Um exemplo é apresentado no Esquema 1 para $\circ$ me tabolismo do acetaminofeno, um analgésico amplamente utilizado $(6,7)$. Em altas doses, esse composto induz necrose hepátí ca em animais experimentais e no homem, sendo a toxidez media 
da por um metabólito reativo, formado durante a sua oxidação microssomal.

A baixas doses, o intermediário reativo pode ser eficientemente destoxicado pela glutationa; em doses altas ou em outras coǹdìções intracelulares, nas quais a concentração da glu tationa não seja suficiente para a reação de conjugação, o intermediário pode reagir com outras biomoléculas levando à necrose celular (Esquema 1).

o exemplo apresentado no Esquema 1 enfatiza dois pontos importantes para os nossos interesses de pesquisa e pa ra o desenvolvimento desta introdução. O primeiro é a estreita relação entre os processos de destoxicação e os de toxicação,o que torna o estudo do metabolismo de um determinado xenobiótico uma necessidade para a compreensão, ao nível moleculár, de seus possíveis efeitos tóxicos. O segundo é que intermediários reạ tivos, formados, em geral, durante a oxidação microssomal,são normalmente postulados como os desencadeadores de efeitos tóxicos e/ou terapêuticos; contudo, a alta reatividade desses interme diārios tem dificultado a sua identificação e, consequentemen te, o estabelecimento das bases moleculares de suas ações. Ape sar dos problemas experimentais envolvidos, em muitos casos tem sido possivel identificar os metabólitos reativos, examinar as suas interações com biomoléculas e caracterizar os tores celulares que facilitam e modulam tais interações.o que fica evidente é que muitos desses intermediārios reativos são radicais livres formados durante o metabolismo microssomal. Passaremos, assim, a abordar o sistema microssomal de transporte de elétrons e os problemas envolvidos na deteção de rađicais livres em sistemas biológicos. 


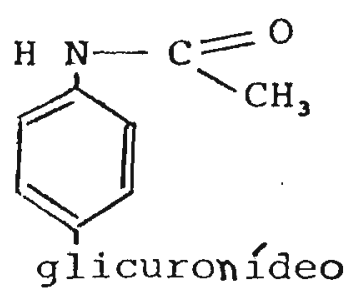

Fase II

(Destoxicação)
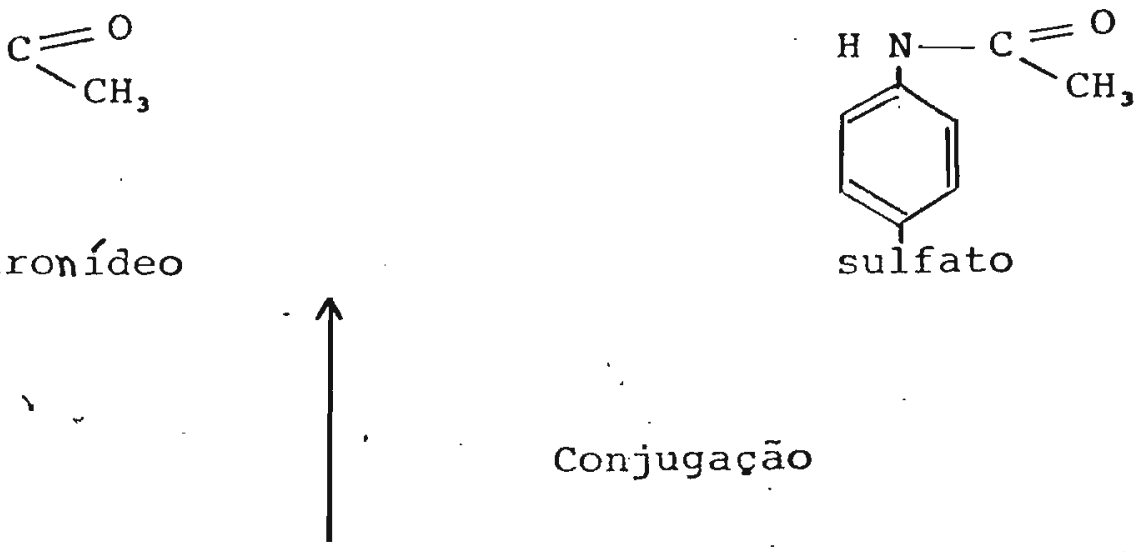

Conjugação<smiles>CC(=O)Nc1ccc(O)cc1</smiles>

Acetaminofeno

Fase I

(Destoxicação e Toxicação)
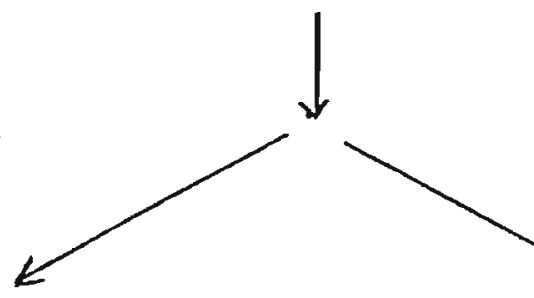

\section{Toxicacãol}
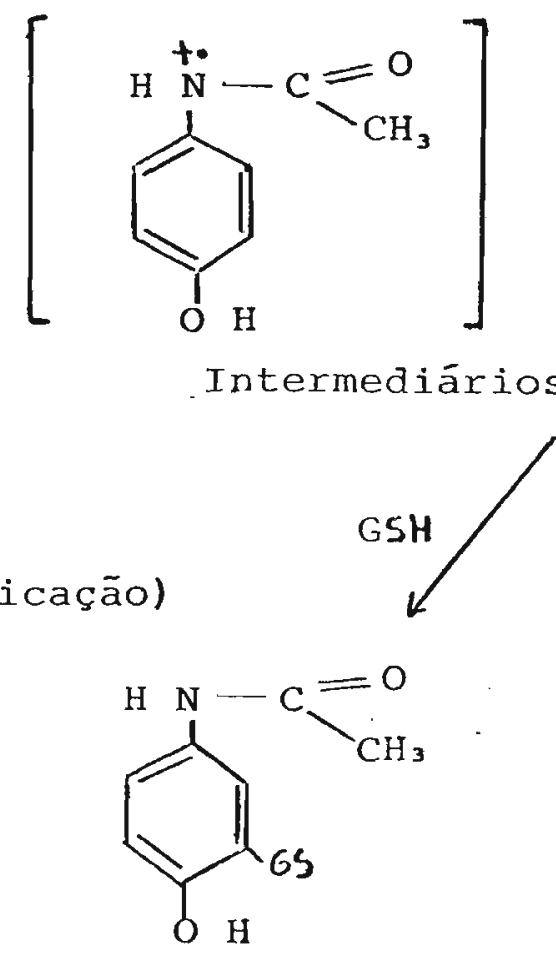

Ligação Covaleńte a Biomoléculas

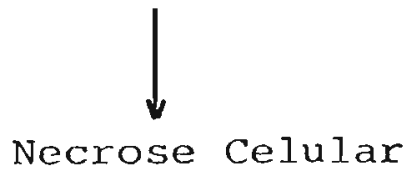

(ESQUEMA 1) 
1.3. SISTEMA MICROSSOMAL DE TRANSPORTE DE ELETRONS

o retículo endoplasmático é uma rede contínua de membranas lipoproteicas que se extende da membrana plasmática ao núcleo e mitocondria da célula. Suas funções biológicas in cluem o metabolismo de esteróides, ácidos graxos e xenobióticos, a sintese de colesterol, fosfolipideos, triglicerídeos e proteinas, bem como o transporte desses produtos. No hepatóci to de rato pode-se estimar que $19 \%$ da proteina, $48 \%$ dos fosfolipídeos e 58\% do RNA da célula estão associados a essa or ganela (8).

Contrariamente a outras organelas como mitocondria, cloroplastos e 1isossomos, o retículo endoplasmático sofre extensiva ruptura por homogeneização formando vesículas fechadas, os chamados microssomos. Estes podem ser $\underline{i}$ solados por vários métodos como precipitação com $\mathrm{CaCl}_{2}$, cro matografia de coluna e a clássica centrifugação diferencial, que continua sendo o mëtodo mais empregado (8).

o reticulo endoplasmático da maioria dos te cidos, consequentemente os microssomos dele derivados,con tém flavoproteinas e citocromos firmemente ligados à mem brana que funcionam em reações de transporte de elétrons dependentes de oxigênio e coenzimas piridinicos reduzidos (9). Uma visão simplificada dessas reações aparece no Esquema 2, e as enzimas envolvidas são consideradas abaixo, principalmente quanto ao seu papel no metabolis mo de xenobióticos. 


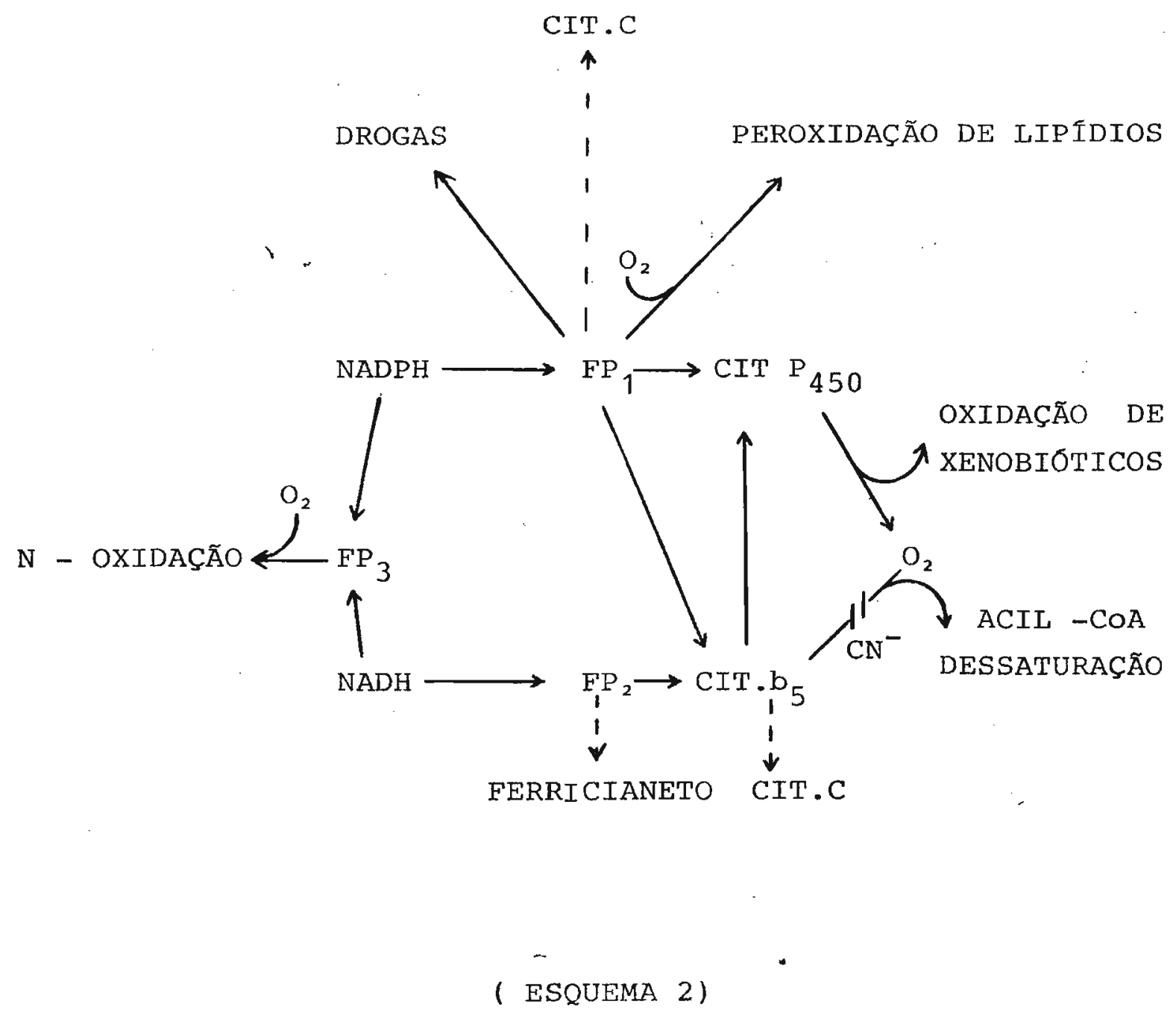

Proteína de Ferro não Heminica - A enzima estearil CoA dessaturase, recentemente purificada, contēm um átomo de ferro que parece ser cataliticamente ativo pela rápida redução que sofre em presença de cịtocromo $b_{5}$. A proteina está envolvida no metabolismo de ácidos graxos, promovendo preferencialmente a dessaturação nas posições 9,10 de derivados de acil COA contendo de 12 a 19 átomos de carbono (10).

Flavoproteínas - A mais extensivamente estudada é a NADPH- cí tocromo $\mathrm{P}_{450}$ redutase (E.C. 1.6.2.4) $\left(\mathrm{FP} \mathrm{P}_{1}\right)$, também denominada NADPH - citocromo c redutase. O enzima hepático tem um peso molecular de 78.000 daltons e possui um mol de FAD e um de 
FMN como grupo prostético. Em contraste com a multiplicidade de isoenzimas de citocromo $\mathrm{P}_{450}$, parece existir apenas uma úni ca forma de redutase em um dado tecido. Além de reduzir o citocromo $\mathrm{P}_{450}$, tendo um papel fundamental no metabolismo de xe nobióticos, a' proteina é capaz de transferir elétrons para acep tores externos como o citocromo c, certos corantes e várias dro gas. Existem tambēm evidências que esse enzima participa na iniciação da peroxidação de lipídios e na degradação oxidativa do heme, via ion superóxido formado durante sua re-oxidação aeróbica $(9,11)$.

Uma outra flavoproteína é a NADH-citocromo $\mathrm{b}_{5}$ re dutase (E.C. 1.6.2.2.) $\left(\mathrm{FP}_{2}\right)$, que contém FAD como grupo prostético. Ela transfere elétrons do $\mathrm{NADH}$ ao citocromo $\mathrm{b}_{5}$ e também a acep tores externos como ferricianeto. Seu papel essencial na oxidação de ácidos graxos está bem estabelecido, havendo discussões quanto ao seu possivel papel no metabolismo de xenobióticos $(9,10,12)$.

A terceira flavoproteina microssomal $\left(\mathrm{FP}_{3}\right)$ é de caracterização relativamente recente e contém FAD como grupo prostético. Ela pode receber elétrons tanto do NADH como do NADPH e participa ativamente do metabolismo de xenobióticos, promovendo a oxigenação de aminas secundárias e terciárias e de compostos contendo enxofre $(13,14)$.

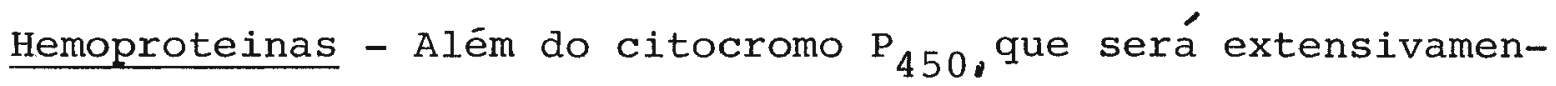
te abordado no item 1.4 ., está presente o citocromo $b_{5}$ que è reduzido por elétrons provenientes do NADH, via NADH citocromo $\mathrm{b}_{5}$ redutase, ou do $\mathrm{NADPH}$, via a NADPH- citocromo $\mathrm{P}_{450}$ redu tase. O fato de que certas oxidações microssomais respon dem sinergisticamente à presença de $\mathrm{NADH}$ e $\mathrm{NADPH}$, suge 
re um possivel envolvimento do citocromo $b_{5}$ na transferentor do segundo elétrón ao citocromo $\mathrm{P}_{450}$ (Esquema 2). A não generalidade do efeito sinergístico, bem como estudos com sistemas reconstituídos, tornam ainda discutivel esse possivel pa pel do citocromo $b_{5}$ no metabolismo de xenobióticos $(9,11,12)$.

1.4. CITOCROMO $\mathrm{P}_{450}$ : PROPRIEDADES E MECANISMO DE CATÁLISE

O termo citocromo $\mathrm{P}_{450}$ é utilizado para se refé rir a um grupo de hemoproteinas cuja caracteristica marcante, é formarem complexos com Co cujo máximo de absorção de luz ocorre por volta de $450 \mathrm{~nm}$, um comprimento de onda consideravel mente maior que os usuais para hemoproteinas. Essa foi a denominação dada ao citocromo $\mathrm{P}_{450}$ quando do seu descobrimento, e ainda continua a ser empregada devido às dificuldades de nomear essa famîlia de enzimas, segundo sưas funções. Além de catalisarem vários tipos de reações, eles são capazes de transformar um grande número de diferentes substratos $(15,16)$. Po dem catalisar a hidroxilação de compostos aromáticos e alifáticos, a N-oxidação, a sulfoxidação, a epoxidação, a N-, S- e o-dealquilação, a peroxidação, a deaminação, dessulfuração e dealogenação. Parecem também capazes de atuar como um citocro mo clássico, transferindo elétrons para a redução de compostos com grupos azo, nitro, N-óxido e epóxido. Seus substratos além de quimicamente diversos, podem ser tanto xenobiōticos como lipídeos de ocorrência fisiológica, incluindo ācidos gra xos, prostaglandinas e esteróides $(15,16)$.

Assim, essa familia de hemoproteinas presentes na 
maioria dos tecidos e organelas de animais, plantas e microor ganismos, parece ter como principal função a monooxigenação de substratos lipofilicos segundo a estequiometria abaixo:

$\mathrm{RH}+\mathrm{O}_{2}+{ }^{2}, \mathrm{NAD}(\mathrm{P}) \mathrm{H}+\mathrm{H}^{+} \longrightarrow \mathrm{ROH}+\mathrm{H}_{2} \mathrm{O}+\mathrm{NAD}(\mathrm{P})^{+}$

Em alguns casos, como nos microssomos hepáticos, a NADPH - citocromo $\mathrm{P}_{450}$ redutase catalisa a transferência de elétrons dos coenzimas piridínicos reduzidos ao citocromo. Em outros, como na mitocôndria adrenal e pseudomonas putida, uma proteina de ferro e enxofre serve como intermediārio entre uma redutase contendo FAD e o citocromo $(15,16)$.

o citocromo $\mathrm{P}_{450}$ é a principal proteina do fíga do, constituindo-se em 2-3\% da proteina total e 15\% da protei na microssomal. Está assim, presente principalmente no retícu lo endoplasmático mas é tambēm encontrado na membrana nuclear, lisossomos, mitocondria e aparelho de Golgi (17).

Os citocromo $\mathrm{P}_{450}$ microssomal hepáticos são hemo proteinas hidrofóbicas, integrais e com pesos moleculares que variam de 48.000 a 58.000 daltons. Cada enzimá contém uma mo lécula de heme, 2-3 moléculas de glicosamina e 400-500 resíduos de aminoácidos (18). A elucidação de suas estruturas prí mária, secundária e terciária, tem sido um desafio constante de vido aos problemas de isolamento e purificação e só muito recentemente, com as técnicas de DNA recombinante, tem sido pos sivel determinar a estrutura primária de algumas dessas isoenzimas pelo sequenciamento dos DNA cópias (19-21).

Esses recentes avanços oferecem novas perspectivas de abordagem de um dos mais fascinantes problemas da área

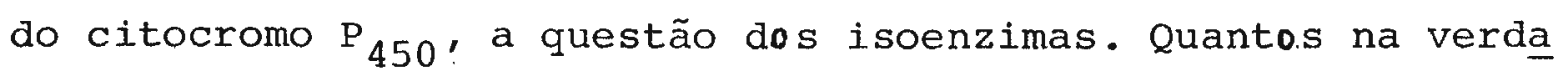


de existem e quais são as diferenças entre eles? Além das dí ficuldades de isolamento e sequenciamento, o problema tornase mais complicado pelo fato de que os niveis das diferentes formas proteicas variam em função da prévia exposição do animal a diversós ägentes. Por exemplo, a exposição a 3-metilcolantreno, fenobarbital, pregnolenona - $16-\alpha$ - carbonitrila, misturas de hidrocarbonetos aromáticos policlorados ou benzo flavona, induz os niveis de certas formas do citocromo $\mathrm{P}_{450} \cdot$ le vando a alterações tanto morfológicas como das velocidades me tabólicas. Já foi sugerida a possibilidade de existirem centenas de diferentes formas num determinado tecido, que apre sentariam uma estrutura primária quase homóloga e especificidades superpostas (22).

Atualmente acredita-se na existência de um núme ro finito de isoenzimas, entre cinco e sete no caso de fígado de rato não induzido $(23,24)$.

Nesse caso, a existência de pelo menos quatro for mas já foi demonstrada por estudos de seletividade quanto a substratos, e também, por purificação até homogeneidade aparente. Tais formas foram utilizadas em estudos de reconstituição quando, em presença da redutase e de fosfatidilcolina, mostra ram-se cataliticamente ativas. Esses isoenzimas tambëm apresentam diferenças quanto ao comportamento eletroforético, pro priedadesespectrais, atividades cataliticas, propriedades imu nológicas e aminoácidos N- e C- terminal (23).

o tratamento de animais com diferentes agentes indutores estimula também diferentemente, a oxidação de drogas. Essas alterações na velocidade e especificidade do meta 
bolismo de xenobióticos, reflete a complexidade das mudanças ocasionadas pelos agentes indutores. Acredita-se que tais mudanças ocorram principalmente por um aumento da síntese dos enzimas, sendo pequeno o papel atribuído a uma redução na ve locidade de dégradação das proteinas $(22,25-28)$.

A indução por certos agentes como o barbiturato fenobarbital aumenta, não só o conteúdo de certas formas de citocromo $\mathrm{P}_{450}$, mas também, o peso total do figado, a quantida de de NADPH- citocromo $\mathrm{P}_{450}$ redutase e de glicuronil transferase, além de causar uma proliferação generalizada do reticulo endoplasmătico. Por outro lado, a indução por 3-metilcolantreno parece afetar somente a distribuição dos diferentes iso enzimas, sem aumentar o conteúdo total de citocromo $\mathrm{P}_{450}$, nem promover mudanças marcantes no peso do fígado ou no nível da redutase. Além desses indutores clássicos, o citocromo $\mathrm{P}_{450}$ é passível de indução por vários outros compostos, o que levou à sugestão de que cada xenobiótico poderia induzir um enzima específico. Isso implicaria num número ilimitado de isoenzimas mas, os conhecimentos atuais favorecem um número entre 15 e 20, que poderia explicar o metabolismo de toda uma variedade de compostos (24). De qualquer forma, a questão da multiplicidade do citocromo $\mathrm{P}_{450}$ permanece abexta e um dos mais fas cinantes problemas atuais da pesquisa biomédica. Ciclo Catalitico do Citocromo $\mathrm{P}_{450}$ - Além da questão dos iso enzimas, um outro aspecto crucial para a compreensão do papel do citocromo $\mathrm{P}_{450}$ no métabolismo de compostos estruturalmente tão distintos, seria a definição dos aspectos químicos da catálise. Essa é complexa, envolvendo múltiplas interações, 
entre o citocromo $\mathrm{P}_{450}$, o substrato, o oxigênio e equivalentes redutores. Estudar os detalhes desse processo não tem si do uma tarefa fácil, devido não só à presença de diferentes isoenzimas mas também, ao ambiente natural do citocromo e enzimas coadjuvantes. Evidentemente, a membrana pode impor restrições no número de interações efetivas necessārias à catālise. Parece assim, altamente improvável que um único mecanis mo seja operante para todas os isoenzimas, e em todas as inte rações possiveis com tão diferentes substratos. Apesar das di ficuldades, alguns dos passos da catálise vem sendo elucida dos e algumas generalizações podem ser tentadas $(15,29)$.

Ạs diferentes oxidações catalisadas pelo citocro mo $\mathrm{P}_{450}$ podem ser agrupadas em três tipos gerais: (i) inserção de um átomo de oxigênio na ligação entre um átomo de hi drogênio e um átomo, mais pesado, para formar o derivado hidro xilado; (ii) adição de um átomo de oxigênio a uma ligação $\pi$ entre 2 átomos de carbono para formar um epöxido e (iii) adi ção de um átomo de oxigênio ao par de elétrons de um heteroātomo para formar um óxido dipolar (Esquema 3) (30).
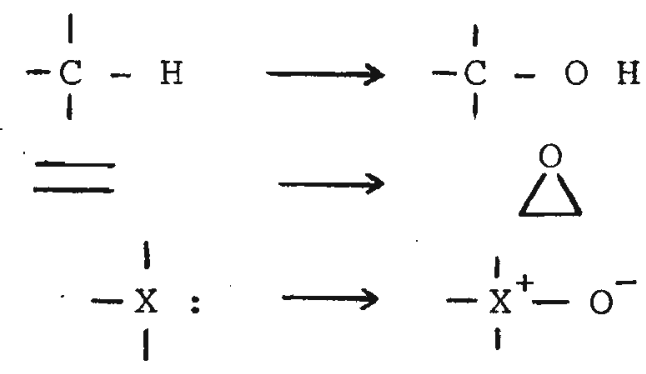
A característica central de todas essas reações é a transferência de um átomo de oxigênio cataliticamente ati vado, formalmente ao nível de oxidação do oxeno, do enzima pạ ra o substrato. Os detalhes mecanístịcos dessa transferência permanecem poucö conhecidos, enquanto que os passos preceden tes estão razoavelmente elucidados $(15,29)$.

o esquema mais aceito para o ciclo catalítico do citocromo $\mathrm{P}_{450}$ é apresentado no Esquema 4, e as vārias etapas são discutidas abaixo.

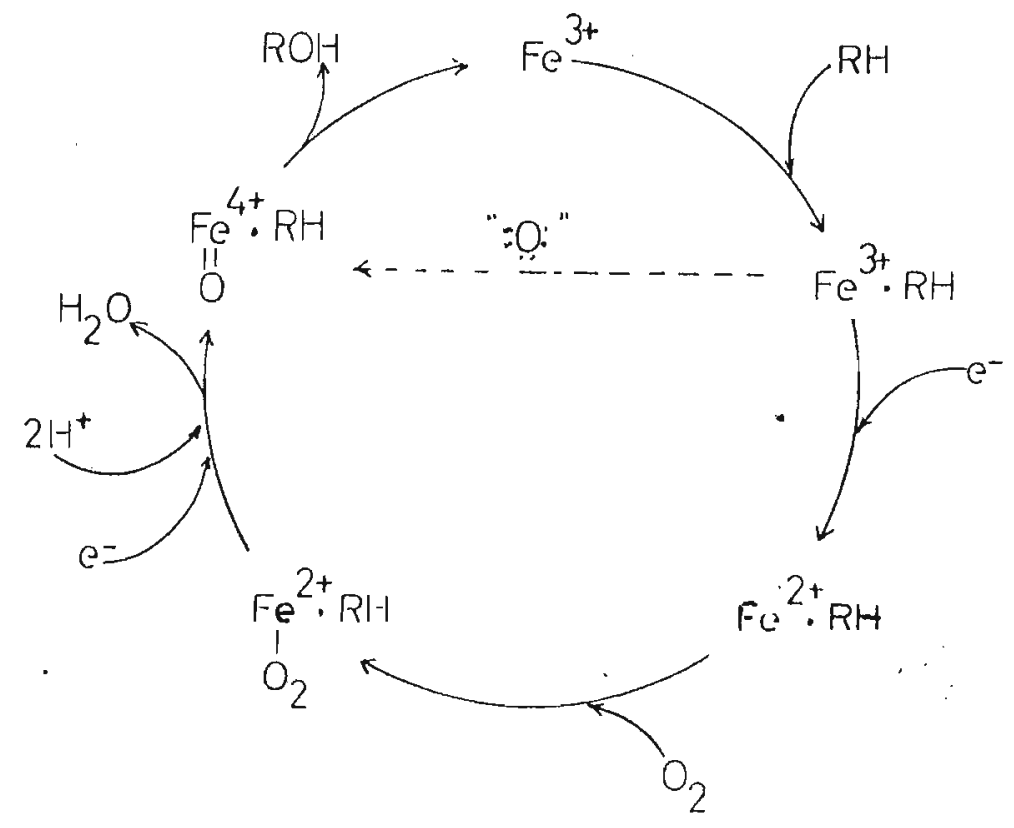

( Esquema 4)

Ligação do Substrato - No estado de repouso o citocromo ${ }_{450}$ aparece como Fe(III), onde ạs quatro posições equatorias de coordenação estão ocupadas pelos nitrogênicos pirrólicos,e as duas posições axiais estão disponíveis para ligação. Seus ocu pantes tem sido matéria de muita controvérsia e, se hoje é bem 
aceito que a quinta posição é ocupada pelo tiolato, provavelmente derivado de um resíduo de cisteina (31), ainda se discu te se a sexta posição é ocupada pelo imidazol ou água (32-35).

A ligação de um substrato ao. citocromo $\mathrm{P}_{450}$ pode ser acom panhada por espectrofotometria diferencial, uma vez que o espectro de absorção eletrônica reflete o estado de spin do grupo prostético.

A maioria das formas do citocromo, no estado de repouso, contém um sexto ligante suficientemente forte para favorecer a configuração de baixo spin (spin 1/2), na qual o ferro está no plano da porfirina. Neste caso, o espectro de absorção de luz visível apresenta a banda soret a $418 \mathrm{~nm}$ bem como bandas $\alpha$ e $\beta$ bem definidas. Um caso particular é a for ma citocromo $\mathrm{P}_{450}$ L M 4, O isoenzima predominante obtidc por indução com 3-metilcolantreno, que não possui um sexto ligante ou possui um ligante fraco. Neste caso, o heme está no esta do de alto spin $(\operatorname{spin} 5 / 2)$, apresentando uma banda soret a $394 \mathrm{~nm}$; a adição de butanol a essa preparação leva ao apareci mento do espectro normal, de baixo spin (15) .

Quando um composto apolar, hidrofóbico, 1iga-se ao sítio ativo, ele desloca o sexto ligante endógeno mas, ou não se coordena diretamente, ou não tem força suficiente para manter o estado de baixo spin. O equilíbrio vai sendo desloca do para o estado de alto spin, (spin 5/2), que possui a soret a $394 \mathrm{~nm}$. Essa interação, chamada tipo I, pode ser acompanhada pelo espectro diferencial que mostra o pico a $394 \mathrm{~nm}$ e um va le a $418 \mathrm{~nm}$ ( Fig. 1). Inversamente, um substrato que possua grupos funcionais fortemente ligantes, como uma amina, deslo 
ca o equilibrio para a forma hexacoordenada de baixo spin, re sultando num espectro diferencial com um vale a $394 \mathrm{~nm} e$ um máximo na região de $420 \mathrm{~nm}$; essa interação ẻ chamada tipo II (Fig. 1) $(15,35)$
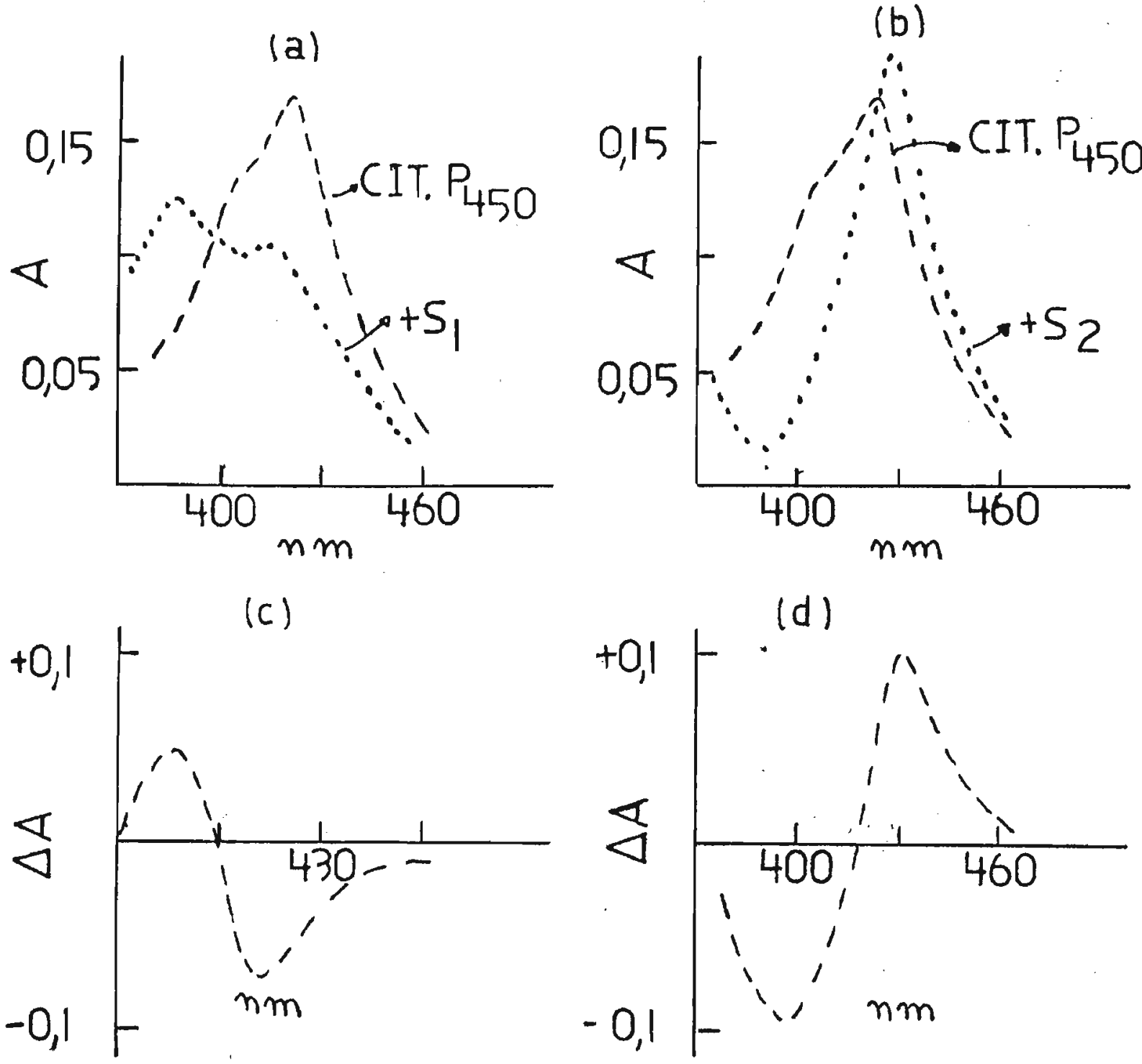

$$
\begin{aligned}
\text { Figura } 1 \text { - Espectro absoluto (a), (b) e espectro diferencial } \\
\\
\text { (c) e (d) do citocromo } \mathrm{P}_{450} \text {, mostrando uma típica } \\
\text { interação tipo } \mathrm{I} \text { (a) e (c) e uma tipica interação } \\
\text { tipo II (b) e (d) }
\end{aligned}
$$


Transferência do primeiro elétron e ligação do dioxigênio

A oxidação do substrato pelo citocromo $\mathrm{P}_{450}$ requer dois equi valentes redutores. O primeiro simplesmente reduz o ferro (III) para ferro (II). Nesta forma, de manẹira análoga à hemoglobina e mioglobina," o enzima liga-se rapidamente ao dioxigênio ou Co. A formação desse complexo com co é a responsável pela de nominação citocromo $\mathrm{P}_{450}$, banda soret na região de $450 \mathrm{~nm}$, e torna o co um inibidor clāssico das oxidações catalisadas por esses isoenzimas. A ligação do oxigênio também pode ser acom panhada espectrofotometricamente em microssomos de ratos prētratados com fenobarbital (36). Experimentos com preparações purificadas também confirmaram a presença do complexo; tais estudos foram realizados à baixas temperaturas porque o complexo se decompõe rapidamente em Fe(III) e íon superóxido ou reverte a $\mathrm{Fe}$ (II) mais dioxigênio $(37,38)$.

A redução do citocromo $\mathrm{P}_{450}$ por $\mathrm{NADPH}$, mediada pe la redutase, apresenta uma cinética bifásica tanto em prepara cões microssomais como nos sistemas reconstituỉos $(39,40)$. A velocidade de redução depende não só do isoenzima como também, do tipo de substrato. Tais diferenças são provavelmente deví das à modulação do equilỉbrio entre os diferentes estados de spin do citocromo, pelos substratos e ambiente do sitio ativo $(15,39,40)$

Formação do oxigênio ativo - A fase final do ciclo catalítico, formação de água e do substrato oxidado a partir do complexo Fe(II) - dioxigênio, é o passo menos compreendido de todo o processo. A estequiometria da reação requer a adição de mais um elétron e dois prótons; contudo, a ordem da adição, e os 
possíveis intermediários envolvidos são matéria de intenso de bate.

Parece que a oxidação do substrato é precedida pe la quebra redutiva do dioxigênio e formação de ãgua, caso em que o oxigêniò ătivo seria um átomo de oxigênio ligado ao fer ro. A evidência mais clara para a existência dessa espécie é - fato de que o iodosobenzeno, doador de um oxigênio,pode subs tituir tanto $\mathrm{O}_{2}$ como os equivalentes redutores nas reações mediadas pelo citocromo $\mathrm{P}_{450}$ (41) (Esquema 5).

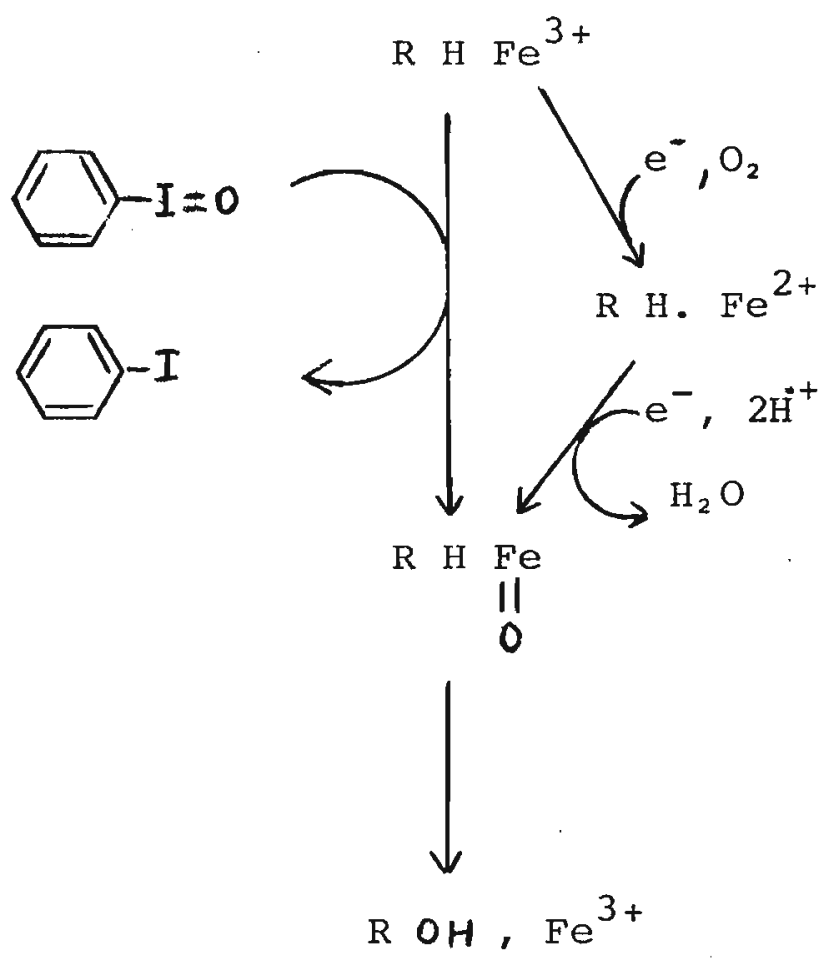

(Esquema 5)

o intermediārio oxidante, que seria o mesmo nos dois casos, é formalmente composto por Ferro III ligado ao en- 
zima e oxigênio atômico, embora não se possa precisar a exata distribuição dos elétrons. Todas as estruturas apresentadas abaixo (Esquema 6) são viāveis, existindo uma certa preferēncia em se asşumir o complexo perferril (2) por extrapolação de resultados obtidos com sistemas modelos $(15,42)$.

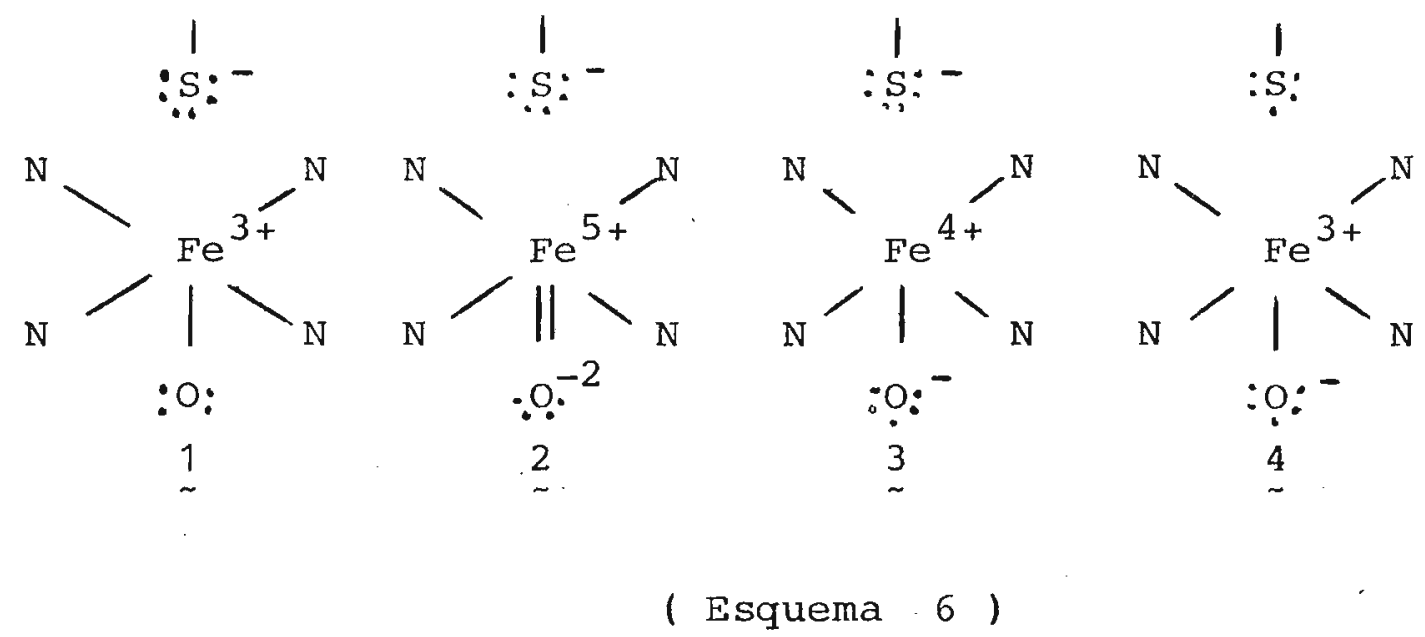

É importante ressaltar que além do iodosobenzeno, vários outros compostos, como hidroperóxido de cumeno, periodato de sódio, peróxido de hidrogênio e vários perácidos, po dem substituir o oxigênio e o $\mathrm{NADPH}$ em reações catalisadas por citocromo $\mathrm{P}_{450}$. Contudo, no caso de peróxidos, observam-se diferenças significativas em relação à especificidade ao substrato, velocidades de oxidação e mesmo distribuição de produ tos. Também, nessas reações o enzima consegue realizar somente um pequeno número de transformações sendo rápida e irrever sivelmente inativado; provavelmente pela oxidação do seu gru po prostético. Tais resultados sugerem que as reações dependentes de peróxidos são mecanisticamente diferentes daqueles dependentes de dioxigênio e NADPH (15).

Mesmo assumindo que nessas últimas o intermeđiā- 
rio oxidante é o complexo perferril (Esquema 6, 2), falta ain da estabelecer como se dá a transferência desse oxigênio ativado ao substrato. Ela ocorreria de maneira concomitante ou em passos e, se em passos, ocorreria através de intermediärios contendo elétrońs livres ou elétrons emparelhados? Embora não se tenha a resposta definitiva a essas questões, estudos recentes sugerem que os três tipos gerais de reações catalisa das pelo citocromo $\mathrm{P}_{450}$ (Esquema 3) ocorrem por passos de um elétron. Groves e colaboradores apresentaram evidências de que as reações de hidroxilação ocorrem de maneira não concomi tante, com o provável envolvimento de radicais livres $(43,44)$. Também, Ortiz de Montellano e colaboradores, pela análise da regioestereoespecificidade das reações de epoxidação, puderam sugerir o envolvimento de radicais nesses processos (45). Finalmente, nós próprios apresentamos a primeira evidência dire ta de que o citocromo $P_{450}$ atua como oxidante de um elétron na transformação de compostos nitrogenados (30).

Esses estudos recentes, além de fornecerem contribuições gerais para o clássico problema do mecanismo das oxidações biológicas, apresentam óbvias implicações toxicológicas. o principal enzima envolvido no metabolismo de xenobió ticos pode formar radicais livres durante o seu ciclo catalitico; essas espëcies, escapando do sítio ativo, poderiam desencadear os processos tóxicos muitas vezes associados aos xenobióticos.

1.5. DETECÇÃO DE RADICAIS LIVRES EM SISTEMAS BIOLOGICOS: Método do Captador de Spin (Spin Trapping) 
o atual reconhecimento da formação e envolvimento de radicais livres em vários processos biológicos, não nos pode fazer esquecer que os progressos nessa área tem sido bas tante lentos. A própria importância de radicais livres em rea cões orgānicà's em fases condensadas só começa a ser aventada em 1937, e a química dos radicais só começa a ser efetivamente desenvolvida a partir da 2 ạ Guerra Mundial. Também, embora o equipamento de ressonância paramagnética eletrōnica (RPE) se torne disponivel a partir do início da década de 50, a deteccão de radicais livres, não só em sistemas biológicos mas em fases condensadas no geral, tem sido um dificil problema experimental $(46-48)$.

A maior limitação para a deteç̧ão e identificação direta de radicais livres nessas condições é a baixa concentra ção de estado estacionário que se consegue obter dessas espé cies em fases condensadas. Para determinações por RPE se requer uma concentração maior que $10^{-8} \mathrm{M}$, de 100 a 1000 vezes esse valor para uma resolução espectral razoável. Também, o tempo de medida varia de décimo de segundo a horas, enquanto que os tempos de vida de radicais em solução são, em geral, bem menores que 1 milisegundo; isso faz com que suas concen trações de estado estacionário se mantenham em geral, abaixo de $10^{-7}$ M. Para contornar os problemas de deteç̧ão, vārias abor dagens experimentais tem sido desenvolvidas, seja para aumentar a velocidade de produção de radicais seja para diminuir a sua velocidade de desaparecimento. Como exemplo, temos o tra tamento da amostra em "situ" com radiação de alta energia ou luz de alta intensidade. De aplicação mais geral são as técni 
cas de fluxo rápido, que tem sido amplamente empregadas para o. estudo, por RPE, de várias reações químicas e algumas poucas reações enzimáticas (47-49). Esse método dinâmico de manutencão das concentrações de estado estạcionārio apresenta várias vantagens, prińcipalmente a de ser uma técnica direta. Contudo, além de exigir uma enorme quantidade de material, servirá para detectar radicais de relativa estabilidade o que limita sua aplicabilidade; de fato, a sua utilização mais elegante em sistemas enzimáticos continua sendo o clássico estudo de Yama zaki e colaboradores, de reações catalisadas por peroxidases formando radicais do tipo quininoide (49-51).

Evidentemente existem casos em que os radicais li vres são suficientemente estāveis para atingir concentrações de estado estacionário acima dos limites de detecção do espeç trômetro de RPE, como é o caso inclusive, de vários produtos de xenobióticos. Mason e colaboradores tèm se dedicado ao estudo do metabolismo de vários desses compostos e seus resultá dos e conclusões são sintetizados em duas revisões recentes $(52,53)$. Nosso maior interesse são justamente' os radicais mais instáveis, principalmente radicais centrados no carbono, cuja formação em sistemas biológicos, em fases condensadas e à tem peratura ambiente, não pudera ser comprovada por nenhuma das técnicas citadas até aqui.

Técnica do Captador de Spin - Essa abordagem experimental foi introduzida independèntemente por quatro grupos em 1968-1969 (54-58). A técnica é bastante simples, fazendo uso de um composto diamagnético (captador de spin) que reagindo com um ra dical instável, forma um radical relativamente estável, geral 
mente um nitróxido, observável por RPE em fase líquida e à tem peratura ambienté (Esquema 7 ).

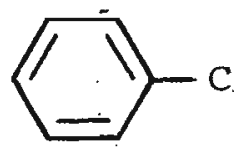<smiles>[R][C@H](C)C(C)(C)[N+]([O-])[O-]</smiles><smiles>CCCC</smiles><smiles>[R]Cc1ccccc1</smiles><smiles>CC(C)(C)N[O]</smiles>

PBN (captador de spin) Radical

PBN - aduto EPR não observável EPR não observāvel EPR observável diamagnético (bajxa concentração) (alta concentração)

Tem-se assim uma forma indireta de aumentar a con centração de estado estacionário, por acúmulo de um radical a duto razoavelmente estável.

Embora simples e vantajosa quanto à quantidade de material necessário, e não requerimento de instrumentação a dicional ao espectrômetro de RPE, a tēcnica apresenta várioś problemas, principalmente quando aplicada a sistemas biológi$\cos (59-62)$.

Primeiro, é uma técnica indireta e como tal introduz uma perturbação no sistema em estudo. Também, não se detecta o radical primário e a estrutura deste não é facilmen te deduzida a partir do espectro de $\mathrm{RPE}$ do radical estável la duto)

Os adutos dos captadores de spin pertencem, em geral, à função nitróxido, um radical cujo elétron desempare- 
Ihado ocupa um orbital $\pi^{*}$ entre o nitrogênio e o oxigênio.Tal função é em geral representada como um hábrido das estruturas abaixo, sendo a delocalização eletrônica a responsável pela estabilidade desses radicais.
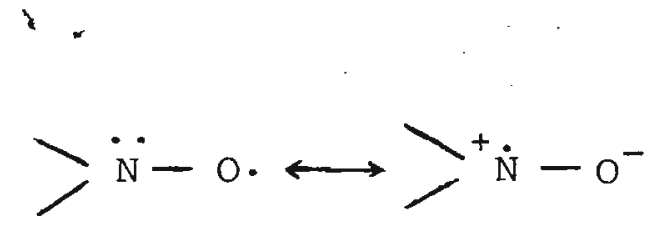

O espectro de RPE de nitróxidos, em solventes não viscosos, é caracterizado por um largo desdobramento hiperfino devido ao nitrogênio $\left(a_{\mathrm{N}}\right)$; esse é resultado da interaçãodo elētron livre com o momento magnético nuclear do nitrogênio $(I=1 ;$ no de linhas $=2 I+1=3)$, podendo ocorrer outros desdobramentos hiperfinos, se existirem núcleos com momentos mag néticos nos substituintes ligados ao nitrogênio. Os captadores de spin, ao reagir com um radical, formam um nitróxido que possuem pelo menos um átomo de hidrogênio ( $I=1 / 2$, no de linhas $=2 I+1=2$ ) no carbono $\alpha$, e portanto, apresentam pelo menos 6 linhas (Fig. 2). Os valores das constantes de desdobramento hiperfino do radical aduto, $a_{N}$ e $a_{H}$, dependerão, além do sol vente, da natureza e tamanho dos substituintes no nitrogênio. Contudo,como aúnica modificação nos adutos formados entre um mesmo captador e diferentes radicais é só o grupo R ( Fig.2), as variações de $a_{\mathbb{N}}$ e $a_{H}$ não são suficientes para uma identifi cação inequívoca do grupo $R$. Os valores coletados na Tabela 1 mostram que é apenas possível conjecturar sobre a natureza do radical, se de carbono, oxigênio ou nitrogênio, quando teríamos um número superior de linhas; atribuir a estrutura exata dependerá de outras abordagens experimentais, embora o procedi 
mento mais utilizado seja comparar os parâmentros de RPE dos adutos obtidos em sistemas biológicos com aqueles de adutos obtidos em reações químicas que, se espera, produzam os mesmos radicais (59-63).

DMPO
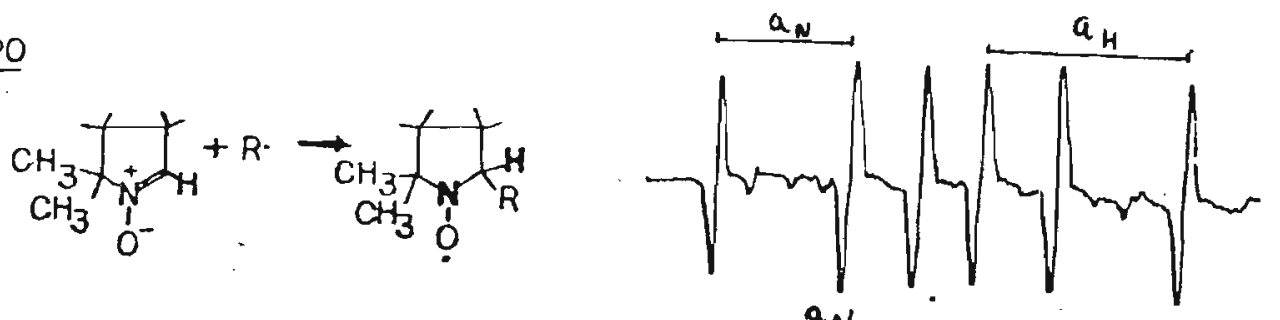

$\underline{\text { PBN }}$

$\underline{T-N B}$
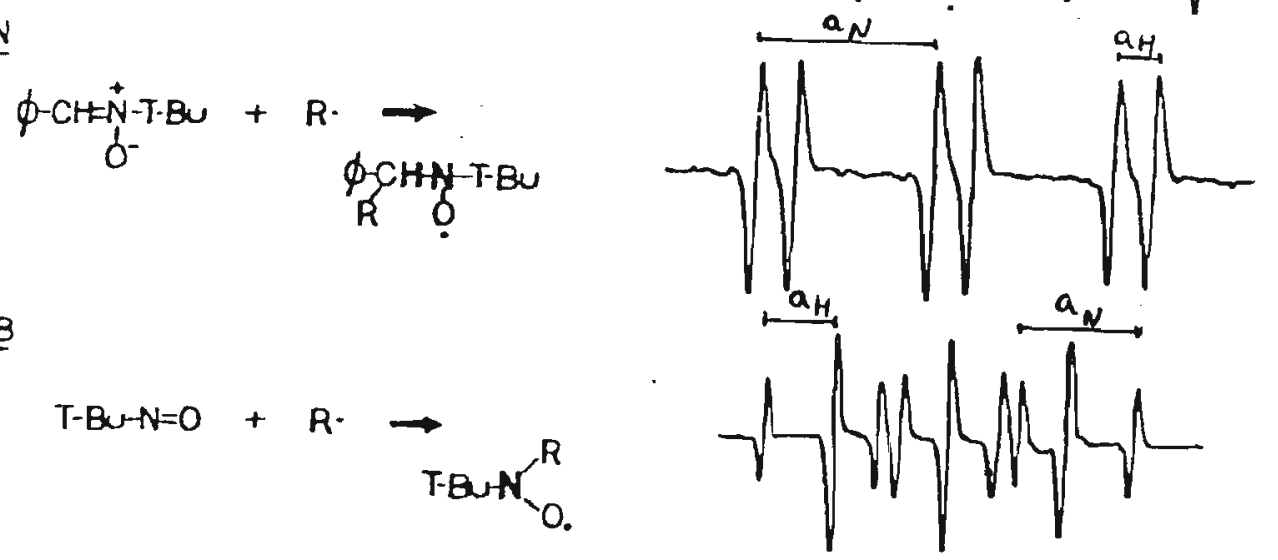

Figura 2 - Captadores de spin comumente emprégados em sistemas biológicos: estruturas e espectros caracteristicos dos adutos formados pela adição de um radí cal alquila, de fórmula geral $\mathrm{R}-\mathrm{CH}_{2}$.

Em contraste com os captadores de spin da classe das nitronas, como DMPO e PBN, os captadores da classe dos ni troso derivados, como T-NB, são adequados para a identificação do grupo $R$. Neste caso a adição do radical se dá diretamente no nitrogênio e assim, os desdobramentos devidos aos átomos do prọprio grupo R são espectroscopicamente observáveis (Fig.2). Contudo, outros fatores dificultam a utilização desses compos 
Tabela 1. Variações nos Parāmetros Espectrais, em Benzeno, pạ ra Diferentes Classes de Adutos de Nitronas Captadoras de Spin

\begin{tabular}{|c|c|c|c|c|c|}
\hline \multirow{2}{*}{ Classe } & \multirow{2}{*}{ Aduto } & \multicolumn{2}{|c|}{ PBN } & \multicolumn{2}{|c|}{ DMPO } \\
\hline & & $\mathrm{a}_{\mathrm{N}}$ & $a_{H}$ & $a_{N}$ & $a_{H}$ \\
\hline \multirow[t]{4}{*}{ ROO. } & $t-B u O O$ & 13,40 & 1,57 & & \\
\hline & Cumil 00 . & 13,55 & 1,82 & & \\
\hline & HOO. & 13,28 & 2,25 & & \\
\hline & - & & & & \\
\hline \multirow[t]{4}{*}{ RO. } & $t-B u O$ & 14,21 & 1,83 & 13,17 & 7,93 \\
\hline & Eto. & 14,01 & 2,01 & 13,22 & 6,96 \\
\hline & MeO. & 13,76 & 2,00 & 13,58 & 7,61 \\
\hline & HO. & 14,48 & 2,17 & 14,83 & 14,83 \\
\hline
\end{tabular}

$\mathrm{R} \cdot$

Cumil.

Et.

Me •

Benzil•

Fenil.
14,25

14,32

14,81

13,78

14,41
2,19

3,22

14,20 20,49

3,47

14,31

20,52

2,01

14,16

20,66

2,21

13,79

19,22

a

Valores coletados da referência 48 
como captadores de spin. Primeiro, são instáveis térmica e fo. toquimicamente produzindo radicais secundários que dificultam a interpretação do fenômeno em estudo. Também, são bastante in solúveis em āgua e tendem a formar dímeros que não funcionam como captadores" de radicais (60).

Até aqui discutimos apenas um dos fatores que de vem ser considerados na escolha do captador de spin adequado a um determinado estudo, a possibilidade de identificação do radical primário. Outros fatores, como as constantes de velocidade da reação de captação (kt, Esquema 7) e a estabilidade do radical aduto, são igualmente importantes.

A reação de captação de spin tem sido extensivamente estudada por Janzen e colaboradores; as rápidas velocidades de adição de um radical a uma nitrona foram racionaliza das por analogia com a adição de um radical ao butadieno, por que, em ambos os casos, o elétron desemparelhado no produto de adição é estabilizado pela delocalização em orbitais $\Pi$ de 2-3 átomos (64). Vários valóres deconstantes de velocidades tem sido determinados e alguns deles são apresentados na Tabela2. Fica evidente que a maioria das reações de captação podem com petir com outras reações radicalares desde que se use altas concentrações de captadores. Uma exceção é o ion superóxido que não reage com nenhum dos captadores a velocidades apreciāveis; o problema particular da captação do ín superóxido e outros radicais de oxigênio tem sido extensivamente estudado por Rosen e colaboradores $(61,65)$.

Quanto à estabilidade dos adutos dos captadores de spin, muitos estudos são ainda requeridos. A química de ni 
Tabela 2. Constantes de Velocidade Aparente $\left(M^{-1} S^{-1}\right)$ Para a Reação de Captação de spin a

\begin{tabular}{|c|c|c|c|c|}
\hline RADICAL & DMPO & & PBN & $\mathrm{T}-\mathrm{NB}$ \\
\hline $\mathrm{O}_{2}=$ & 10 & & & $\mathrm{~b}$ \\
\hline$\cdot \mathrm{OH}$ & $3.4 \times 10^{9}$ & 1 & $\times 10^{9}$ & $\mathrm{~b}$ \\
\hline $\mathrm{RO}^{\circ}$ & $5 \times 10^{8}$ & 5.5 & $\times 10^{6}$ & $1.5 \times 10^{6}$ \\
\hline $\mathrm{R} \dot{\mathrm{C}} \mathrm{H}_{2}$ & $2.5 \times 10^{6}$ & 1.3 & $\times 10^{5}$ & $9.0 \times 10^{6}$ \\
\hline $\mathrm{R}_{1} \underset{\mathrm{R}_{2}}{\dot{\mathrm{C}} \mathrm{H}}$ & $4.2 \times 10^{5}$ & 6.5 & $\times 10^{4}$ & $6.1 \times 10^{6}$ \\
\hline $\mathrm{R}_{1} \dot{\mathrm{CR}}_{3}$ & & 1 & $\times 10^{4}$ & $3.3 \times 10^{6}$ \\
\hline
\end{tabular}

a Valores coletados da referēncia 62

b Aduto instável

tróxidos tem sido bastante estudada, principalmente devido às suas aplicações na técnica de marcação de spin. Contudo, os nitróxidos obtidos por captação de spin diférem dos utiliza dos como marcadores pela presença de um hidrogênio no carbo no $\alpha$. O efeito positivo dessa presença é fornecer um parâmetro adicional de $\mathrm{RPE}, \mathrm{O} \mathrm{a}_{\mathrm{H}}$ além do $\mathrm{a}_{\mathrm{N}^{\prime}}$ para auxiliar na iden tificação do radical primário. O efeito negativo é que esses nitróxidos são mais instāveis devido à reação de desproporcio namento $(60,65-69)$ :

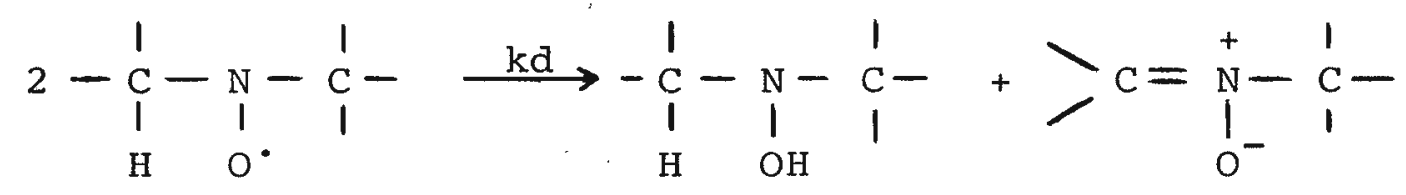


O mecanismo desse processo foi estudado por Ingold e colabora dores, que estabeleceram que no caso do dietil nitróxido, ocorre a formação inicial de um dímero que se decompõe nos produtos; a constạte de velocidade é altá, de $1 \times 10^{4} \mathrm{M}^{-1} \mathrm{~s}^{-1}$, a $25^{\circ} \mathrm{C}$, em benzeno. Para nitróxidos mais substituídos o decaimento é mais lento, por exemplo, $\mathrm{kd}=100 \mathrm{M}^{-1} \mathrm{~S}^{-1}$ a $40^{\circ} \mathrm{C}$, em benzeno para o n-hexil tercio-butil nitróxido (65-68). Embora esses estudos sugiram que a velocidade de decaimento de cresça com o aumento do grau de substituição e do tamanho dos grupos ligados ao nitrogênio, não existem estudos quantitativos sobre os adutos dos captadores de spin comumente utilizados em sistemas biológicos. o único estudo aparece numa revisão de Evans (69) cujos resultados preliminares sugerem que, de fato, a meia-vida é proporcional ao tamanho do radical de carbono adicionado e também, que os adutos de PBN são mais es táveis que os correspondentes adutos de DMPO; no caso de radi cais de oxigênio o inverso é vālido, sendo os adutos de DMPO os mais estáveis $(61,65)$. Evidentemente faltam estudos sistemáticos sobre a estabilidade desses adutos radicais, inclusive frente a sistemas biológicos. Na ausência de dados mais quantitativos, o procedimento mais usual tem sido extrapolar os resultados obtidos com os nitróxidos totalmente substituidos. Nesses casos, o mais importante processo de decaimento é a redução, por redutores endógenos usualmente presente em pre parações biológicas, muito mais comum que a possivel oxidação (Esquema 8) (69-71). 


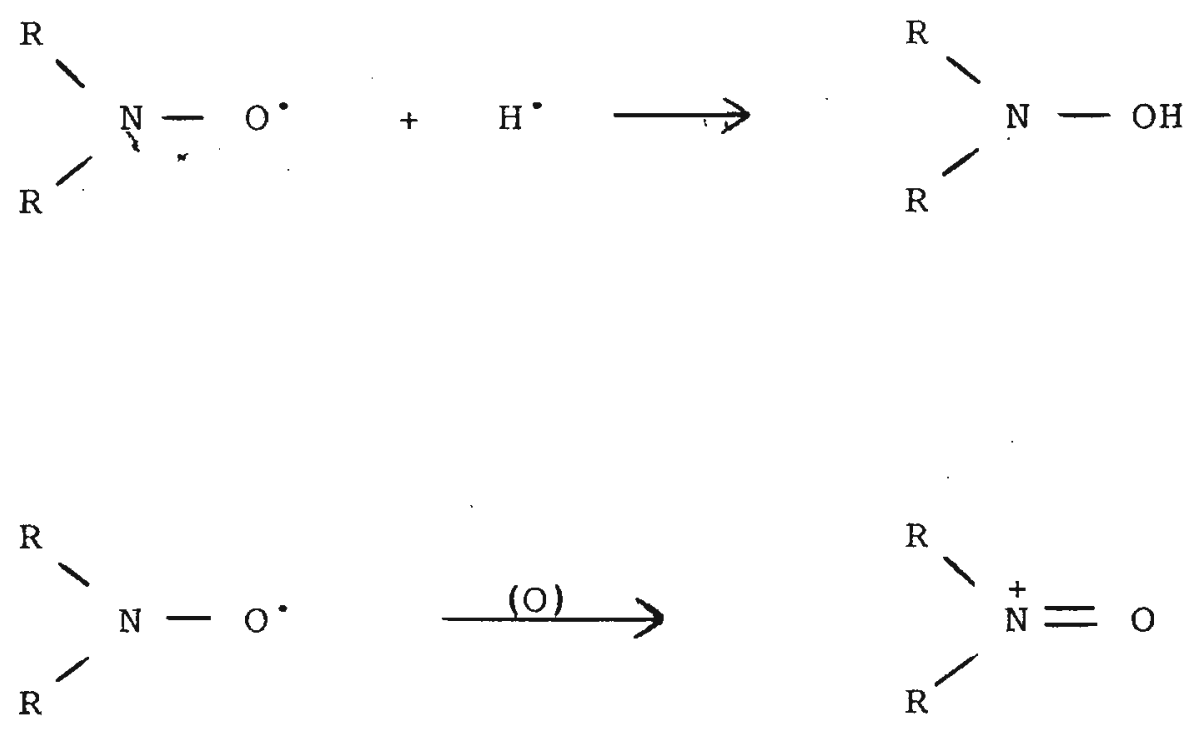

( Esquema 8)

Discutimos até aqui os critêrios envolvidos na seleção do captador de spin adequado a determinado estudo, a saber: (a) possibilidade de identificação do' radical captado a partir do espectro de RPE do aduto de spin; (b) a velocidade das reações de captação e (c) a estabilidade do aduto de spin. Esses fatores levaram ao uso extensivo do DMPO, PBN e T-NB em sistemas biológicos (Fig. 2). Além desses captadores tem sido empregados, embora menos extensivamente o POBN, ni trosobenzeno, o 2,4,6-tri-t-butil-nitroso benzeno e a base con jugada do tautômero do nitrometano (Esquema 9) (62). 


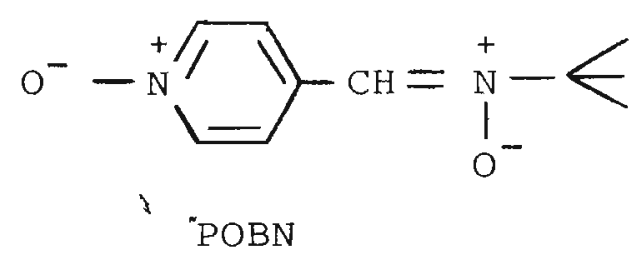

$\sim_{1}^{\circ}$

nitrosobenzeno

$$
\mathrm{CH}_{2}=\mathrm{N}^{+}=\mathrm{O}^{-}
$$

base conjugada do nitrometano

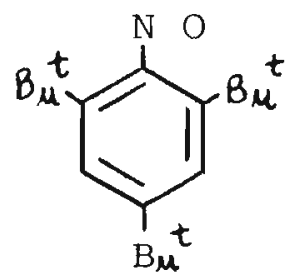

$2,4,6-t r i-t-b u t i l$

nitrosobenzeno

( Esquema 9$)^{\star}$

Também salientamos as dificuldade's de interpretạ ção dos resultados obtidos, principalmente em sistemas comple xos como os biológicos. Permanece a dificuldade de identifica ção inequívoca do radical captado e também, o fato de que o aduto mais estável não é, necessariamente, o radical primário formado num determinado processo. Tais problemas não impediram que a técnica de captação de spin permitisse a deteção de vários radicais reativos em sistemas biológicos, espécies essas que não são detectáveis pela espectroscopia de RPE de estado está cionārio. Entre as espēcies identificadas incluem-se:radicais 
superóxido e hidroxila, por captação com DMPO $(61,65)$; radical de carbono, derivado de lipídeos durante o metabolismo do ácido araquidônico pela prostaglandina sintetase, por captação com T-NB (72); o radical triclorometila, formado durante o metabolismo de tetracloreto de carbono marcado, por captação com PBN (73). Uma revisão recente sobre a técnica do captador de spin apresenta também, os resultados obtidos com a técnica em sistemas químicos e fotoquímicos, inclusive a captação de radicais centrados no nitrogênio, fósforo e enxofre (62).

Um dos problemas que permanecia pouco considerado era aquele comum a toda tēcnica indireta, ou seja, a perturbação que o captador de spin pode introduzir no sistema em estudo. A nossa devida atenção ao problema com relação ao sis tema microssomal nos propiciou sermos os primeiros a isolar biologicamente e caracterizar espectroscópicamente os adutos de radicais de carbono formados durante $0^{\circ}$ metabolismo de DDEP (3,5-bis-etoxicarbonil)-4-etil-2,6 dimetil-1,4-diidropiridina) e 2-feniletilidrazina (fenelzina), resultados que apresentare mos neste trabalho. 
2. MATERIAS E METODOS

2.1. MATERIAIS

Os "captadores de spin PBN, DMPO e POBN foram obtidos da Aldrich Chem. Co.; DMPO foi purificado como descrito por Buettner e Oberley (74). Também foram obtidos da Aldrich Chem. Co., os radicais 4-hidroxi-2,2,6,6-tetrametil-piperidinooxila e 2,2-difenil-1-picrilidrazila.

Os substratos, etilidrazina (75) e DDEP (76) fo ram sintesidados como descrito nas referências citadas. A benzé tamina foi gentilmente cedida pelo Dr. G. Miwa. Os outros derivados de hidrazina foram obtidos da Aldrich Chem. Co. na forma de seus cloridratos com exceção da 2-feniletilhidrazina, obtida da ICN Pharmaceuticals, Inc. As soluções estoques dos derivados de hidrazina foram preparadas em HCL 0,01 N, mantidas a $0^{\circ} \mathrm{C}$ e usadas até 12 hs após suas preparações.

Catalase bovina, superóxido dismutase bovina (Ti po I), isocitrato desidrogenase, isocitrato, g'licose-6-fosfato desidrogenase, glicose-6-fosfato, NADH e NADPH foram obtidos da Sigma Chemical Co. A catalase foi dissolvida em tampão fosfato $0,1 \mathrm{M}, \mathrm{pH} 7,4$ a uma concentração de $3 \mathrm{mg} / \mathrm{ml}$ e foi extensivamente dialisada contra o mesmo tampão para remover antioxidantes contaminantes. A monoamino oxidase foi obtida co mo descrito por Salach (77).

Os demais reagentes foram obtidos comercialmente e utilizados sem purificação adicional a não ser quando descrito no item 2.2. A água utilizada foi deionizada e destila- 
da de vidro.

\subsection{METODOS}

a. Microssomos Hepáticos - Foram obtidos como previamente des crito (78) de ratos machos, Sprague-Dawley, de 250-300.g de peso e após pré-tratamento com fenobarbital $(80 \mathrm{mg} / \mathrm{Kg} /$ dia) por quatro dias.

b. Dosagem da Proteina Microssomal - Foi determinada com o conjunto da Bio Rad.

c. Estudos com Citocromo $\mathrm{P}_{450}$ "in vitro" - A destruição do cí tocromo $\mathrm{P}_{450}$ pelos substratos é expressa em porcentagem, co mo a quantidade de citocromo $\mathrm{P}_{450}$ remanescente apōs a incu bação com o substrato, em relação à quantidade inicialmente presente. As quantidades de citocromo $\mathrm{P}_{450}$ presentes nas preparações foram determinadas num espectrofotometro Aminco DW-2A como descrito por Estabrook e colaboradores (78). o tempo de incubação foi contado a partir da adição de NADPH e sempre foi controlada a perda da enzima devida à peroxidação de lipídeos (ausência de substrato e presença de $\mathrm{NADPH})$, cujos valores, de aproximadamente $2 \%$, foram des contados dos valores apresentados nos resultados. Para os estudos com DDEP (item 3.1), a incubação foi por 30 min. a $37^{\circ} \mathrm{C}$ e a mistura continha $1 \mathrm{mg} / \mathrm{ml}$ de proteina microsso$\mathrm{mal}, 10 \mathrm{mM} \mathrm{DDEP}, 150 \mathrm{mMKCl}, 1,5 \mathrm{mM}$ EDTA, 1,0 mM NADPH em tam pão fosfato $0,1 \mathrm{M}, \mathrm{pH} 7,4$. Para os estudos com fenelzina (item 3.2 ), a incubação foi realizada durante $60 \mathrm{~min}$. a $37^{\circ}$ $C$, a concentração de proteina microssomal foi de $2 \mathrm{mg} / \mathrm{ml}$, - EDTA foi substituído por DETAPAC e o NADPH por um siste- 
ma gerador contendo, 0,78 mM NADP, 7,8 mM glicose-6-fosfato, 0,8 unidades /ml glicose-6-fosfato desidrogenase e $2,55 \mathrm{mM} \mathrm{MgCl}_{2}$.

A ligação dos substratos e dos captadores de spin ao citocromo $\mathrm{P}_{450}$ foi determinada por espectroscopia diferencial (35). A difexença entre o máximo e o mínimo de absorção foi medida a várias concentrações dos substratos e os valores obtidos foram utilizados para determinar as constantes aparentes de ligação. No caso dos captadores de spin, as concentrações reais são conhecidas; no caso do DDEP, bastante insolūvel em āgua, foi preparada uma solu ção saturada na suspensão microssomal. Essa solução foi fill trada através de lã de vidro e a concentração de DDEP foi determinada, após extração com acetato de etilia/eter etíli co $(1.5, \mathrm{v} / \mathrm{v})$, por cromatografia gasosa como sendo $0,06 \mathrm{mM}$. A solução saturada de DDEP em microssomos foi utilizada co mo solução estoque para adição de volumes conhecidos nas experiências de espectroscopia diferencial.

d. Análise de Metabólitos - O metabolismo do DDEP foi acompanhado indiretamente, pela destruição do citocromo $\mathrm{P}_{450}$ por ele induzida (76). Embora o seu metabólito desalquilado, a 3,5-bis(etoxicarbonil)-2,6-dimetilpiridina, possa ser acompanhado por cromatografia gasosa após extração, a sua decomposição durante o procedimento analitico tornava difí cil a sua quantificação.

A N-demetilação da benzftamina foi ensaiada nas condições usadas por Correia e Mannering (80), sendo o for maldeido quantificado pelo método de Nash (81). 
Para a dosagem dos metabólitos da fenelzina, a mistura de reação e as condições de incubação foram as mes mas utilizadas para acompanhar a destruição do citocromo $\mathrm{P}_{450}$. Nas misturas controle o sistema gerador NADPH foi omitido. A concentração de substrato foi $5 \mathrm{mM}$ e o volume nal de $25 \mathrm{ml}$. As incubações foram realizadas sob agitação a $37^{\circ} \mathrm{C}$ e a reação terminada pela adição de ácido tricloroacético a uma concentração final de $5 \%$ (peso/volume). As misturas foram centrifugadas para remover os microssomos pre cipitados e os sobrenadantes extraídos com $10 \mathrm{~mL}$ de hexano (grau UV da Burdick e Jackson, Inc.). Adicionou-se aos extratos orgânicos uma quantidade conhecida de propilbenzeno, como padrão interno, e eles foram analisados por cromatografia gasosa, numa coluna de 6 pés empacotada com 10\% Car bowax 20 M em 120/140 mesh Chrom Q. A temperatura da coluna, inicialmente a $50^{\circ} \mathrm{C}$, foi programada para atingir $200^{\circ}$ C com uma velocidade de incremento de $15^{\circ} \mathrm{C} / \mathrm{min}$. Esses estudos foram realizados num cromatógrafo da Varian, modelo 2100 com deteç̧ão por ionização de chama, é a integração do cromatogramas foi realizada com um integrador da HewlettPackard, modelo 3390 A. As estruturas dos metabólitos foram estabelecidas pela comparação de seus tempos de reten ção cromatogräficos e de seus espectros de massa com aque les obtidos para amostras autênticas. Esses estudos foram realizados num espectrômetro de massa Kratos MS-25 acoplado a um cromafógrafo de gás da Varian, modelo 3700; nestes casos a coluna utilizada foi capilar, de $24 \mathrm{~m}$ de silica fundida com oV - 1 e a sua temperatura foi programada para 
aumentar quatro minutos após a injeção, a uma velocidade de $15^{\circ} \mathrm{C} / \mathrm{min}$. até atingir $250^{\circ} \mathrm{C}$.

e. Purificação e Caracterização do Aduto de Heme - A fenelzina dissolvịda em ãgua foi administrada por injeção intrape ritonial numa dose de $60 \mathrm{mg} / \mathrm{Kg}$ a 18 ratos machos, SpragueDawley, de 250-300 g de peso, que tinham sido pré-tratados por 4 dias com fenobarbital $(80 \mathrm{mg} / \mathrm{Kg} / \mathrm{dia})$. Três horas após a dose de fenelzina, os ratos foram decapitados e seus fígados removidos após perfusão com solução salina. Os fígados foram homogenizados e extraídos com $5 \% \mathrm{H}_{2} \mathrm{SO}_{4} \mathrm{em}$ meta nol $(100 \mathrm{~mL} / \mathrm{f} \mathbf{g}$ ado $)$ como descrito anteriormente $(79,82)$. As frações de porfirinas, complexadas com zinco obtidas seguin do esse procedimento, foram submetidas duas vezes a cromatografia de camada delgada em placas de sílica gel ( 2000 $\mu m$ de espessura) usando como solvente $\mathrm{CHCl}_{3} /$ acetona ( 3:1, $\mathrm{v} / \mathrm{v})$. A fração verde, de fluorescênciä vermelha, foi extraída das placas e purificada novamente, por cromatografia líquida de alta pressão, numa coluna Whatman 10-PAC de 4,6 X $250 \mathrm{~mm}$. A eluição foi acompanhada a 590nm e o complexo de zinco da porfirina transformada por fenelzina, elui com um tempo de retenção de $8 \mathrm{~min}$. O zinco foi removido por trata mento com $5 \% \mathrm{H}_{2} \mathrm{SO}_{4}$ em metanol e a porfirina, livre do metal, foi novamente submetida à cromatografia liquida de alta pressão, nas mesmas condições acima descritas, exceto quanto ao acompanhamento da eluição que foi a $510 \mathrm{~nm}$. A porfirina elui como um único pico com um tempo de retenção de 3 min. O espectro de massa (field desorption) foi obtido num instrumento AEI MS-902, como descrito para ou- 
tros adutos de porfirinas (82). O aduto de fenelzina, apro ximadamente $400 \mu \mathrm{g}$, foi re-convertido no seu complexo de zinco (83) e dissolvido em clorofórmio deuterado a uma con centração final de $1 \mathrm{mM}$ para os estudos de RMN. Esses espec tros foram obtidos em um instrumento Nicolet NT - 360 FT nas facilidades de ressonância magnética nuclear da Unịver sidade da California, Davis. Os espectros de absorção eletrônica foram obtidos num espectrofotômetro Hewlett-Packard HP - 8450 A.

f. Estudos de RPE - As incubações microssomais utilizadas foram as mesmas descritas para os estudos de inativação do citocromo $\mathrm{P}_{450}$ "in vitro". mais os captadores de spin, cujas concentrações finais estão descritas nos resultados a presentados. Aliquotas das incubações eram transferidas pa uma pipeta capilar de $50 \mu \mathrm{J}$, fechada numa ponta, e seus es pectros analisados em espectrômetros dả Varian; foram utilizados os modelos E-3, E-4 ou E-109 na University of Cali fornia, Berkely ou no V.A. Hospital, San Francisco, dependendo das disponibilidades. As possiveis diferenças estão normalizadas e a maioria dos resultados aqui apresentados, foram obtidos num instrumento E-3. Alguns espectros foram obtidos num tubo permeāvel a gás (diâmetro interno0,81 mm, espessura da parede 0,05 $\mathrm{mm}$ da Zeus Industrial Products). Isso foi necessário para manter a mistura da reação aeróbi ca, pois que a présença de redutores endógenos e das próprias hidrazinas em excesso, l leva à redução do nitróxido aduto e consequentemente, do sinal de RPE; em outras circunstâncias, o uso do tubo permeável a gás foi para manter 
a mistura sob nitrogênio. No caso da utilização de solventes orgânicos é necessário remover o oxigênio que pelo seu paramagnetismo e maior solubilidade em solventes orgânicos, leva a uma distorção dos espectros.

Paŕa estimar as concentrações dos adutos obtidos, utilizou-se como padrão o radical 4-hidroxi-2,2,6,6-tetra metil-piperidinioxila. As determinações dos valores de $g$ foram feitas utilizando-se como padrão interno a 2,2- dife nil-1-picrilidrazila (84)

9. Purificạão e Caracterização do Aduto Etill-POBN - Para obter um padrão autêntico que propiciasse o desenvolvimento de um protocolo de purificação, os radicais etila foram ge rados, na presença de POBN, pela oxidação de etilidrazina catalizada por $\mathrm{Cu}^{2+} / \mathrm{OH}^{-}$(85). A $5 \mathrm{~mL}$ de uma solução 0,2 mM de $\mathrm{CuCl}_{2}$ em tampão carbonato $0,05 \mathrm{M}, \mathrm{pH} 10$, foram adicio nadas $100 \mathrm{mg}$ de $P O B N$ e $30 \mathrm{mg}$ de etilidarazina; a solução per maneceu sob agitação por 2 hs. à temperatura ambiente (20$25^{\circ} \mathrm{Cl}$. A mistura resultante foi liofilizada e o resíduo extraido com $5 \mathrm{ml}$ de acetona. O extrato foi concentrado num rotavapor e em seguida submetido a cromatografia de camada delgada (placas de Silica gel de $500 \mu \mathrm{m}$ de espessura) usan do como solvente 5우 $(\mathrm{v} / \mathrm{v})$ metanol em clorofórmio. A banda contendo o radical aduto $\left(\mathrm{R}_{\mathrm{F}}\right.$ aproximadamente 0,4$)$ foi remo vida da placa, extraída com o mesmo solvente e re-cromatografada nas mesmas condições. A localização do radical adu to nas placas foi feita por extrações de frações da placa e análise de RPE. A quantificação do radical antes da puri ficação indicou a formação de aproximadamente $0,5 \mathrm{mg}$ que 
se reduziu a aproximadamente $0,2 \mathrm{mg}$ após as cromatografias. o espectro de massa do material isolado foi obtido num ins trumento Kratos MS - 25 sob condições de impacto de elétrons, com $70 \mathrm{eV}$ de voltagem de ionização. Ùmá incubação microssomal de larga escala ( 100 $\mathrm{mL})$ contendo $1 \mathrm{mg} / \mathrm{mL}$ de proteina, $10 \mathrm{mM}$ DDEP, $1 \mathrm{mM} \mathrm{NADPH}$ e $20 \mathrm{mM}$ POBN, foi incubada $30 \mathrm{~min}$. a $37^{\circ} \mathrm{C}$. A mistura foi en tão centrifugada por $30 \mathrm{~min}$, a $4^{\circ} \mathrm{C}$, a $.100 .000 \mathrm{xg}$. O sobrenadante foi liofilizado e o residuo extraido com acetona. o extrato foi concentrado e submetido à cromatografia como descrito para a etilidrazina, sö que a cromatografia foi repetida três vezes. A quantidade de radical obtida du rante a incubação microssomal foi de aproximadamente 0,1 mg que se reduziu a aproximadamente $0,02 \mathrm{mg}$ após a purificação. O espectro de massa do produto formado biologicamen te foi obtido nas mesmas condiçōes utillizadas para o espec tro do aduto derivado da etilidrazina.

h. Purificação e Caracterização do Aduto de POBN derivado da Fenelzina - Novamente, primeiro isolamos o aduto de POBN obtido durante a oxidação química da fenelzina para podermos dispor de um padrão. A $10 \mathrm{~mL}$ de uma solução $0,1 \mathrm{mM}$ $\mathrm{CuCl}_{2}$ em tampão carbonato $0,05 \mathrm{M}, \mathrm{pH} 10$, foram adicionadas $39 \mathrm{mg}$ de POBN e $52 \mathrm{mg}$ de fenelzina; a solução permaneceu sob agitação à temperatura ambiente, $20-25^{\circ} \mathrm{C}$, e a formação do radical aduto foi acompanhada por RPE. Após $90 \mathrm{~min}$. a mis tura foi neutralizada com $\mathrm{HCl}$ e liofilizada. O resíduo foi extraído com $10 \mathrm{~mL}$ de acetona, esta removida num rotavapor e o novo resíduo, dissolvido em $\mathrm{CHCl}_{3}$, foi submetido a cro 
matografia numa coluna de silica gel 60 , de $10 \times 260 \mathrm{~mm}$, e eluido com 5\% de metanol em clorofórmio. As frações èluidas foram analisadas por RPE para detectar o aduto e por espectroscopia de UV para detectar o POBN. As frações que apresentavam sinal de RPE e pouca contaminação de POBN fo ram combinadas, concentradas e recromatografadas numa colu na Merck Lobar, pré-empacotada, de silica gel de 10 x 240 mm. A coluna foi eluida com o mesmo solvente, 58 metanolem clorofórmio, em condições de baixa pressão. As frações elui das, de $0,5 \mathrm{~mL}$, eram acompanhadas continuamente a $280 \mathrm{~nm}$ ( o máximo de absorção do radical aduto). As frações apro priadas foram combinadas e o solvente removido sob nitrogê nio. O radical aduto obtido, aproximadamente $300 \mu \mathrm{g}$ por pe so numa balança Cahn, foi caracterizado por espectroscopia de absorção eletrônica e de massa.

o aduto obtido biologicamente foi isolado de uma incubação microssomal em larga escala (125 mL) contendo 1 $\mathrm{mg} / \mathrm{mL}$ de proteina microssomal, 5mM fenelzina, 20mM POBN, $0,3 \mathrm{mM} \mathrm{NADP}{ }^{+}, 5$ unidades $/ \mathrm{mL}$ de isocitrato desidrogenase, 5 $\mathrm{mM}$ isocitrato, $5 \mathrm{mM} \mathrm{MgSO}_{4}, 150 \mathrm{mM} \mathrm{KCl}$ e 1,5 mM DETAPAC em tampão fosfato $0,1 \mathrm{M} \mathrm{pH} \mathrm{7,4.} \mathrm{A} \mathrm{mistura} \mathrm{foi} \mathrm{incubada} \mathrm{a} 37^{\circ} \mathrm{C}$ por $60 \mathrm{~min}$. e então centrifugada a $100.000 \mathrm{xg}$ por $30 \mathrm{~min}$. o sobrenadante foi liofilizado, o resíduo extraído com 20 ml de acetona e o aduto de spin foi então purificado como descrito acima para o aduto gerado quimicamente. Contudo, devido ao grande excesso de POBN, a cromatografia na colu na Merck Lobar foi realizada duas vezes para purificação do aduto formado biologicamente. 
Os espectros de absorção eletrônica dos adutos fo ram obtidos num espectrofotômetro Hewlett-Packard HP 8450 A e os espectros de massa no instrumento Kratos MS-25 sob con dições de impacto de elétrons $(70, \mathrm{eV})$. 


\section{REsultados e Discussão}

3.1. Efeito dos Captadores de Spin sobre o Metabolismo Micros somal: Isolamento Biológico do Aduto Etil-POBN

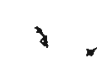

Os nossos primeiros estudos de aplicação da téc-

nica do captador de spin em sistemas microssomais, já nos co locara a questão da diferença de efetividade observada com dois dos captadores mais comumente empregados em sistemas bio lógicos. Assim, a oxidação microssomal da etilidrazina leva a obtenção de um aduto estável de PBN mas a nenhum aduto observável de DMPO (85). Todavia, ambos os compostos apresentam cons. tantes de velocidade aparentes bastante similares para a rea ção de captação de radicais de carbono (Tabela 2). Também, nos sos estudos demonstravam que eles eram igualmente eficientes para captar radicais de carbono gerados em sistemas aquosos, como àqueles formados durante a oxidaçăo de derivados de hidrazina catalisada por $\mathrm{CuCl}_{2}$ em meio alcalino, ou por oxiemoglobina em tampão fosfato $(85,86)$. Esses nossos resultados eram compatíveis com outros descritos na literatura que contudo,não fornecia explicaçöes para esse comportamente diferenciado. Ha via, inclusive, a colocação de uma possível idiossincrasia dos diferentes captadores de spin (59).

Apesar de todas as lacunas exitentes na literatú ra sobre a técnica do captador de spin, vislumbrávamos a sua potencialidade e resolvemos continuar aplicando-a, tentando contribuir para o preenchimento daquelas lacunas.

Os nossos estudos preliminares, aplicando a téc 
nica na oxidação microssomal do DDEP (ver Fig. 8, abaixo) indicaram a formação de radicais de carbono por captação com PBN (87). Contudo, a quantidade de aduto de spin obtida era muito pequena e nos colocava frente ao problema da identifica ção do radical căptado. O DMPO, que poderia ser mais adequado para a identificação do radical primário (Tabela 1), novamente se mostrava inefetivo no sistema microssomal. Na ausência de uma base racional para a escolha do captador de spin, uti lizamos a abordagem das tentativas e ensaiamos o POBN em nosso sistema. Para nossa surpresa, o rendimento do radical adu to obtido durante a oxidação microssomal do DDEP em presença de POBN, era cerca de cinco vezes maior que o obtido em presen ga de PBN (Fig. 3) .

Esse resultado inesperado recolocava uma sērie de questões. Primeiro, não eram conhecidas as estabilidades re lativas āos adutos de $\mathrm{PBN}$ e POBN. Também, .não era possível de terminar se os dois compostos estavam captando o (s) mesmo (s) radical (is). Supondo que estivessem e que as estabilidades dos adutos fossem comparāveis, como, novamente, explicar as diferenças de efetividade? Para responder essas questões era necessário fazer um estudo sistemático sobre os efeitos dos captadores de spin sobre o metabolismo microssomal. Não se po de esquecer que ao adicionar o captador de spin se está intro duzindo uma perturbação no sistema microssomal, nem tampouco, que esse sistema enzimático é bastante inespecífico quanto ao substrato, sendo capaz de interagir com toda uma gama de diferentes compostos químicos. 

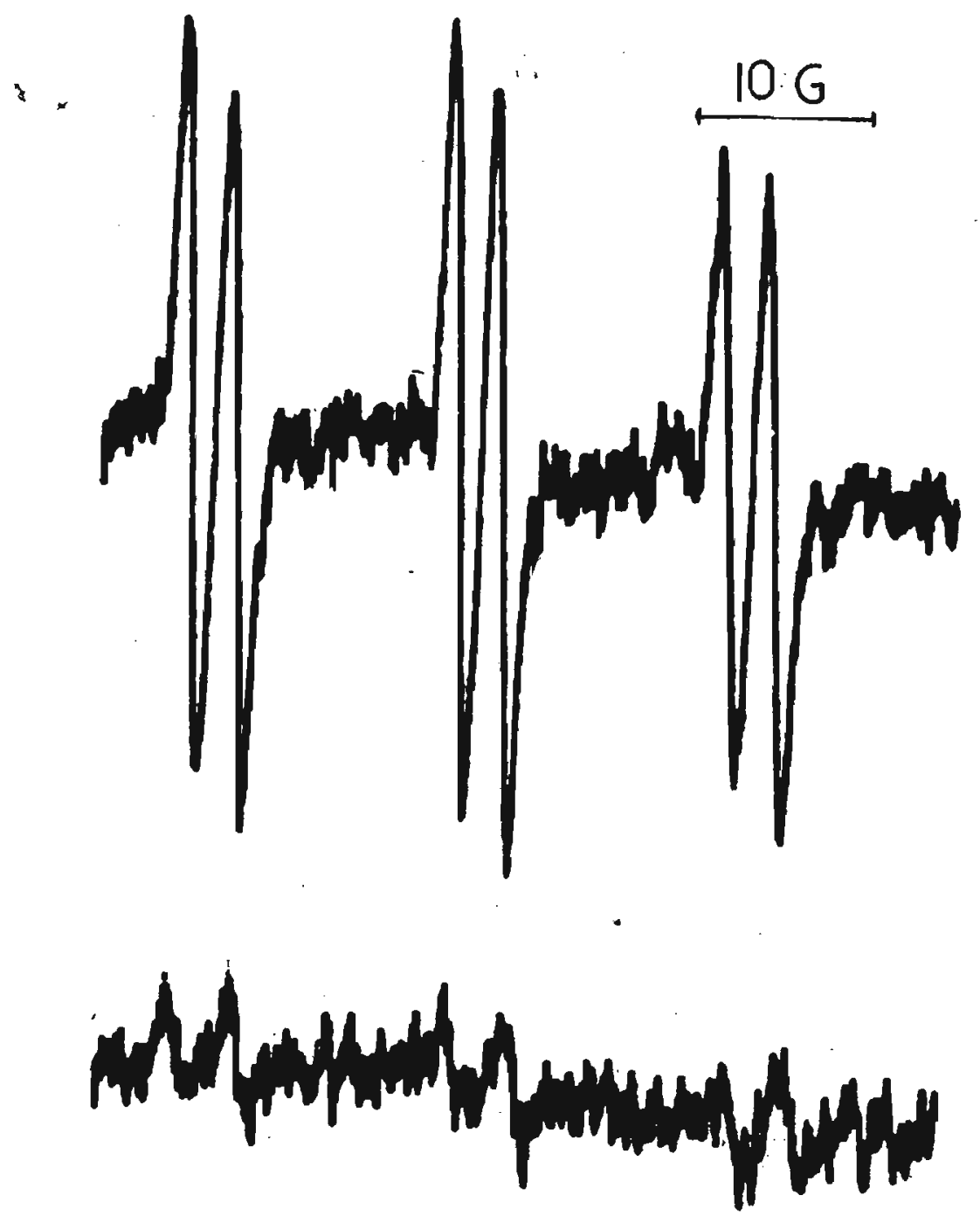

Figura 3. - Comparação do espectro de RPE obtido após 30 min. de metabolismo microssomal de DDEF em presença de $100 \mathrm{mM}$ POBN (espectro superior) ou $100 \mathrm{mM}$ PBN (es pectro inferior): "A incubação foi realizada nas condições padrão como descrito em Materiais e Métodos. Ajustes do instrumento: potência, $10 \mathrm{~mW}$; amplitude de modulação $1,0 \mathrm{G}$; constante de tempo 1,0 $\mathrm{s}$; intervalo de varredura, $200 \mathrm{G}$, tempo de varredura $30 \mathrm{~min}$. 
a. Efeito dos Captadores de Spin Sobre o Metabolismo Microssomal. - Escolhemos como substrato o DDEP, de nosso interesse imediato,e a benzftamina um clássico substrato do citocromo $\mathrm{P}_{450^{\circ}}$ O metabolismo do DDEP foi acompanhado indiretamen te, pela destruição do citocromo $\mathrm{P}_{450}$ por ele induzida (79) e a N- demetilação da benzftamina foi acompanhada pela formação de formaldeido. Os resultados obtidos são apresentados na Fig.4, e mostram que os captadores inibem ambos os processos e o f zem numa extensão que se correlaciona com a habilidade des ses compostos formarem adutos estāveis, observáveis por RPE , durante o metabolismo microssomal do DDEP.

O DMPO, que não forma adutos estáveis nessa con dições, não inibe praticamente nem a destruição do citocromo ${ }^{P_{450}}$ mediada por DDEP, nem a N-demetilação da benzftamina. Por sua vez, o PBN inibe fortemente ambos os processos, e o POBN, o capta dor mais eficiente no sistema do DDEP, não inibe a destrui ção do enzima e tem um efeito intermediário, entre o do DMPO e do PBN, sobre a N-demetilação da benzftamina (Fig. 4).

b. Ligação dos Captadores de spin ao Citocromo $\mathrm{P}_{450}$ - Uma pos sível explicação para os efeitos inibitórios observados é a de que $\circ$ PBN e $\circ$ POBN competem efetivamente com os subs tratos para ligação no sỉtio ativo, enquanto que o DMPO não $\circ$ faz. Essa hipótese pode ser facilmente testada, acom panhando-se a ligação dos captadores de spin ao citocromo $\mathrm{P}_{450}$ microssomal, por espectroscopia diferencial (35). De fato, o DMPO produz um espectro tipo II quando se liga ao citocromo $\mathrm{P}_{450}$ oxidado, mas a interação é caracterizada por uma alta constante de dissociação aparente (Ks=6100 $\mu \mathrm{M})$ (Fig.5) . 


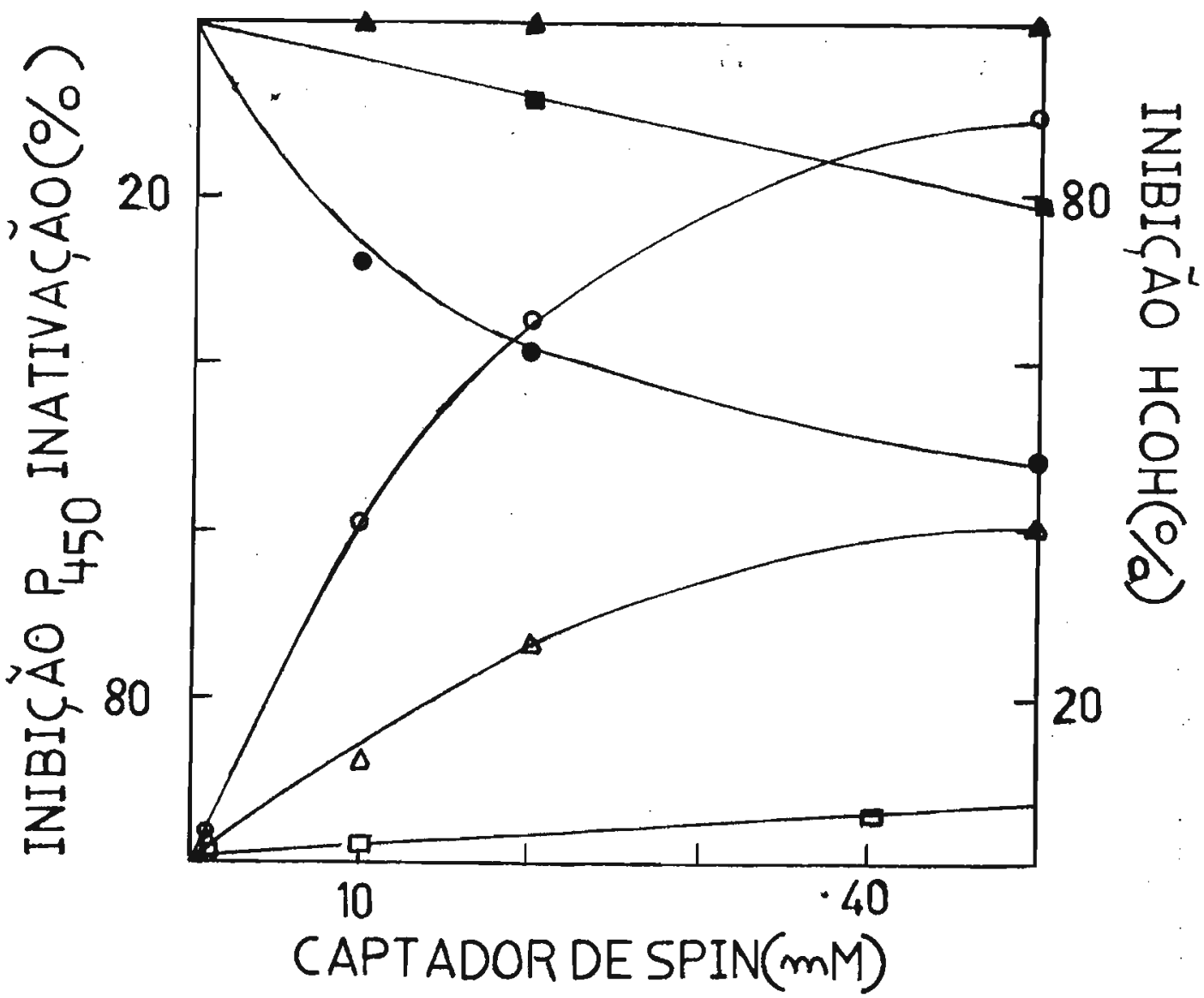

Figura 4. - Inibição, por três captadores de spin, da destrui ção do citocromo $\mathrm{P}_{450}$ mediada por DDEP e da $\mathrm{N}$-demetilação da benzftamina. As ordenadas à esquerda referem-se à porcentagem de inibição da destruição do citocromo pelas concentrações estipuladas de $\operatorname{DMPO}(\bullet), \operatorname{PBN}(\bullet)$ e $\operatorname{POBN}(\bullet)$. As ordenadas à direita correspondem à porcentagem de inibição da $\mathrm{N}$-demetilação da benzftamina pelas concentrações estipuladas de DMPO (口), PBN $(0)$ e POBN $(\Delta)$.As condições de incubação são as descritas em Materiais e Métodos. A máxima destruição do citocromo $\mathrm{P}_{450}$, em ausência dos captadores, corresponde a $39 \%$ do total da enzima presente nas preparações micirossomais 
A ligação de $\mathrm{PBN}$ resulta no aparecimento de um espectro tí po I e uma constante de dissociação aparente de $150 \mu \mathrm{M}$, enquanto que a do POBN resulta num espectro tipo II, a partir da qual se determina uma constante de dissociação aparente de $700 \mu \mathrm{M}$ (Fig. 5). Assim, o PBN parece ligar-se ao citocro mo $\mathrm{P}_{450}$ oxidado cinco vezes mais fortemente que o POBN e trinta e cinco vezes mais fortemente que o DMPO. Deve-se con tudo lembrar que esse tipo de abordagem experimental não estabelece que os três captadores estejam ligados ao mesmo isoenzima. Também, para propósitos comparativos, apresentamos os valores das constantes de dissociação aparente para - DDEP, um substrato tipo I, de $2 \mu \mathrm{M}$ (Fig. 5) e para a benzf tamina, também um substrato tipo I, de $10 \mu \mathrm{M}$ (88).

Os resultados sumarizados na Fig. 4 e Fig.5, mos tram que a inibição da demetilação da benzftamina correlaciona muito bem com as afinidades relativas dos captadores de spin pelo citocromo $\mathrm{P}_{450}$. O DMPO se liga fracamente e inibe pouco a demetilação; 0 PBN se liga fortemente e inibe bastante, enquanto que o POBN ocupa uma posição intermediária tanto quanto à ligação como quanto à inibição. Os resul tados também explicam a relativa ineficiência do PBN para captar os radicais derivados do DDEP. Se o isoenzima que catalisa o metabolismo do DDEP é inibido fortemente pelas altas concentrações de PBN utilizado nos experimentos de captação, só se pode esperar um baixo rendimento de adutos de spin. Para testar definitivamente essa hipótese, comparou-se o sinal de RPE obtido durante o metabolismo microsso mal de DDEP na presença de cada um dos captadores, e de am- 

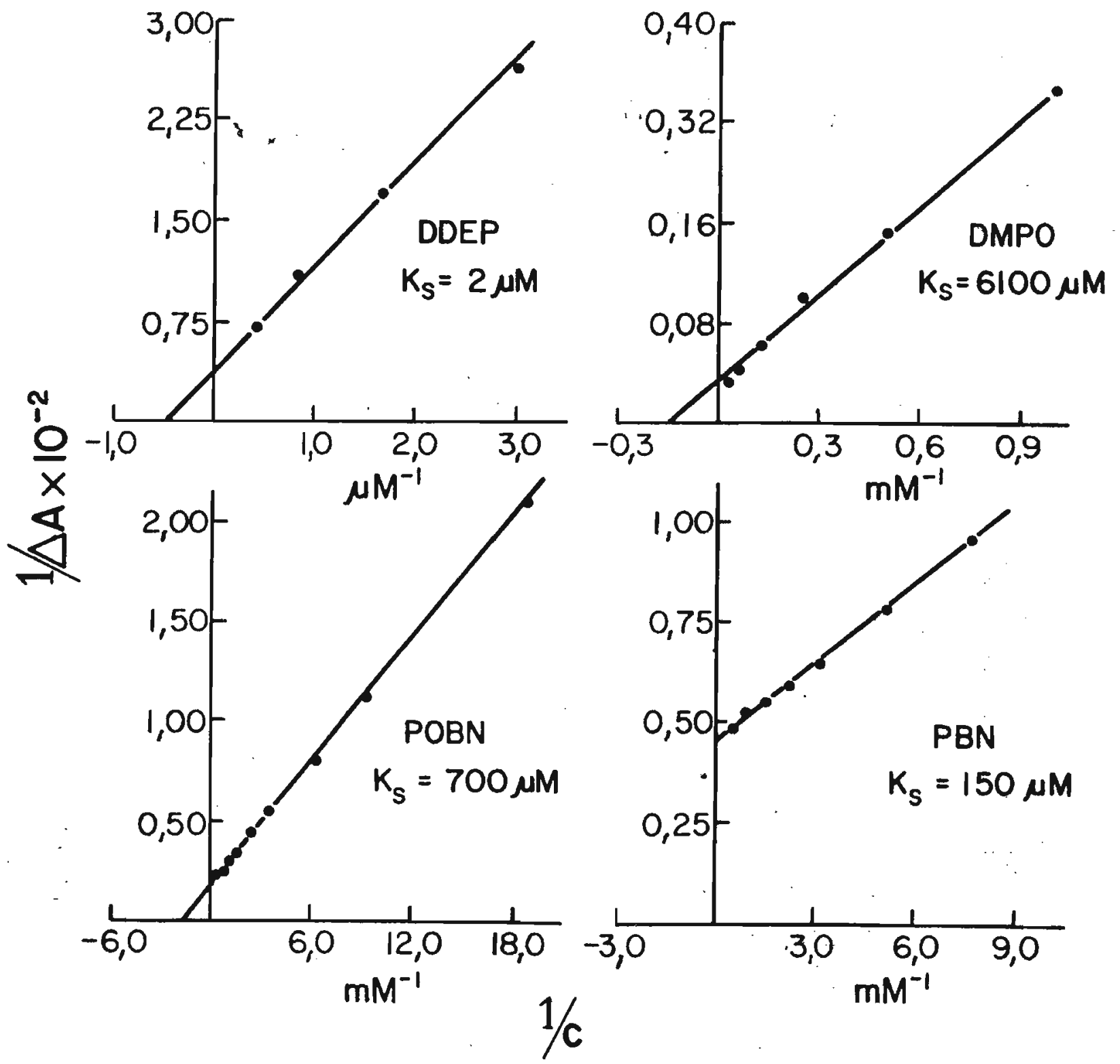

Figura 5. - Ligação do DDEP e dos captadores de spin ao citocromo $\mathrm{P}_{450}$ de ratos pré-tratados com fenobarbital. As constantes aparentes de dissociação foram obtidas como descrito em Materiais e Métodós. 
bos, ao mesmo tempo. A Tabela 3 mostra que o sinal de RPE obtido em presença de POBN sozinho é reduzido em $70 \%$ de seu valor quando PBN está presente. Assim, os . captadores não funciog̣am independentemente e o PBN inibe, de fato, a formação de radicais durante o metabolismo microssomal do DDEP .

Tabela.3. - Rendimento de Adutos de Spin Durante o Metabolismo Microssomal do DDEP

Adições à Mistura Padrão
de Reação a

Nenhuma

DMPO $(50 \mathrm{mM})$

PBN (50mM)

POBN $(5 \mathrm{mM})$

POBN $(10 \mathrm{mM})$

POBN (20mM)

POBN (50mM)

PBN (50mM) + POBN (20mM)
Altura do Sinal de $\operatorname{RPE}(\mathrm{cm})^{\mathrm{b}}$
ND

1,7

4,6

6,4

9,3

8,1

3,1

a Mistura de reação contém $1 \mathrm{mg} / \mathrm{ml}$ de proteina microssomal,1mM NADPH e $10 \mathrm{mM}$ DDEP em tampão fosfato $0.1 \mathrm{M} \mathrm{pH} 7.4$ contendo $150 \mathrm{mM} \mathrm{KCl}$ e $1.5 \mathrm{mM} \mathrm{EDTA}$

b Altura do pico de RPE de baixo campo após $30 \mathrm{~min}$. de incubação a $37^{\circ} \mathrm{C}$

C ND, não detectável 
c. Isolamento e Propriedades Espectroscópicas do Aduto Radical Etil-POBN - Esses nossos estudos sistemáticos, alēm de oferecerem uma explicação bem fundamentada para a maior efetividade do POBN em captar radicais de carbono durante - metabolismó microssomal do DDEP, nos levou a conjecturar sobre a possibilidade de isolar e caracterizar estruturalmente o aduto obtido. Como já colocado várias vezes, os pa râmetros do espectro de RPE são insuficientes para uma iden tificação inequívoca dos adutos dos captadores de spin, e a situação é ainda pior para o caso dos adutos de POBN. Este captador só foi introduzido em 1979, tem sido pouco utilizado e estudado, não havendo ainda uma compilação dos parâmetros de RPE de seus adutos, como existe para o T-NB, PBN e DMPO (ver, por exemplo, a Tabela 1).

A concentração do aduto de POBN obtida durante o metabolismo microssomal do DDEP (aproximadamente 10 $\mu \mathrm{M}$ ) é alta, quando comparada ao rendimento de outros radicais de carbono, mas ainda insuficiente para o desenvolvimento de um protocolo de purificação do adu'to, principalmen te quando se parte de um sistema tão complexo.

A ausência de tentativas anteriores de isolamento desses adutos, nos levou a desenvolver um protocolo de purificação partindo de um sistema mais simples e que gerasse um alto rendimento dos radicais adutos. Escolhemos a oxidação da etilidrazina catalisada por $\mathrm{CuCl}_{2}$ em meio alca lino. Nós já haviamos demonstrado a obtenção de um alto ren dimento de radicais adutos de DMPO e PBN (da ordem de mM) durante a oxidação de alquilidrazinas catalisada por $\mathrm{Cu}^{2+} /$ 
$\mathrm{OH}^{-}(85,86)$. Escolhemos a etilidrazina, porque era o radi cal etila aquele que esperāvamos obter durante o metabolis mo microssomal do DDEP (Ver Fig. 8, abaixo).

Após algumas tentativas, conseguimos de fato purificar, por sucessivas cromatografias em silica gel (ver Materiais e Métodos), o aduto de POBN obtido durante a oxi dação química da etilidrazina. o espectro de massa do radi cal estável purificado (Fig. 6), apresenta o pico do íon molecular a m/e 223 e um pico mais intenso a m/e 222 , que seria esperado pela perda de um hidrogênio do aduto etilPOBN (PM = 223); o pico a m/e 166 pode ser atribuído à per da do grupo t-butila e de fato, essa quebra é também obsex vada no espectro de massa do POBN, que apresenta um forte pico a m/e 138, consistente com a perda daquele grupo a partir do íon molecular a m/e 194 (não apresentado).

Desenvolvido o protocolo, ełe foi adaptado ao sistema microssomal. Considerando a relação existente entre as concentrações do radical aduto, aproximadamente $\mu$, e a do POBN adicionado ao sistema, da ordem de $100 \mathrm{~mm}$ em estudos clássicos de captação de spin, primeiro procuramos diminuir a concentração de POBN numa extensão que não afetasse o rendimento de radicais adutos. A tabela 3 , mostra que $20 \mathrm{mM}$ de POBN pode ser considerada uma concentração óti ma e essa foi aquela utilizada nos nossos experimentos de purificação. Mesmo assim, tivemos que introduzir mais sepa rações cromatográficas para o sistema microssomal e o radi cal aduto purificado apresentou ainda uma certa contaminação de POBN, detectável no espectro de massa. Apesar dessa con 
taminação, é indescutível que, tanto no processo químico co mo no enzimátić, ocorre a formação do aduto etil-POBN. Ambos adutos purificados apresentam o mesmo espectro de massa (Fig. 6) e o mesmo espectro de $\operatorname{RPE}$ com $a_{N}=15,73$ e $a_{H}=2,74$ em àgua e $a_{N}=14,43$ e $a_{H}=2,50$ em benzeno $(\mathrm{F} \underline{i}$ gura 7).

a.
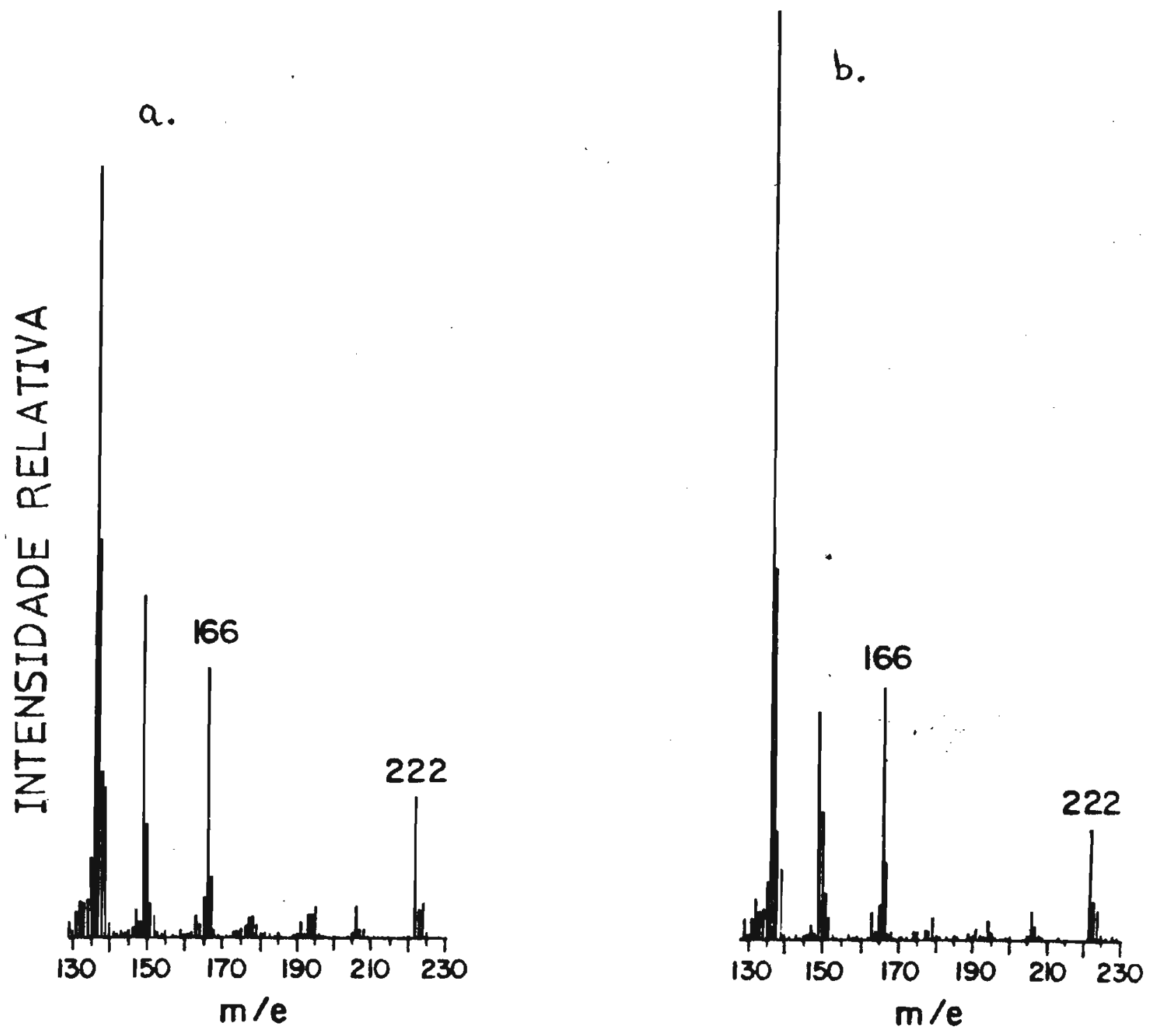

Figura 6. - Região superior do espectro de massa do aduto etilPOBN obtido a partir de: (a) etilidrazina/ $\mathrm{Cu}^{2+} / \mathrm{OH}^{-}$ e (b) incubações microssomais de DDEP. O espectro (b) foi corrigido por subtração dos picos devido ao POBN contaminante. 

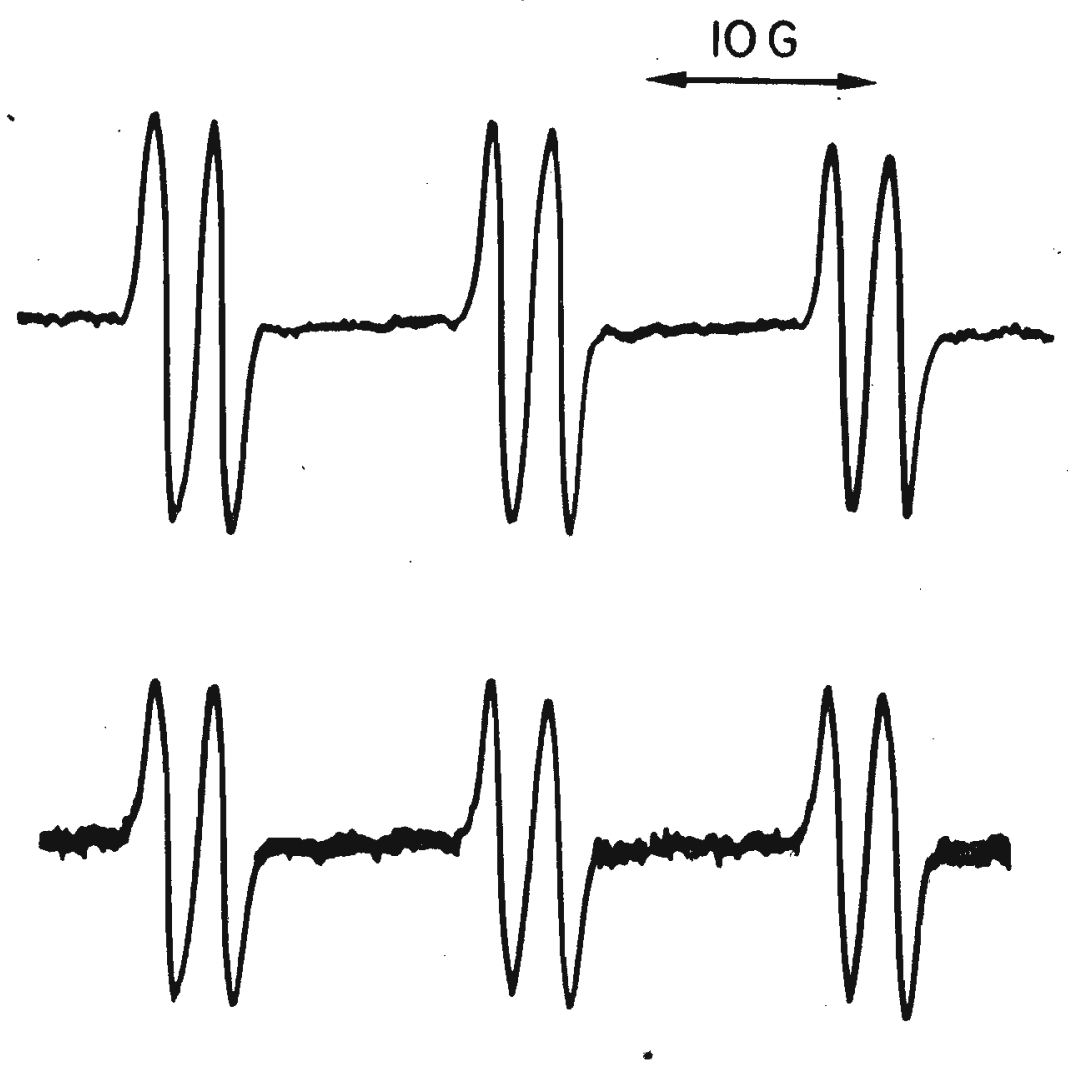

Figura 7. - Comparação do espectro de RPE em benzeno dos adū tos de POBN obtidos a partir de (a.) etilidrazina/ $\mathrm{Cu}^{2+} / \mathrm{OH}^{-}$e (b) incubações microssomais de DDEP.

Ajustes do instrumento: potência, $10 \mathrm{~mW}$; amplitude de modulação, 0,5G; constante de tempo, $0,3 \mathrm{~s}$; in tervalo de varredura, 100G; tempo de varredura 8 min.

d. Conclusões - Esses estudos sitemáticos forneceram uma expli cação racional para as diferentes efetividades dos captado res de spin em sistemas microssomais. Explorando essas di ferenças conseguimos, pela primeira vez na literatura, iso lar e caracterizar espectroscopicamente, um aduto de radi cal de carbono formado durante o metabolismo microssomal. 
Isso nos abriu a possibilidade de abordar mecanisticamente, detalhes do metabolismo de xenobióticos que não fora possí vel até então. Apresentaremos no item 3.2. um estudo completo, abordanđo não só a formação de radicais de carbono, como as sụas ìnterações com biomoléculas.

No caso do metabolismo microssomal do DDEP, a cą racterização inequívoca da formação do aduto etil-PoBN foi um passo fundamental para demonstrarmos que, pelo menos no caso do DDEP e compostos relacionados, a oxidação do nitro gênio pelo citocromo $\mathrm{P}_{450}$ ocorre por passos de um elétron. $\mathrm{Na}$ verdade, nossos estudos foram mais abrangentes e além da técnica de captação de spin, empregamos outras abordagens experimentais, inclusive sintese de derivados de DDEP, como N-etil-DDEP para definitivamente eliminar uma das possiveis vias de oxidação (viac, Fig. 8), e outros derivados para estudar a relação estrutura versus metabolismo versus capacidade de transalquilação do grupo prostético do citocromo $\mathrm{P}_{450}$. Esses resultados são detalhadamente descritos na referência 30 . 


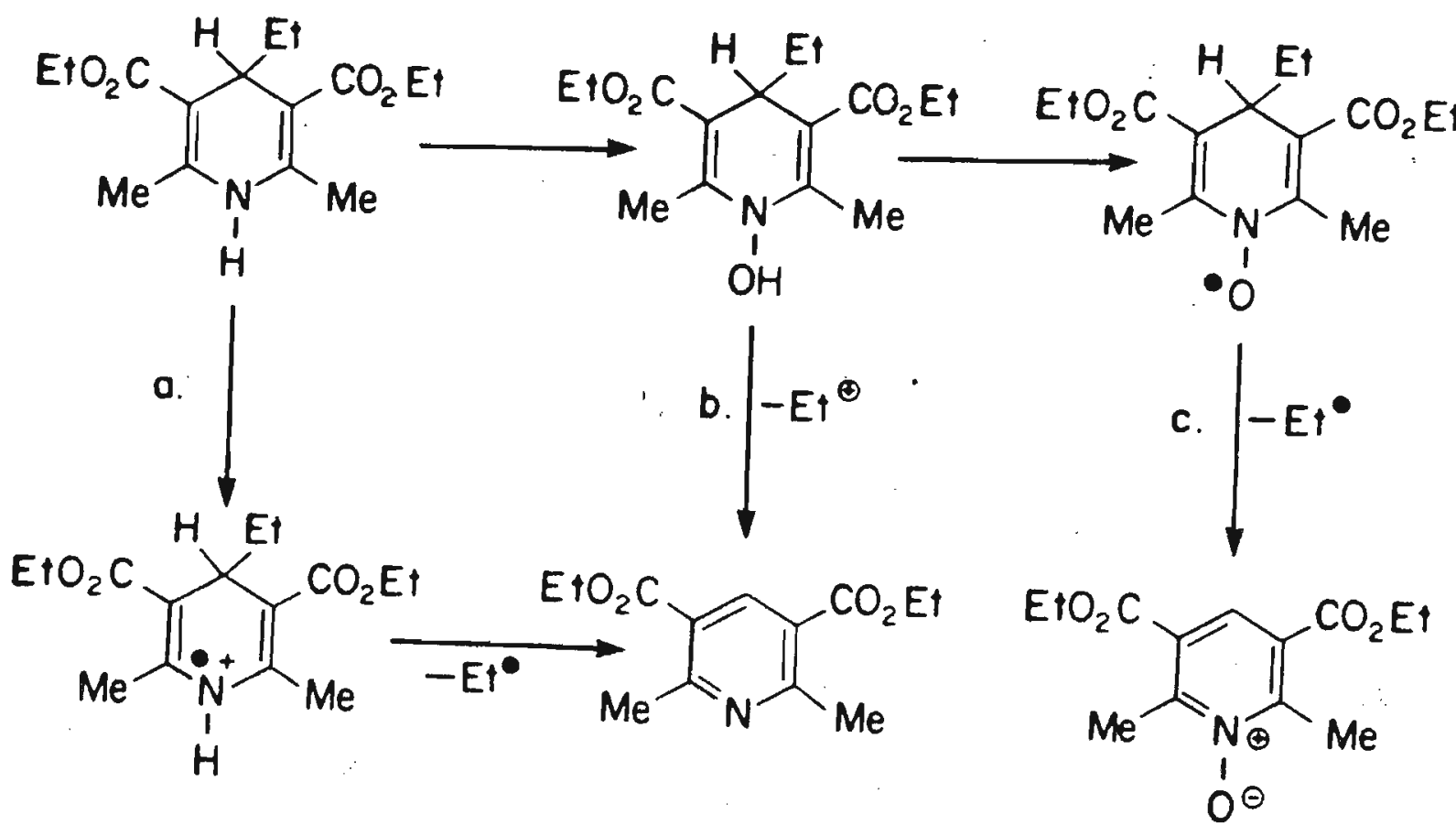

Figura 8. - Possíveis vias para a oxidação microssomal do DDEP. A ünica via compativel com nossos estudos completos (30) é a via a.

3.2. Formação de Radicais de Carbono durante o Metabolismo da Fenelzina: Implicações Toxicológicas e Terapêuticas

Os derivados de hidrazina apresentam vārias apli cações industriais e tecnológicas destacando-se o seu uso como combustiveis de foguetes, antioxidantes, herbicidas e remé dios (89). As drogas atualmente em uso que devem a sua atividade farmacológica à presença do grupo hidrazina nas suas es truturas incluem: (i) inibidores da monoamino oxidase, isocar 
boxazida, nialamida e fenelzina; (ii) o agente antihipertensi vo hidralazina; (iii) o agente antituberculose, isoniazida e (iv) a droga anticancer, procarbazina (90) (Esquema 10)<smiles>CC1=CCC(C(=O)NNCc2ccccc2)O1</smiles>

ISOCARBOXAZIDA<smiles>NNCCc1ccccc1</smiles>

FENELZINA

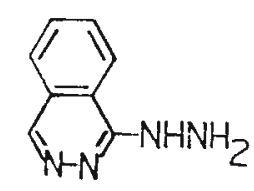

HIDRALAZINA<smiles>O=C(CNNC(=O)c1ccncc1)NCc1ccccc1</smiles>

NIALAMIDA<smiles>NNC(=O)c1ccncc1</smiles>

ISONIAZIDA<smiles>CNNCc1ccccc1</smiles>

PROC ARBAZINA

(Esquema 10)

Todavia,a aplicação de derivados de hidrazina co mo remédios fica comprometida pelo fato de que eles são meta bolicamente ativados a espécies que promovem uma série de efei tos tóxicos. O metabolismo da isoniazida pode levar à necrose hepática em certas circunstâncias (91), o da hidralazina pode resultar em cancer (92) e lupus eritematoso (93) e o da fenel zina, em cancer $(94,95)$. Até recentemente acreditava-se que es pécies catiônicas derivadas das drogas fossem os agentes alqui lantes, responsáveis pelos efeitos tóxicos observados (96).

Alēm da toxidade, há muito era conhecida a propriedade de derivados de hidrazinas inibirem o metabolismo oxi dativo de drogas co-administradas (97-99). Mais recentemente, 
estudos com fenilidrazina (100) e fenelzina (101) demonstraram que a inibição do metabolismo oxidativo por esses agentes era devida, pelo menos em parte, à inativação irreversível do citocromo $\mathrm{P}_{450}$. microssomal. Tal inativação requeria a transformação catalítica dos substratos pelas enzimas vulneráveis e estava associada à acumulação de pigmentos hepáticos não identificados. O desconhecimento da estrutura desses pigmentos, bem como do mecanismo de sua formação nos levou a estudar o metabolismo microssomal de aquilidrazinas, principalmen te da fenelzina, em detalhes.

a. Metabólitos da Fenelzina - Esse composto é extensivamente metabolizado "in vivo", inclusive pelo homem, sendo muito pequena a fração excretada como formas que mantém intacta a função hidrazina (102). Dentre as suas transformações já descritas, incluem-se: (i) ao ácido 2-fenilacético,"in vivo" e por homogenatos de fígado $(103,104) ;$ (ii) à fenilidrazona do 2-fenilacetaldeído, pela monoamino oxidase mitocondrial (105) e (iii) ao N-acetil derivado, pelo citosol he pático de homens e ratos $(106)$.

Nốs estudamos o metabolismo microssomal hepātico da fenelzina, utilizando ratos induzidos com fenobarbital. As misturas de incubação foram extraídas com hexano e submetidas a cromatografia gasosa. Pode-se constatar a formação de cinco metabólitos dependentes da presença de NADPH (Fig. 9). Destes, três foram inequivocamente identificados por cromatografia gasosa e comparação do espectro de massa de amostras autênticas, como: etibenzeno (pico A), 2-fenil acetaldeído (pico D) e 2-feniletanol (pico F) (Fig. 9); os 
metabōlitos correspondentes aos picos C e E não foram iden tificados.

A observação de que a fenelzina é oxidada por mi crossomos ao 2-fenilacetaldeido é consistente com os resul tados obtidos' "in vivo", à medida que sãobem conhecidas as oxidações de aldeidos a ácidos por enzimas do citosol. As pequenas concentrações de 2 -feniletanol obtidas são, pro vavelmente, produto da redução do 2-fenilacetaldeido. De fato, as nossas preparações microssomais são capazes de re duzir o aldeido ao álcool (controle não apresentado) e tam bém, já foi descrito na literatura uma atividade aldeído re dutase microssomal (107). O outro metabólito microsscmal da fenelzina, que aparece em quantidades apreciáveis,é. o etil benzeno (pico A, Fig. 9). Esses nossos estudos mostram que o etilbenzeno é formado por via radicalar e que este processo é o responsável pela destruição do citocromo $\mathrm{P}_{450}$ (ver abaixo).

b. Destruição do Citocromo $\mathrm{P}_{450}$ e sua Relação com a Formação de Metabólitos - A incubação de fenelzina com ... microssomos leva à destruição do citocromo $\mathrm{P}_{450}$ (Fig. 10). Essa perda do enzima também ocorre, embora em menor extensão, na ausēncia de NADPH. Alēm da fenelzina, outras alquilidrazinas promovem a inativação do citocromo $\mathrm{P}_{450}$ e a Fig. 10 inclui também, os efeitos observados durante o metabolismo micros somal da benzilidrazina.

Para estabelecer possiveis relações entre a des truição do enzima e a formação de metabólitos, essa foi acompanhada e quantificada em função do tempo. Os resulta- 


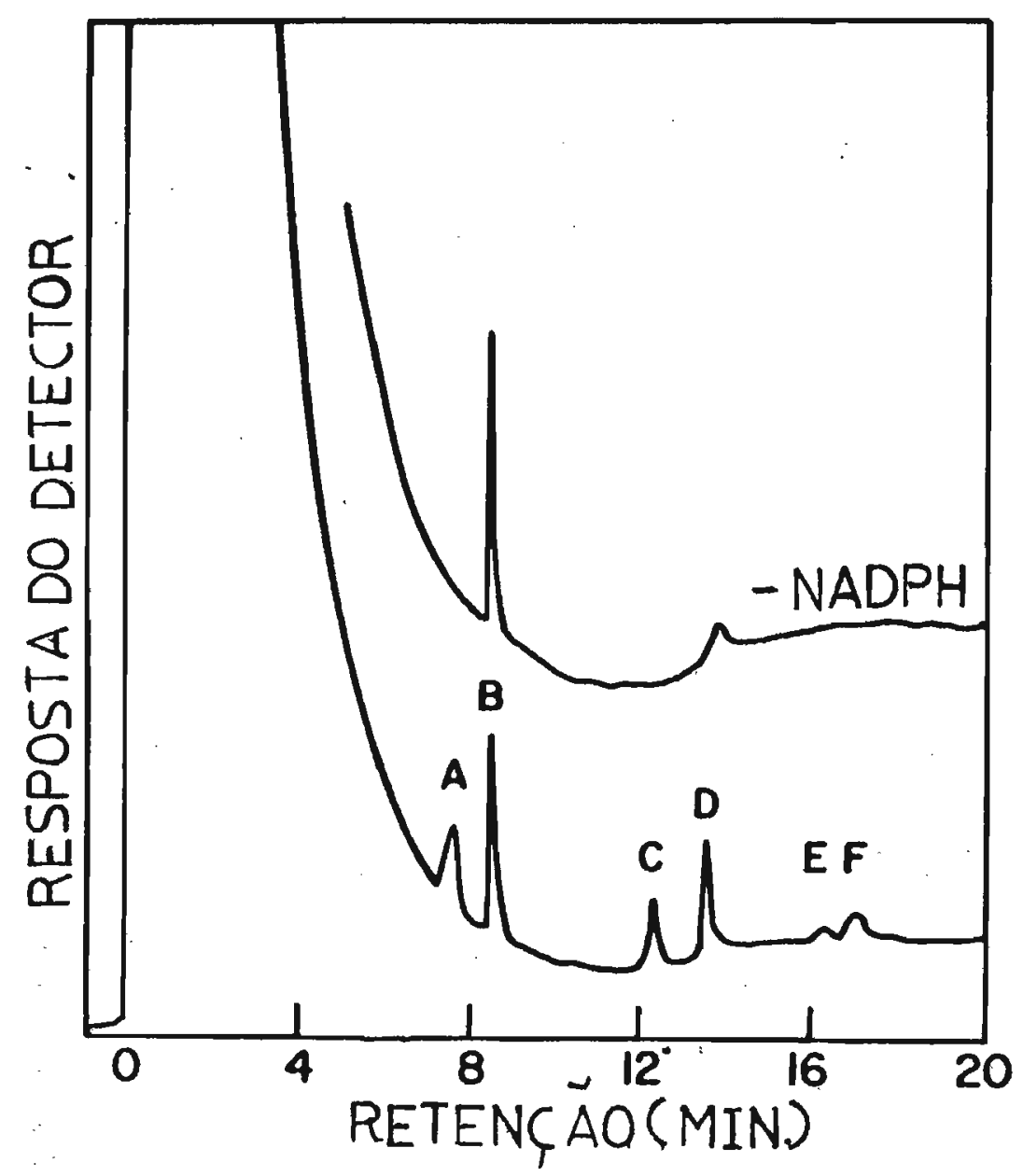

Figura 9. - Análise cromatográfica dos metabólitos extraídos com hexano de incubações microssomais da fenelzina em presença (traço inferior) e em ausência (tra co superior) de NADPH. As condições de incubação estão descritas em Materiais e Métodos. O pico B é devido ao propilbenzeno utilizado como padrão interno. O traço superior foi obtido em condições de maior sensibilidade do instrumento. Durante a obtenção do cromatograma, a temperatura da coluna foi variada de $50^{\circ} \mathrm{C}$ a $200^{\circ} \mathrm{C}$ a uma velocidade de aumento de $15^{\circ} \mathrm{c} / \mathrm{min}$. 
dos apresentados na Fig. 11, mostram que após 60 min.de in cubação são formados 270 nmoles $(11 \mu \mathrm{M})$ de etilbenzeno e $728 \cdot \mathrm{n}$ moles $(29 \mu \mathrm{M})$ de fenilacetaldeído; no mesmo experimento determinou-se a formação de $118 \mathrm{n}$ moles $(4,7 \mu \mathrm{M})$ de 2-feniletanoli (não apresentado). Evidentemente esses números não podem ser tomados como reais quando se considera a al ta volatilidade dos produtos bem como a possibilidade de sofrerem reações químicas e enzimáticas no sistema microssomal. Para a obtenção de números mais próximos dos valores reais, realizaram-se experiências controles.Nessas,quan tidades conhecidas de etilbenzeno e de 2-fenilacetaldeído foram submetidos ao mesmo procedimento experimental utilizado para a fenelzina, da incubação microssomal à extração com hexano e análise cromatográfica. Constatou-se que a quan tidade de metabólitos recuperada nos extratos ficava entre 15-25\% da quantidade inicialmente adicionada. Assim, as quantidades de 2-fenilacetaldeído e etilbenzeno formadas du rante o metabolismo microssomal da fenelzina, são pelo menos quatro vezes maiores que os números aprésentados na Fig. 11 .

Essa figura compara a formação dos metabóltitos com a destruição do citocromo $\mathrm{P}_{450}$. Pode-se notar que praticamente todo enzima suscetível à inativação por fenelzina, es tá destruído nos primeiros 15 min. de incubação. O fato de que a quantidade de etilbenzeno continua a aumentar após os 15 min. iniciais sugere que existem outros caminhos, in dependentes de NADPH, para a sua formação. A ausência de uma quebra na curva de formação do 2-fenilacetaldeído suge 
re que o citocromo $\mathrm{P}_{450}$ deve contribuir muito pouco para a sua produção. Por outro lado, a natureza bifásica da pro dução do etilbenzeno sugere que a fração do citocromo $\mathrm{P}_{450}$ que é passível de destruição, contribui consideravelmente para a formaçã̀o desse metabólito.

A figura 11 permite estimar o número de moléculas de fenelzina que serão oxidadas até que um evento de des truição do citocromo $\mathrm{P}_{450}$ ocorra. Essa razão não correspon de exatamente à razão de partição que caracteriza a destruição de um enzima por um inibidor suicida (108), porque não é uma medida da partição intrínseca do substrato no sí tio ativo do enzima. Apesar disso, aquela razão pode dar uma estimativa da eficiência fisiológica da fenelzina como agente destrutivo do citocromo $\mathrm{P}_{450}$. Para diminuirmos a con tribuição de reações não mediadas pelo citocromo, tomamos a soma dos produtos formados e o número dei molếculas de enzima des truídos,após 15 min. de metabolismo microssomal. A razão entre esses números fica entre 5-6, com os valores da Fig. 11, ou 20-24 se se considera a correção devida à recuperação dos metabólitos durante o procedimento de análise. Assim, um pequeno número de moléculas de fenelzina é oxidada até que ocorra um evento de inativação do enzima, sugerindo que esse composto é um eficiente agente destruidor do citocromo $\mathrm{P}_{450^{\circ}}$

c. Estrutura do Produto da Inativação do Citocromo $\mathrm{P}_{450}$ Mediada pela Fenelzina - Muakkassah e Yang (101) constataram que a destruição do citocromo $\mathrm{P}_{450}$ por fenelzina, "in vitro" , era acompanhada de um descoramento das preparações micros 


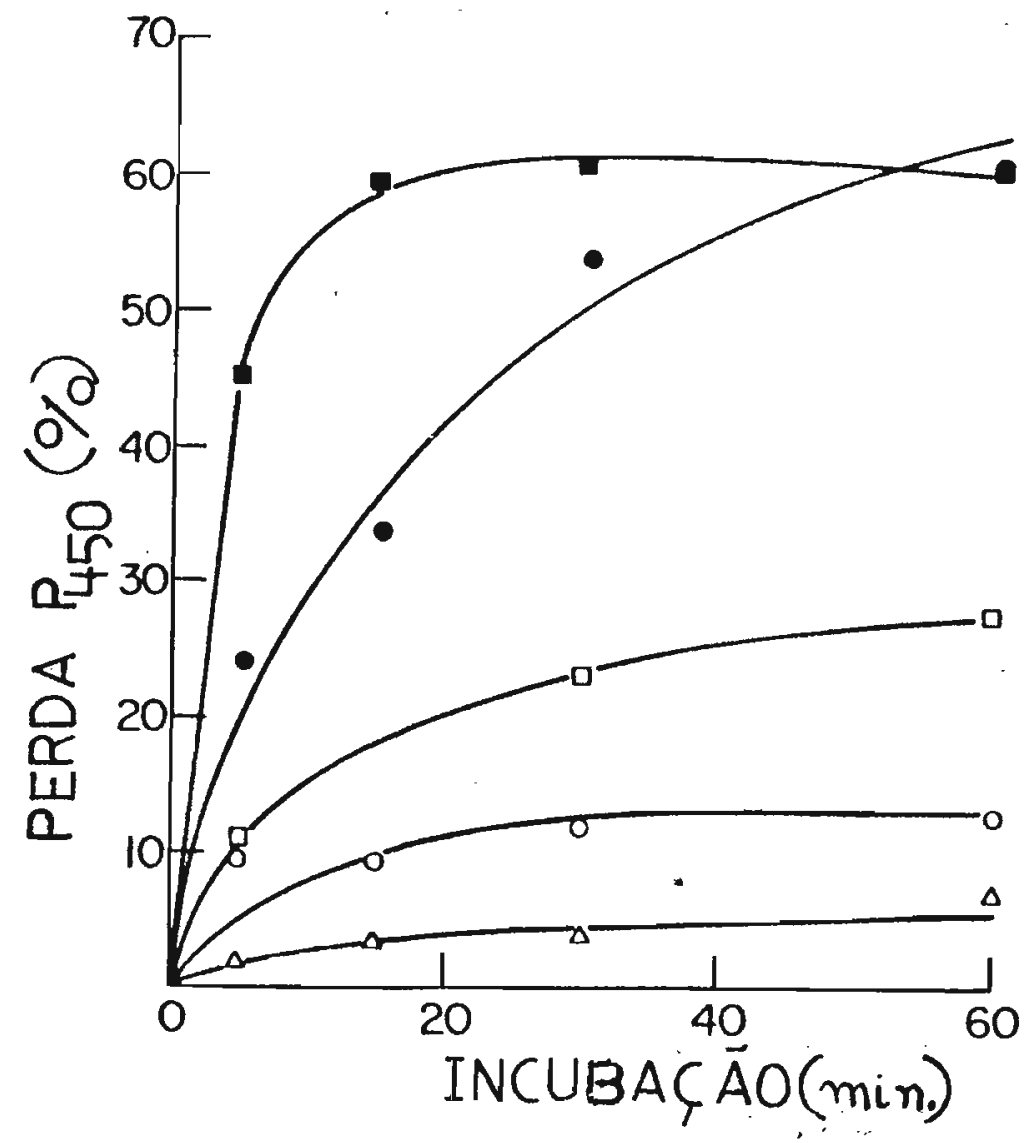

Figura 10. Destruição do citocromo $\mathrm{P}_{450}$ por fenelzina e benzilidrazina em função do tempo de incubação: (i) perda do enzima causada por fenelzina $5 \mathrm{mM}$ na pre sença ( •) e na ausēncia ( 0 ) de NADPH; (ii) perda do enzima causada por benzilidrazina $5 \mathrm{mM}$ na presença ( a) e na ausência ( $a$ ) de NADPH; e(iii) perda do enzima na ausência do substrato ( $\Delta$ ). A mistura dè incubação e suas condições experimentais são aquelas descritas em Materiais e Métodós. 


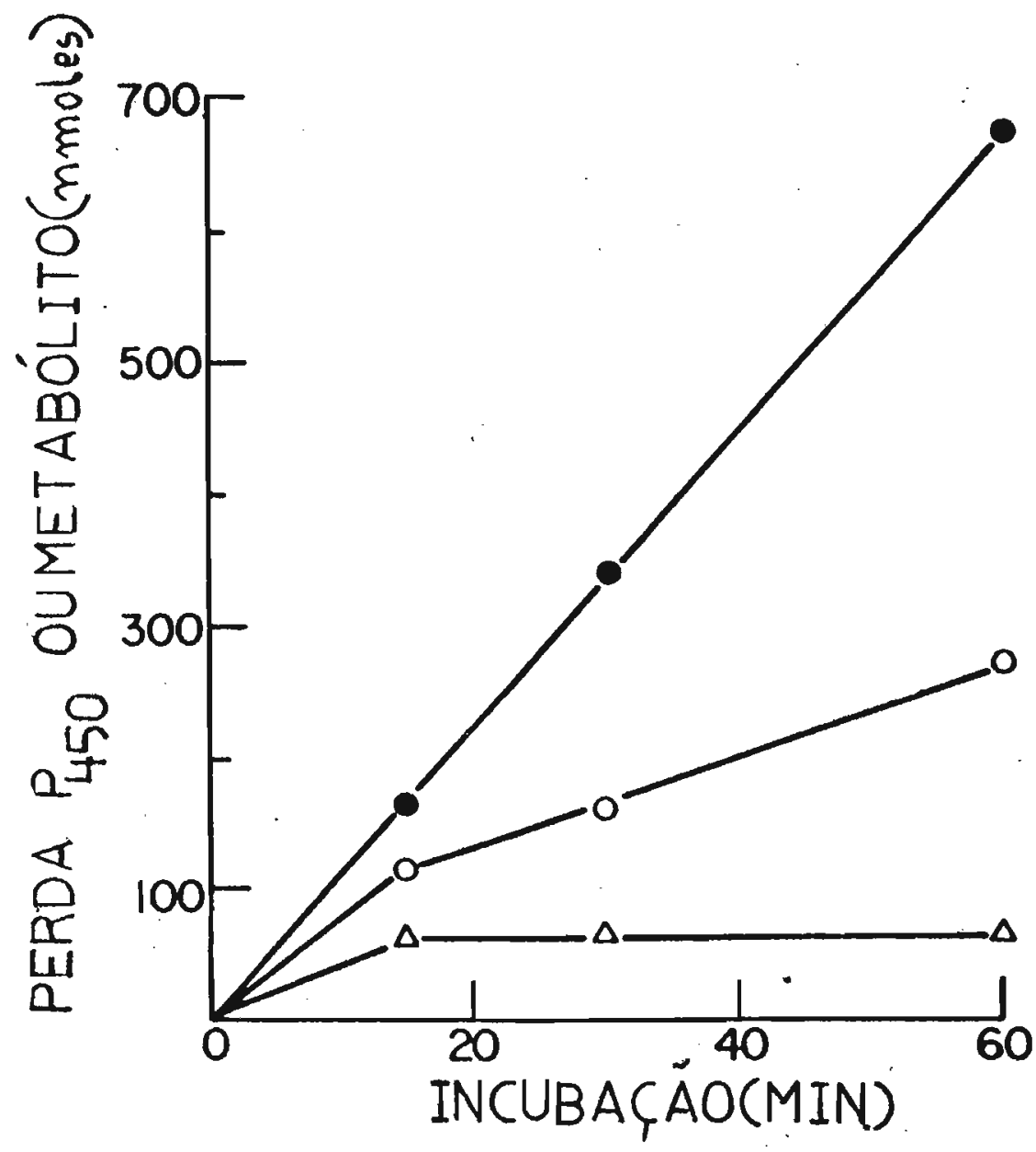

Figura 11. - Formação de produtos e destruição do citocromo $\mathrm{P}_{450}$ durante o metabolismo microssomal da fenelzina 5 mM:formação de 2-fenilacetaldeido ( ) ) , formação de etilbenzeno (o)e destruição do citocromo $\mathrm{P}_{450}(\Delta)$. A mistura de incubação e suas con dições experimentais são aquelas descritas em Materiais e Métódos. 
somais. Nōs confirmamos essa observação e conseguimos isô lar um pigmento anormal a partir de fígados de ratos indu zidos com fenobarbital e tratados com fenelzina $(60 \mathrm{mg} / \mathrm{kg})$. A porfirina isolada pelos procedimentos usuais: Ver Materiais e Mētodos) apresenta um espectro de absorção eletrônica característico de um $\mathrm{N}$-alquil derivado da protoporfirina $\operatorname{IX}(83,109)$. A base Iivre em $\mathrm{CHCl}_{3}$ apresenta uma banda Soret a $416 \mathrm{~nm}$ e picos de intensidade decrescente a 512, 546,592 e $652 \mathrm{~nm}$; ó seu complexo de zinco, no mesmo solvente, apresenta a Soret a $416 \mathrm{~nm}$ e picos adicionais a 548 , 594 e $634 \mathrm{~nm}$ (Fig. 12).

Os únicos picos presentes no espectro de massa ("field desorption"), são o ion molecular monoprotonado a m/e 695 e seus satélites isotópicos a m/e 696 e m/e 697. o pico a m/e 695 é o esperado para uma estrutura resultante da adição de um grupo feniletila $\left(\mathrm{PM}, 10^{\circ}\right)$ ao éster dimetílico da protoporfirina IX $(P M, 590)$. O espectro de absorção e o espectro de massa sugerem que a porfirina isolada dos fígados dos ratos tratados com fenelzina, éó ester dimetí lico da N-(2-feniletil) protoporfirina IX (Fig. 13).

Essa estrutura é confirmada por estudos de RMN do complexo de zinco da porfirina. A Tabela 4 apresenta a posição dos picos do espectro de RMN do complexo, suas mul tiplicidades e os resíduos responsáveis por suas presenças. Deve-se ressaltar que o espectro de RMN mostra a presença de um segundo isômero (10-15\% da amostra total) cujos dados não aparecem na Tabela 4. Os prótons da parte porfirínica foram designados por analogia com os sinais correspon 


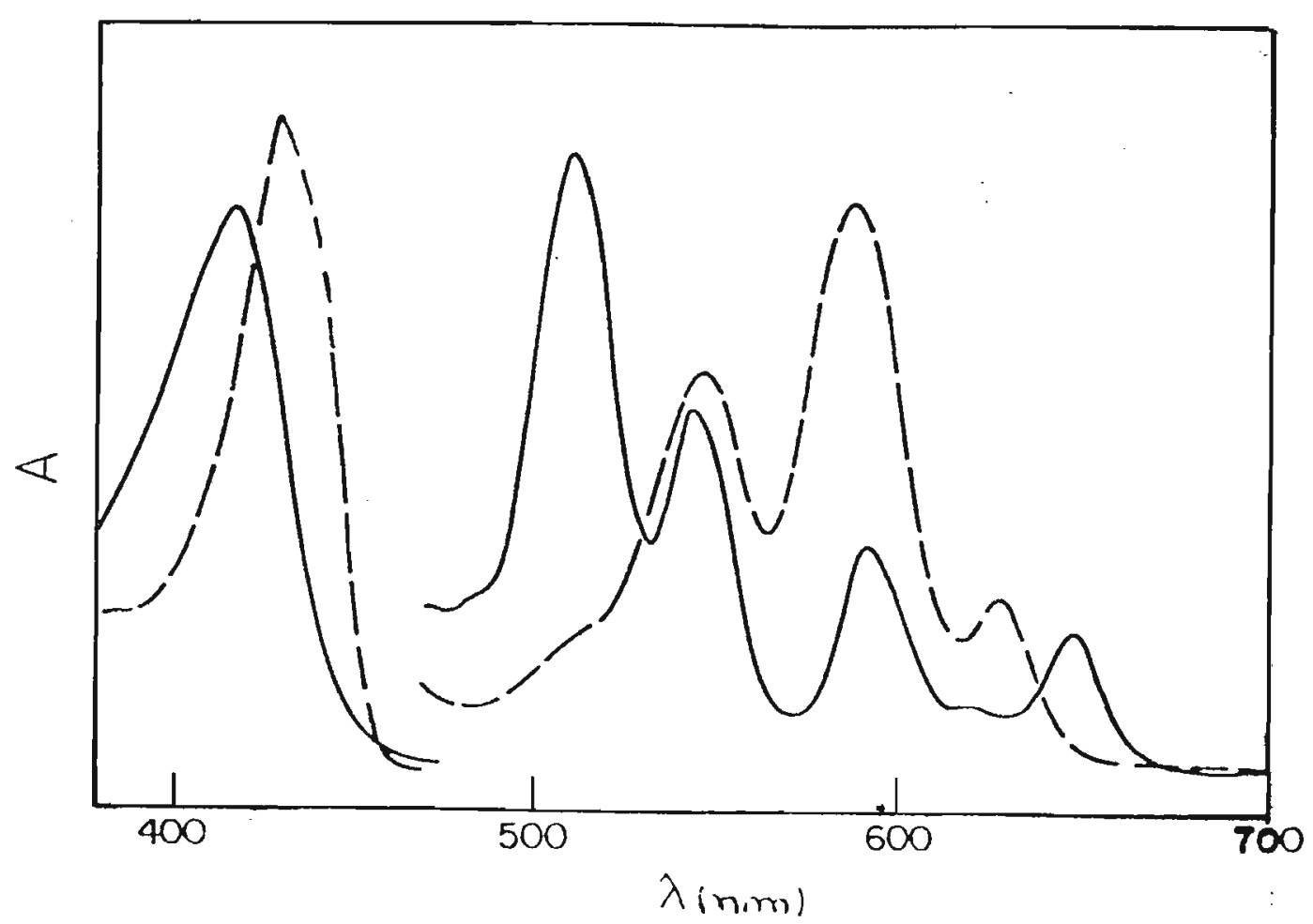

Figura 12. - Espectro de absorção eletrônica da porfirina iso lada de ratos tratados com fenelzina (-) e de seu complexo com zinco (---) em $\mathrm{CHCl}_{3}$. Na região da banda soret a escala das ordenadas é 1/10 da utilizada para o restante do espectro. 


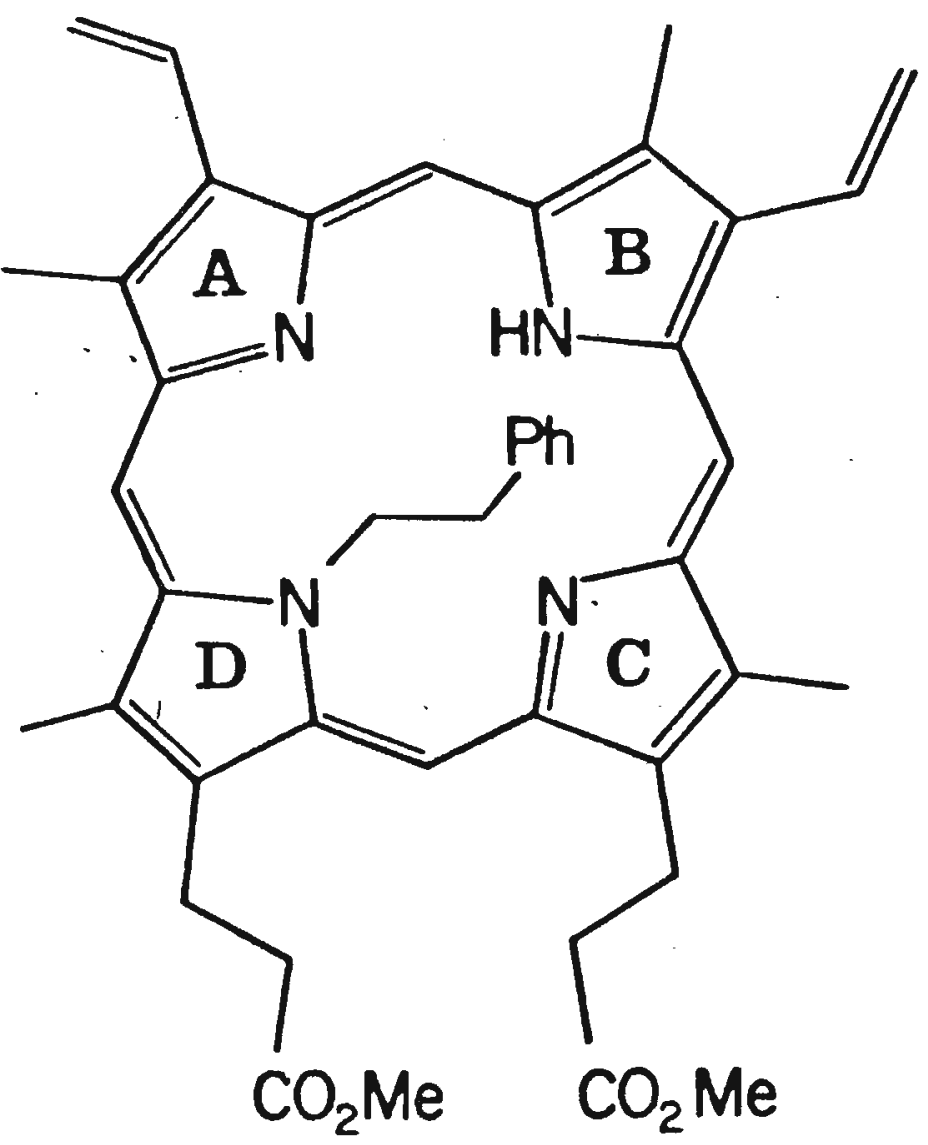

Figura 13. - Estrutura do éster dimetilico da porfirina hepática isolada a partir de ratos tratados com fe nelzina.

dentes de outras porfirinas N-alquiladas $(83,109,110)$; a identidade do grupo $\mathrm{N}$-alquil foi confirmada por experimentos de desacoplamento. Assim, a irradiação dos prótons em orto do grupo fenila a 5,305 ppm leva à transformação do triplete, devido aos protons em meta a 6,508 ppm, em um doublete. O acoplamento residual dos protons em meta é com - próton na posição para a 6,612 ppm. A irradiação do triplet a - 0,196 ppm, designado como devido aos prótons do grupo metileno ligado ao grupo fenila, leva à transformação 
do triplet a $-4,925 \mathrm{ppm}$ em um singlete, mostrando que este sinal é devido aos prótons do grupo metileno ligado ao nitrogênio pirrólico.

A Fig. 13 mostra um dos possíveis isômeros do pig mento hepático. Dependendo do nitrogênio alquilado, quatro isômeros são possíveis mas nossos resultados indicam que o principal produto tem o anel $\mathrm{C}$ ou o anel D alquilado, jā que: (i) não existe um ombro na banda soret do complexo de zinco da porfirina (Fig. 12) $(109,110)$; (ii) o espectro de RMN mostra um maltiplète devido aos dois prótons vinílicos internos: um multiplete devido aos prótons vinílicos terminais e qua tro diferentes multipletes devidos aos oito prótons metilê nicos das duas cadeias laterais de ácido propiônico ( Tabe 1a 4) $(83,109)$.

d. Formação de Radicais Livres Durante o Metabolismo da Fenelzina - O metabolismo microssomal da fenelzina em presença de POBN leva à formação de um aduto de spin estável (Fig.14). Como no metabolismo microssomal do $\operatorname{DDEP}$ (item 3.1), não se obtém nenhum sinal estável em presença de DMPO e aqui, tam pouco com PBN, o que nos levou a utilizar o POBN como captador de spin.

O aduto de spin do POBN não é observado na ausēn cia de NADPH, mas pode ser observado, em menor ooncentração, em presença de NADPH e microssomos pré-inativados por aquecimento (Fig.14). Essa formação não enzimática de radicais deve ser resultado da autoxidação da fenelzina catali sada por heme ou outros complexos metálicos $(111,112)$. 
Tabela 4. Designações dos Sinais de RMN para o Complexo de Zinco da Porfirina Hepática Isolada de Ratos Trata dos com Fenelzina.

\begin{tabular}{|c|c|c|c|}
\hline PROTON (S) & $\begin{array}{l}\text { NUMERO DE } \\
\text { PRÓTONS }\end{array}$ & $\begin{array}{l}\text { POSIÇÃO } \\
\text { ppm }\end{array}$ & MULTIPLTCIDADE ${ }^{a}$ \\
\hline meso & 1 & 10,225 & s \\
\hline meso & 1 & 10,240 & $s$ \\
\hline meso & 1 & 10,204 & s \\
\hline meso & 1 & 10,166 & $\mathbf{s}$ \\
\hline vinilicos internos & 2 & $8,074-8,265$ & $\mathrm{~m}$ \\
\hline para fenilicos & 1 & 6,627 & $t(\mathrm{~J}=7 \mathrm{~Hz})$ \\
\hline meta fenilicos & 2 & 6,508 & $t(\mathrm{~J}=7 \mathrm{HZ})$ \\
\hline vinílicos terminais & 4 & $6,079-6,538$ & $\mathrm{~m}$ \\
\hline orto fenilicos & 2 & 5,305 & $\mathrm{~d}(\mathrm{~J}=7 \mathrm{~Hz})$ \\
\hline \multirow[t]{2}{*}{ metilenos do propionato } & 4 & $4,093-4,240$ & $\mathrm{~m}$ \\
\hline & & $4,303-4,367$ & $\mathrm{~m}$ \\
\hline \multirow[t]{3}{*}{ metila e metoxila } & 18 & 3,$367 ; 3,550$ & $s($ seis $)$ \\
\hline & & 3,$593 ; 3,633$ & \\
\hline & & 3,$585 ; 3,641$ & \\
\hline metilenos do propionato & 2 & 3,252 & $t(J=7 \mathrm{~Hz})$ \\
\hline metilenos do propionato & 2 & 2,816 & $t(\mathrm{~J}=7 \mathrm{~Hz})$ \\
\hline metilenos benzílico & 2 & $-0,196$ & $t(\mathrm{~J}=8 \mathrm{~Hz})$ \\
\hline N-metilenos & 2. & $-4,925$ & $t(J=8 \mathrm{~Hz})$ \\
\hline
\end{tabular}

a Multiplicidade do sinal: s, singlete; d, doublete; m, multiplete; $t$, triplet; as constantes de acoplamento são apresen tados em parênteses. 
A formação de radicais livres dependente de processos enzimáticos, pode ser devida a duas enzimas microssomais, o citocromo $\mathrm{P}_{450}$ e a FAD-amino oxidase $\left(\mathrm{FP}_{3}\right.$, Esque ma 2). Ambas tem sido implicadas nas transformações metabólicas de alquilidrazinas, sendo sempre difícil estipular o papel de cada uma delas $(113,114)$. Nossos resultados suge rem um maior envolvimento do citocromo $\mathrm{P}_{450}$. De fato, a for mação do aduto de $\mathrm{POBN}$ é inibida por CO,SKF 525-A, inibido res clássicos do citocromo $\mathrm{P}_{450}$ e por PBN, que demonstramos anteriormente também ser um inibidor do enzima (Fig.14, Ta bela 5). Também, a cinética de destruição do citocromo $\mathrm{P}_{450}$ se correlaciona, em certa extensão, com a cinética de formação do radical aduto (Fig. 11, comparar com Fig. 15). Na Fig. 15 a concentração do radical aduto foi calculada a partir da altura do pico central de campo baixo, do espectro de RPE da amostra; o fator utilizado para converter al tura do pico em concentração, foi calculado após isolamento e purificação do aduto de POBN (ver abaixo). Por outro lado, pudemos eliminar a participação de supéróxido e $\mathrm{H}_{2} \mathrm{O}_{2}$ na formação do aduto radical estāvel, pelo efeito da superóxido dismutase e catalase adicionadas ao sistema ( Tabela 5). Finalmente, uma forte evidência para a participação do citocromo $\mathrm{P}_{450}$ na formação de radicais livres a partir da fenelzina, è a inativação do enzima por alquilação do grupo heme com formação de 2-feniletila protoporfirina IX (Fig. 12, Fig. 13 e Tabela 4). 


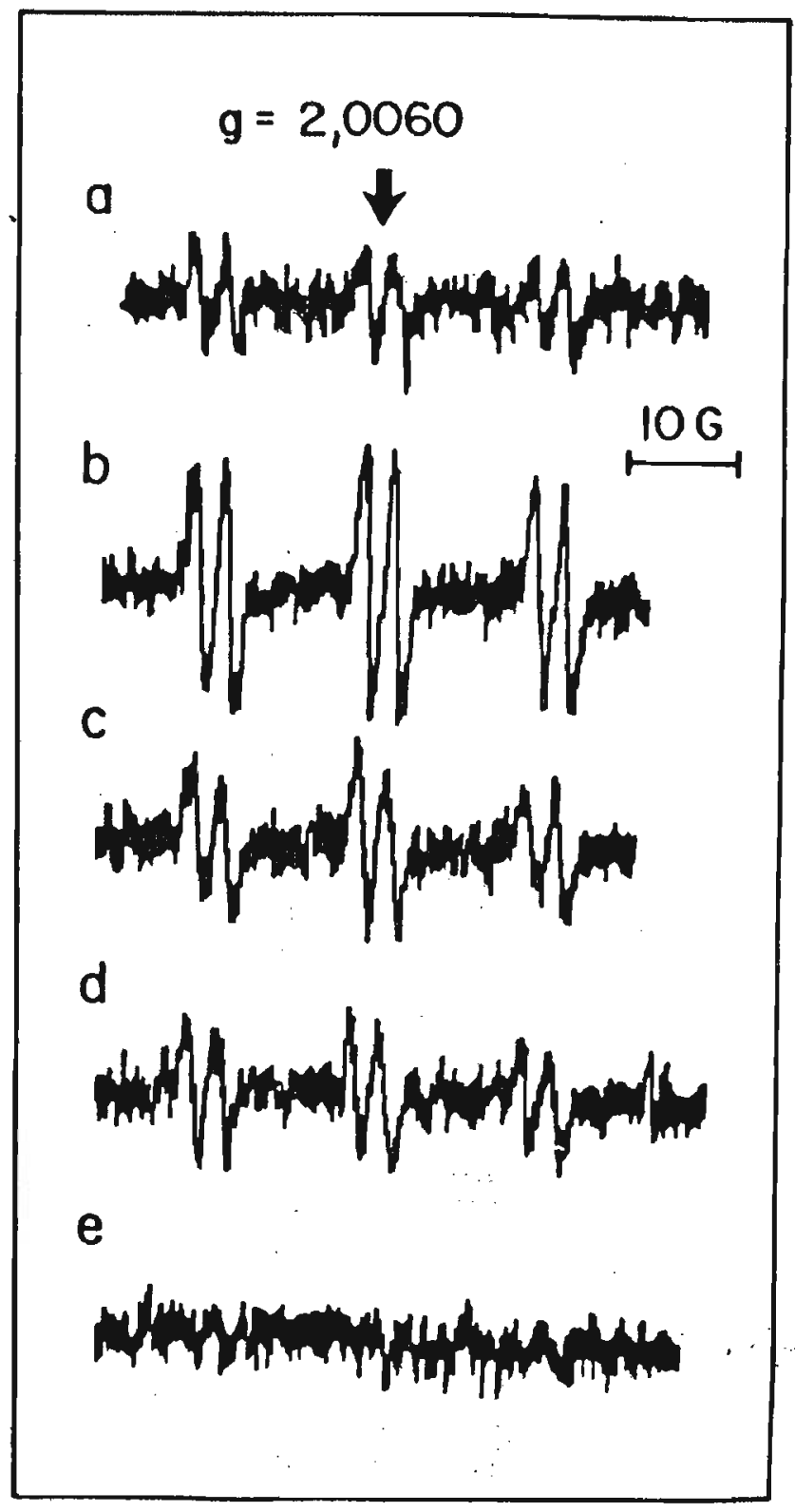

Figura 14. - Espectro de RPE de incubações microssomais de fe nelzina $5 \mathrm{mM}$, em presença de POBN $20 \mathrm{mM}$ : (a) incu bação com microssomos pré-inativados por aquecimen to; (b) incubação normal; (c) incubação normal prêtratada com CO por 2 min.; (d) incubação normal con tendo SKF 525-A 0,1 mM; e (e) incubação sem $N A D P \bar{H}$ (o mesmo resultado é obtido para uma incubação sem fenelzinal. Os espectros foram obtidos após $60 \mathrm{~min}$. de incubação a $37^{\circ} \mathrm{C}$. Ajustes do espectrômetro:po tência $10 \mathrm{~mW}$; amplitude de modulação, 1,0 ; constante de tempo, 1,0 s; tempo de varredura $0,5 \mathrm{~h}$; intervalo de varredura, $200 \mathrm{G}$ ganho $6.2 \times 10^{5}$. 


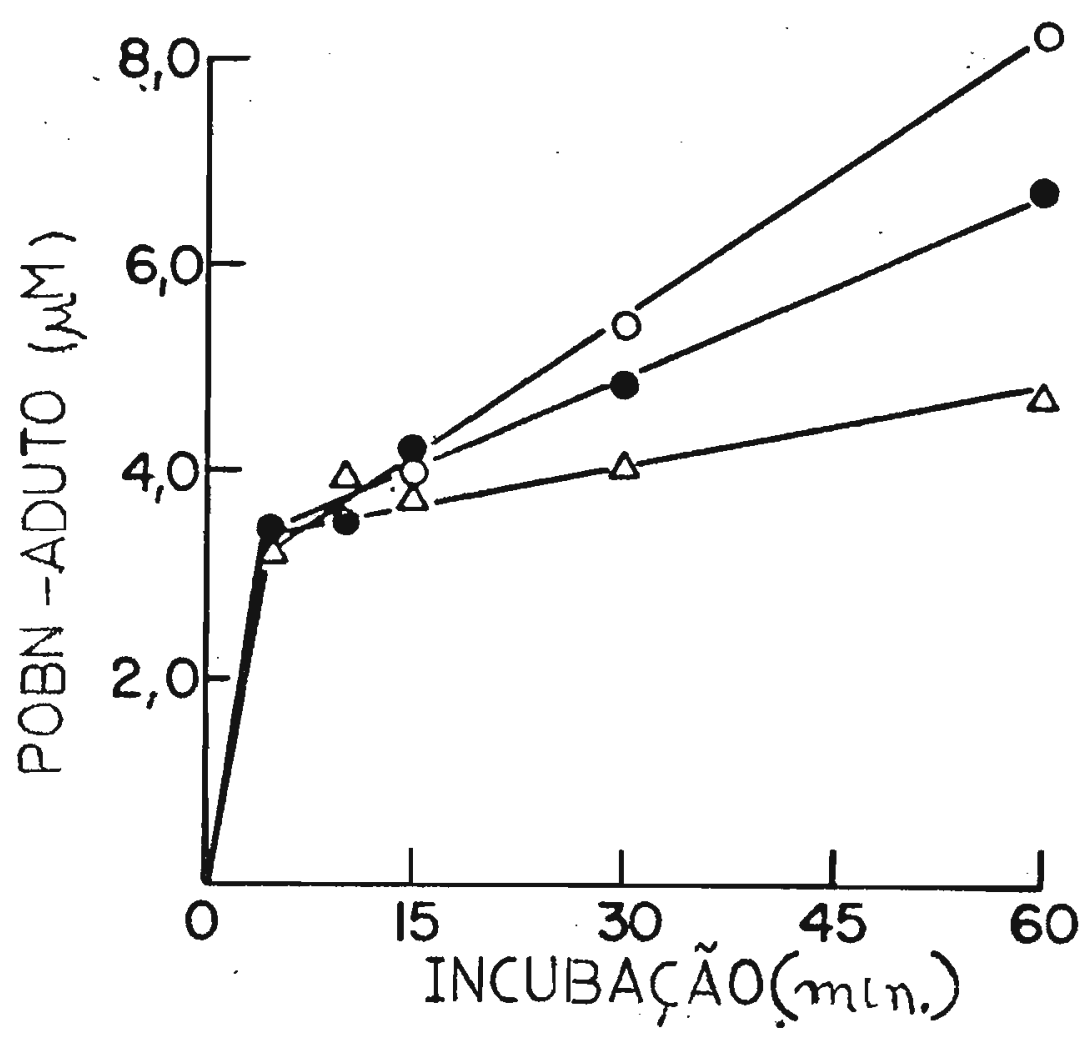

Figura 15. - Efeito da concentração de fenelzina e do tempo de incubação na concentração do aduto radical de POBN : $10 \mathrm{mM}(0) ; 5 \mathrm{mM}(\bullet) ;$ e $1 \mathrm{mM}(\Delta)$. A con centração de POBN é $20 \mathrm{mM}$ e as demais concentrações e conaições experimentais são descritas em Materiais e Métodos. 
Tabela 5. - Concentração do Radical Aduto de POBN Obtido Durante a Incubação Microssomal de Fenelzina em Vạ rias Condições.

\begin{tabular}{lll}
\hline CONDIÇÕES DE & CONCENTRAÇÃO DO & PORCENTAGEM \\
INCUBAÇÃO $a$ & RADICAL ADUTO, $\mu \mathrm{M}$ & DO CONTROLE
\end{tabular}

Normal

$+\mathrm{CO}$

$+\operatorname{SKF} 525-\mathrm{A}(0,1 \mathrm{mM})$

+ Catalase $(0,1 \mathrm{mg} / \mathrm{mL})$

$+\operatorname{SOD}(0,1 \mathrm{mg} / \mathrm{mL})$

$-\mathrm{NADPH}+\mathrm{NADH}(1,0 \mathrm{mM})$

$-\mathrm{POBN}+\mathrm{PBN}(50 \mathrm{mM})$

a Incubação de 60 min.

b N.D. , não detectāvel
100

67

76

100

97

67

$-$

e. Identificação do Radical Aduto de POBN obtido a partir da

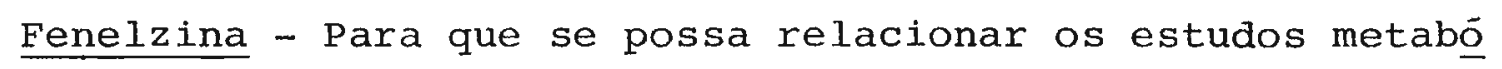
licos com a inativação do citocromo $\dot{\mathrm{P}}_{450}$, é fundamental es tabelecer a estrutura do radical primārio que está gerando - aduto de POBN estável. Como já discutido, os parâmetros de RPE não são suficientes para essa determinação. Aprovei tando a experiência desenvolvida no estudo do metabolismo microssomal do DDEP (item 3.1), tentamos isolar e purificar o aduto de POBN obtido na oxidação da fenelzina. Nova mente, comparamos o aduto obtido quimicamente, por oxidação 
com $\mathrm{Cu}^{2+} / \mathrm{OH}^{-}$, com o isolado após a transformação microssomal. O espectro de RPE dos adutos purificados (ver Materiais e Métodos) são caracterizados por $a_{N}=15,73, a_{H}=2,75$ e $\mathrm{g}=2,006 \mathrm{em}$ água (Fig. 16) e $a_{\mathrm{N}}=14,41$ e $a_{\mathrm{H}}=2,68 \mathrm{em}$ benzeno. O espectro de absorção eletrônica dos adutos em $\mathrm{CHCl}_{3}$ apresentam um máximo a $283 \mathrm{~nm}\left(\varepsilon=19.000 \mathrm{M}^{-1} \mathrm{~cm}^{-1}\right)$ e em metanol a $271 \mathrm{~nm}\left(\varepsilon=22.000 \mathrm{M}^{-1} \mathrm{~cm}^{-1}\right.$ ) (Fig. 17). Portanto o cromôforo do aduto é similar ao N-óxido da piridina, que apresenta um máximo a $276 \mathrm{~nm}\left(\varepsilon=15.136 \mathrm{~m}^{-1} \mathrm{~cm}^{-1}\right)$ em $\mathrm{CHCl}_{3}$ (115), a $282 \mathrm{~nm}\left(\varepsilon=10.000 \mathrm{M}^{-1} \mathrm{~cm}^{-1}\right)$ em hexano (116) e a $263\left(\varepsilon=13.800 \mathrm{M}^{-1} \mathrm{~cm}^{-1}\right.$ ) em metanol (115); o desloca mento de 6-8 $\mathrm{nm}$ observado para o aduto em cada solvente é consistente com a presença de um substituinte na posição 4 do anel piridínico. A fig. 17 mostra também, a grande diferença dos espectros de absorção do aduto e do POBN. Os adutos gerados química e biologicamente também apresentam - mesmo espectro de massa, com íns móleculares a m/e 298 (PM-1) e picos de fragmentação a m/e 283 (PM-15), 242 (PM-57) e 212 (PM-87) (Fig. 18). O íon molecular é aquele esperado para um aduto POBN-2-feniletila, com a perda de um hidrogề nio durante o processo de ionização: Portanto, as propriedades espectroscópicas identificam inequivocamente a espécie captada como o radical feniletila, tanto no processo químico como durante o metabolismo microssomal.

Mais ainda, nossos resultados mostram que é de fato possível isolar e identificar os adutos de radicais de carbono obtidos em sistemas microssomais. Obtivemos sucesso no isolamento do aduto do radical etila (item 3.1) e agora 
do aduto do radical feniletila, mostrando que a validade do método pode ser geral e uma abordagem muito útil para expe rimentos de captação de spin em sistemas microssomais.Qual quer estudo mecanístico sempre exigirá a identificação ine quívoca do radical captado e isso não pode ser conseguido somente pela análise do espectro de RPE obtido. Para enfatizar esse ponto, apresentamos, para comparação, as propriedades espectroscópicas dos dois adutos de POBN que iso lamos e purificamos na Tabela 6 .

Tabela 6. Propriedades Espectroscópicas de Adutos de POBN

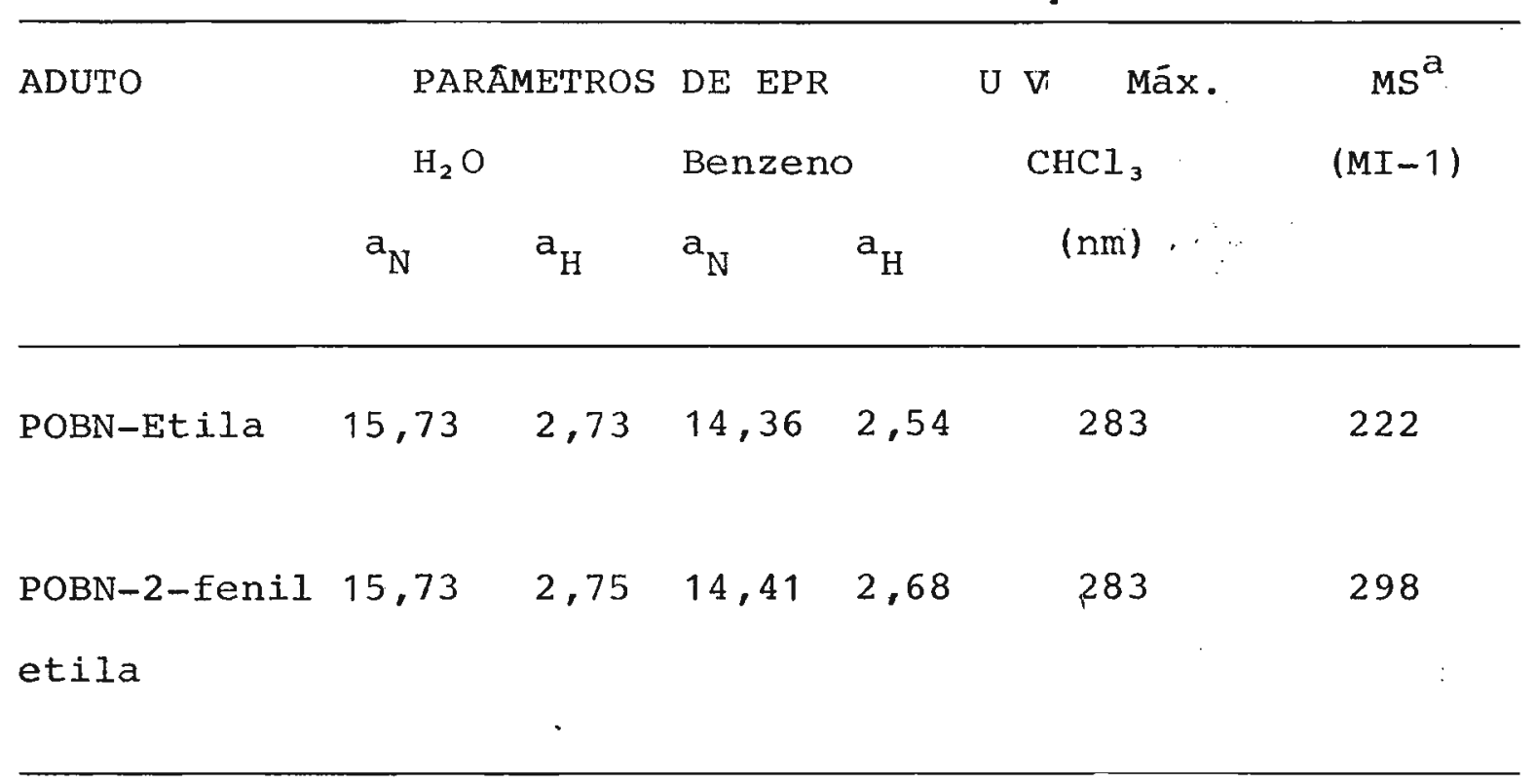

a

Espectro de Massa 

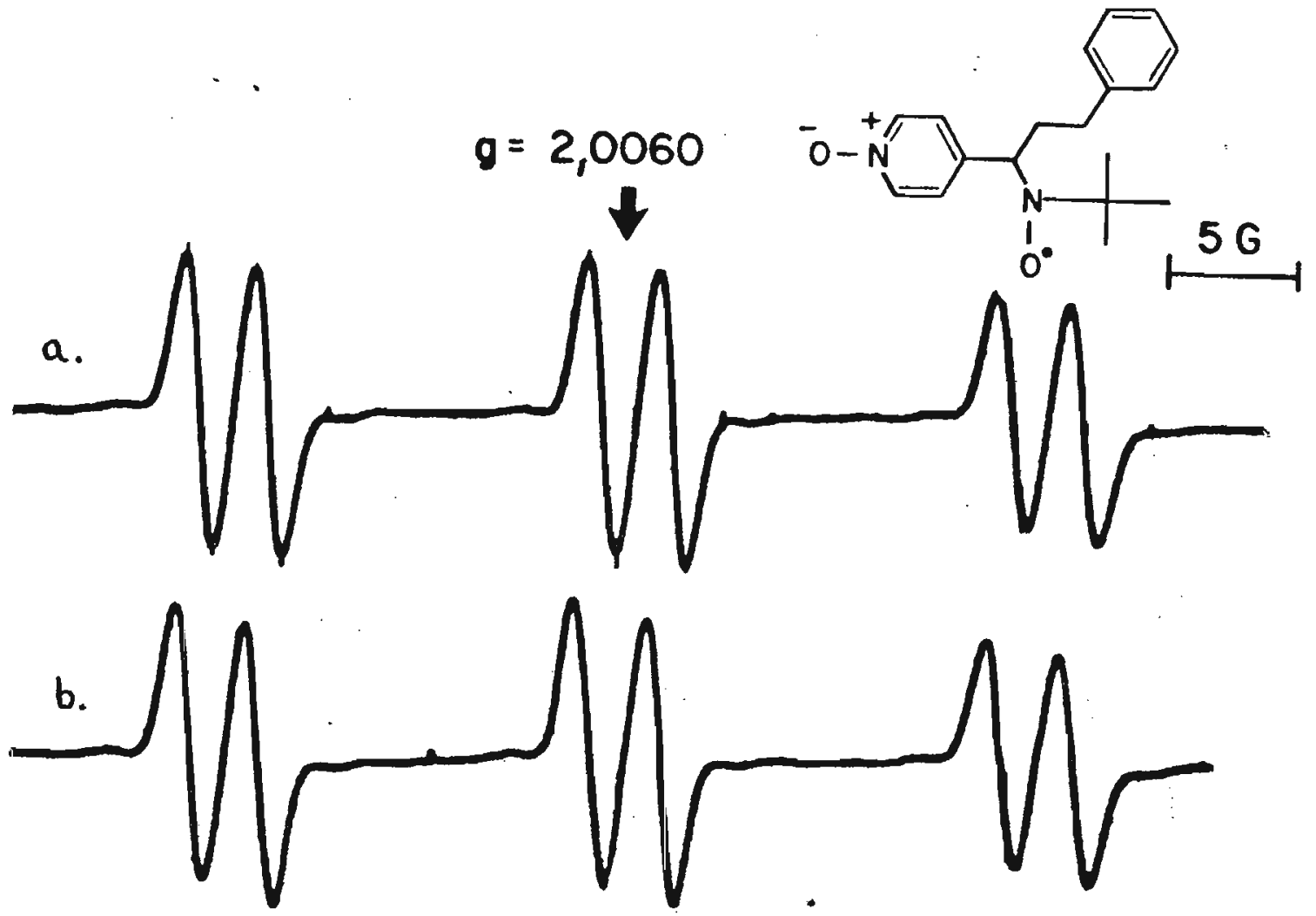

Figura 16. - Espectro de RPE do radical aduto 2-fenietila-POBN isolado e purificado a partir da : (a) oxidação da fenelzina catalisada por $\mathrm{CuCl}_{2}$ a $\mathrm{pH} 10$ e (b) oxidação microssomal da fenelzina. O solvente. é tampão fosfato $0,1 \mathrm{M}, \mathrm{pH} 7,4$; ajustes do instrumento: potência, $10 \mathrm{~mW}$; amplitude de modulação , $1: G$; constante de tempo, $0,3 \mathrm{seg}$; tempo de var redura, $16 \mathrm{~min}$; intervalo de varredura, 100G; ganho $1,5 \times 10^{4}$ para (a) e $8 \times 10^{3}$ para (b). 


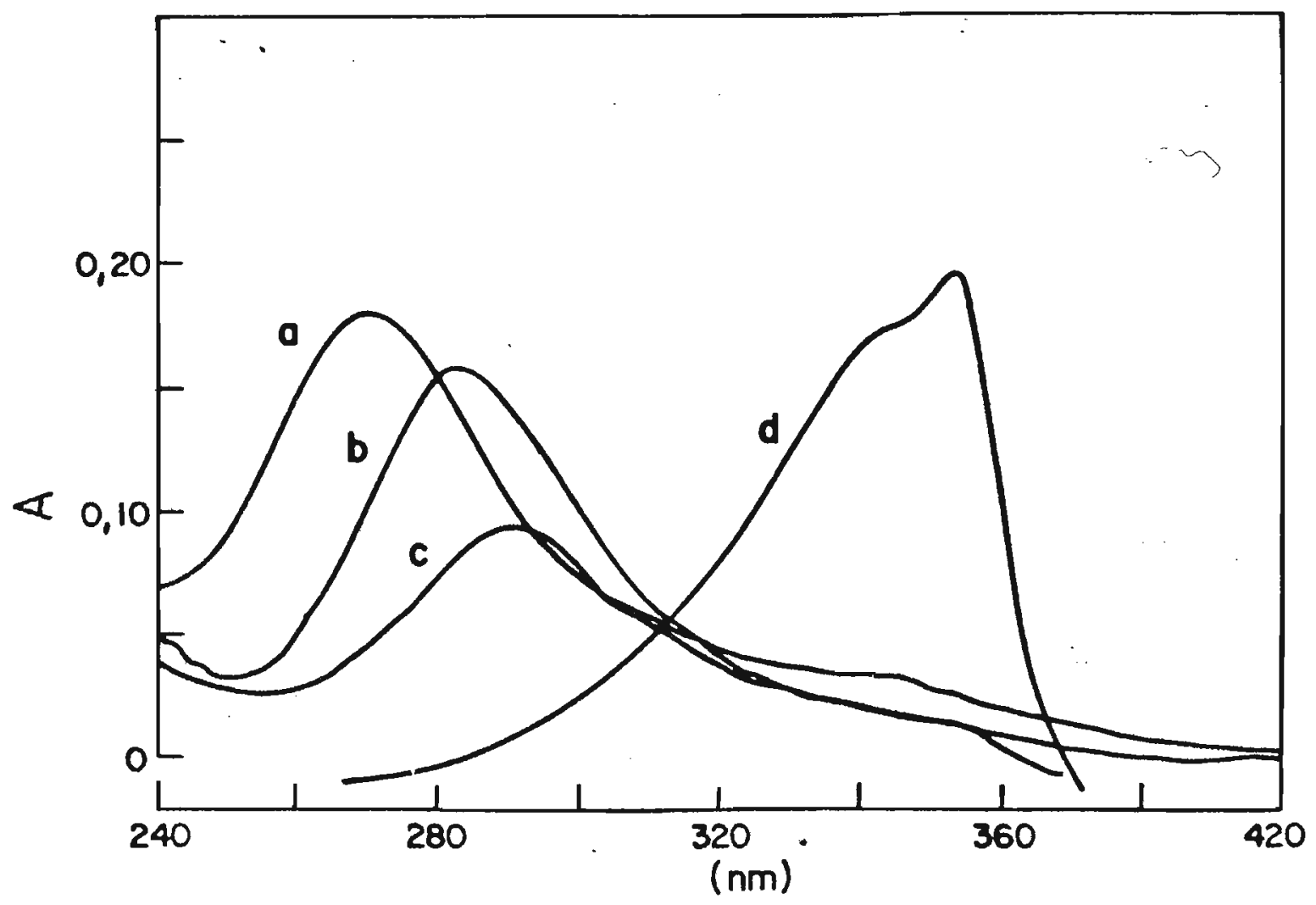

Figura 17. - Espectro de absorcão eletrônica no ultravioleta do aduto radical 2-feniletila-POBN em: (a) me tanol; (b) $\mathrm{CHCl}_{3}$; e (c) hexano: o espectro de POBN em $\mathrm{CHCl}_{3}$ (d) é apresentado para comparação. 


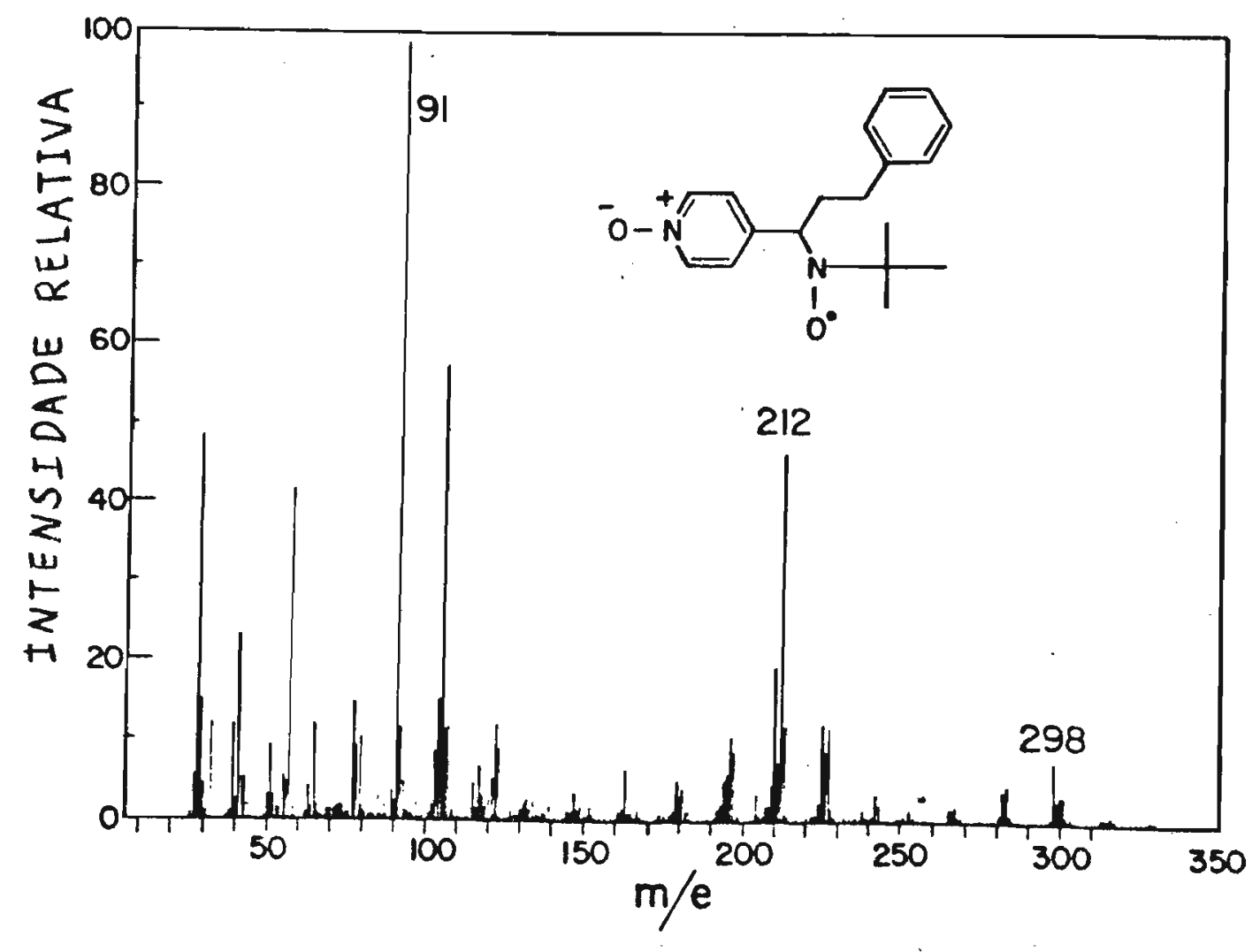

Figura 18. - Espectro de massa, obtido por impacto de elétrons do aduto radical 2-feniletila-POBN purificado de uma incubação microssomal de fenelzina. 
f. Implicações Toxicolögicas e Terapêuticas - Os nossos resuI tados sobre o metabolismo microssomal da fenelzina estão sumarizados no Esquema 10. Identificamos os principais me tabólitos como 2-fenilacetaldeído e etilbenzeno, sendo que somente a formação deste parece depender do citocromo $\mathrm{P}_{450}$. Correlacionando-se com a formação de etilbenzeno ocorre:(i) a formação do radical feniletila que identificamos inequivocamente por espectroscopia de massa do aduto obtido por captação com POBN e (ii) a inativação do próprio citocromo $\mathrm{P}_{450}$ cujo grupo prostético é alquilado com formação do $\mathrm{N}-(2-$ feniletil) derivado (Esquema 10) .<smiles>NCc1ccccc1</smiles>

[0] $\downarrow \mathrm{H}_{2} \mathrm{O}$<smiles>O=CCc1ccccc1</smiles>

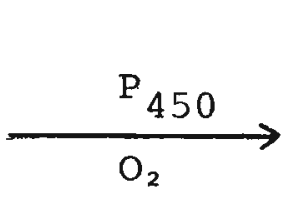

$\underset{\mathrm{HX} \rightarrow \infty}{\longrightarrow}$

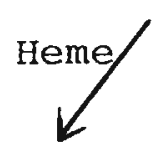

Aduto de

Heme

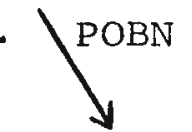

Aduto de POBN

( Esquema 10)

A estrutura do heme alquilado é,formalmente, resultado da adição do radical fenietila a um dos nitrogênios do grupo heme. Essa reação pode ser direta, ou pode ocorrer com a formação intermediária de um complexo $\sigma_{-}$alquilferro (Esquema 11). 


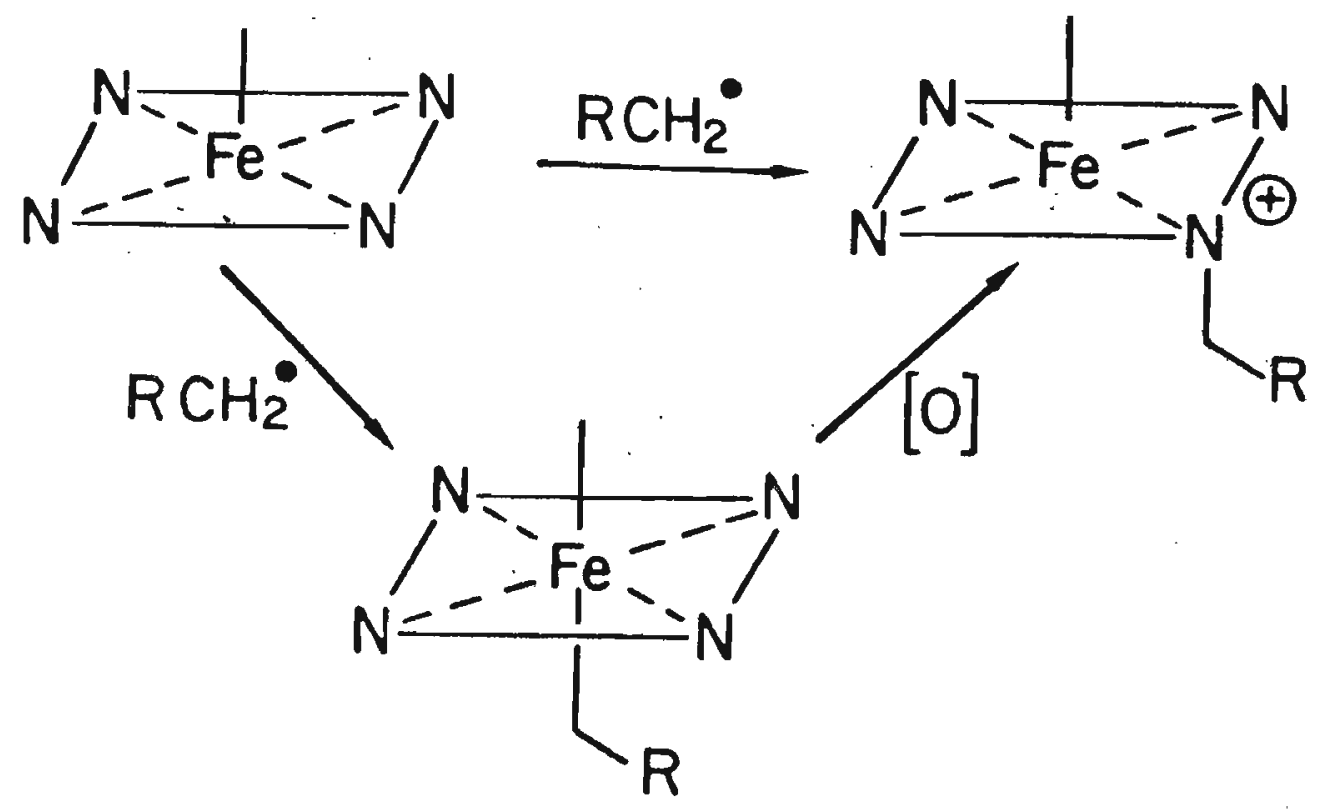

( Esquema 11)

Essa proposição de que a N-alquilação seja precedida de um ataque direto do radical de carbono ao ferro, vem de nossos estudos sistemáticos sobre a'interação entre aril e alquil-hidrazinas e oxiemoglobina $(86,117)$. Eví dentemente, a facilidade de obtenção de grandes quantidades dessa proteina permitiu uma abordagem detalhada do mecanis mo de inativação. Resumidamente, demonstramos que a hemoproteina é inativada por alteraçäo do grupo prostético após transformar 6 moléculas de substrato, segundo a estequiome tria abaixo:

$6 \phi \mathrm{NHNH}_{2}+6 \mathrm{O}_{2}+1$ heme (ativo) $\rightarrow 5 \phi \mathrm{H}+1$ heme (inativo) Mais importante, nós conseguimos determinar a estrutura do 
heme inativo. Ele é um complexo $\sigma$-aril-heme,formadovia radical fenila, muito estável quando na matriz proteica mas que, quando extraído em presença de oxigênio reverte ao he me ou, se além de condições oxidantes estiver em presença de ácido, rearranja-se ao N-aril derivado (Esquema 12) .
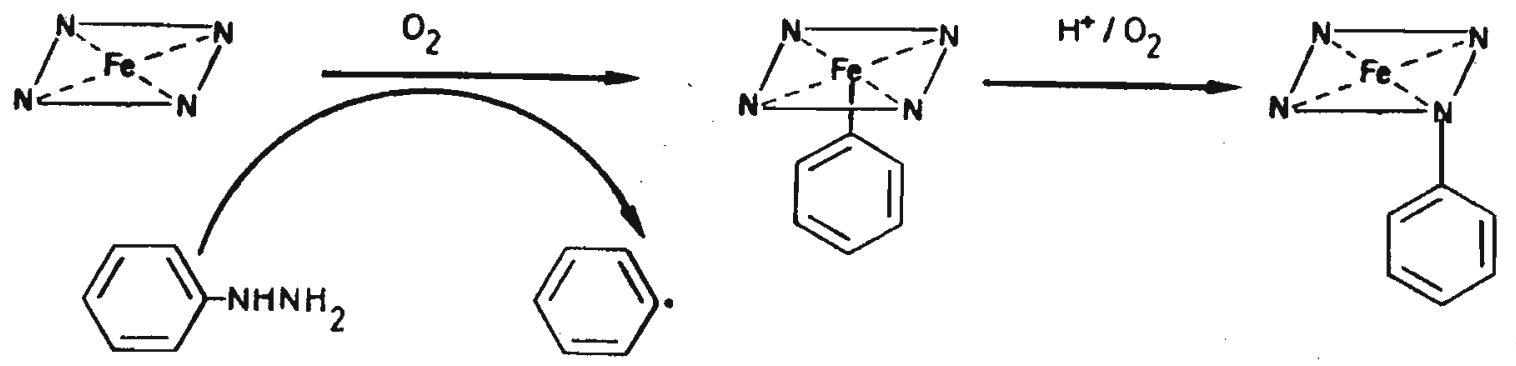

\section{( Esquema 12)}

Assim, além de elucidar a correta estrutura da hemoglobina inativada por fenilidrazina, um problema que vem sendo estudado há quase um século, pudemos demonstrar que as porfi rinas N-ariladas previamente isoladas $(118,119)$ eram produ tos dos procedimentos empregados para a purificação. Esses estudos, foram detalhados para o caso de vārias arilidrazí nas, mas, mesmo no caso de etilidrazina, foi obtido o deri vado N-alquilado (86) .

Embora não possamos extrapolar totalmente esses estudos detalhados sobre aril radicais e a hemoglobina para a interação entre a fenelzina e o citocromo $\mathrm{P}_{450}$, podese fazer analogias. Um cálculo estimativo indicou que a ra zão de produtos formados por citocromo $\mathrm{P}_{450}$ inativado pela 
fenelzina fica entre 20-24; embora muito maior que a razão obtida para a inativação da hemoglobina por fenilidrazina, 6, indica que a fenelzina é um eficiente agente destruidor do citocromo $\mathrm{P}_{450}$, provavelmente via os radicaịs de carbono formados. Essa inativação do tipo suicida, tem óbvias re lações com o efeito de hidrazinas sobre o metabolismo de drogas co-administradas (97-99). Também, pode ter implicações toxicológicas, quando o metabolismo de algum composto tóxico for diminuido pela menor quantidade de citocromo $\mathrm{P}_{450}$ disponivel para transformá-10.

De implicações toxicológicas mais gerais é o fa to de que, além de reagir com o grupo prostético da enzima que os forma, os radicais de carbono podem escapar do sitio ativo e reagirem com moléculas circundantes 1 Esquema 10). Assim como puderam reagir com POBN, eles poderão rea gir com biomoléculas importantes e portanto, serem os res ponsáveis diretos pelos efeitos tóxicos associados à fenel zina e outros derivados de hidrazina farmacologicamente a tivos $(91-96)$.

Por outro lado, o efeito antidepressivo da fenel zina está associado ao fato de que ela atua como um inibidor suicida da enzima monoamino oxidase. Essa flavo enzi ma está presente na fração mitocondrial de vários tecidos inclusive nos neurônios, onde exerce um papel fundamental na manutenção das concentrações aminas biogênicas $(120,121)$.

Embora o mecanismo pelo qual a fenelzina inativa a monoamino oxidase não seja conhecido em detalhes, estudos com fenilidrazina sugerem que a alquilação do grupo prosté- 
tico é a responsável pela perda da atividade enzimática. De fato, em certas circunstâncias o fenil aduto da flavina po de ser isolado e se mostrou arilado na posição 4 a $(122,123)$ :<smiles>[R2]Cc1cc2c(cc1C)N([R])C1(c3ccccc3)C(=O)NC(=O)N=C1N2[R]</smiles>

Nós também realizamos alguns experimentos preliminares de captação de spin no sistema monoamino oxidase / fenilidrazina ( O. Augusto, P.R. Ortiz de Montellano, M. Hussain e T.P. Singer). A Fig. 19 mostra que dois radicais são captados nesse sistema com DMPO; um que decai rapidamente, provavelmente um radical de oxigênio (65) e um radi cal de carbono mais estável. Esse tem os mesmos parâmetros de RPE esperado para um aduto fenil-DMPO, $a_{N}=16,0$ e $a_{H}=14,7$ em água; como já discutido anteriormente, os parâmetros es pectrais dos adutos de DMPO são mais sensíveis à estrutura do radical adicionado do que os adutos de $\mathrm{PBN}$. Considerando esses nossos resultados prelimina- 
res, os estudos de singer e colaboradores sobre a inativação da monoamino oxidase $(120-123)$ e os nossos estudos so bre a inativação da hemoglobina $(86,117)$, parece-nos bastante razoāvel sugerir que a inativação da monoamino oxida se por derivados de hidrazina também ocorra pela reação dos radicais de carbono com o grupo prostético da enzima. Neste contexto é interessante comparar o número de moléculas de substrato transformadas por nümero de moléculas de enzí ma inativadas nesses sistemas (Tabela 7).

Embora os valores apresentados na Tabela 7 sejam estimativos, eles mostram uma eficiencia similar de cada agente destrutivo sobre as diferentes enzimas. Também, cor roboram a nossa sugestão de que são os radicais de carbono os responsāveis diretos pelas inativações. De fato,sabe-se que no caso de alquilidrazinas os principais produtos da oxidação catalisada pela monoamino oxidase; são as hidrazô nas correspondentes $(105,124)$. Isso é esperado, à medida que no caso da fenelzina e outras alquilidrazinas o rearranjo diazeno a hidrazona é possivel $(124,125)$ o que diminuiria a via radicalar e consequentemente, a capacidade do. substrato inativar a enzima (Esquema 13). Tal rearranjo não po de ocorrer no caso de arilidrazinas, o que, além das dife renças em reatividades dos radicais, poderia explicar as suas maiores eficiências como agentes destrutivos tanto de hemoproteinas como da flavoenzima.:

Os resultados aqui discutidos, quando relacionados com nossos estudos concomitantes sobre as transformações biológicas de outros derivados de hidrazina 185, 86, 
117), apresentam fortes evidências de que os radicais de carbono, formados nas suas transformações biológicas, são os responsáveis diretos por efeitos terapêuticos e tóxicos colaterais dessa classe de compostos.<smiles>[R]CCN=NCC([2H])CNCC=O</smiles>

ENZIMA INATIVA 

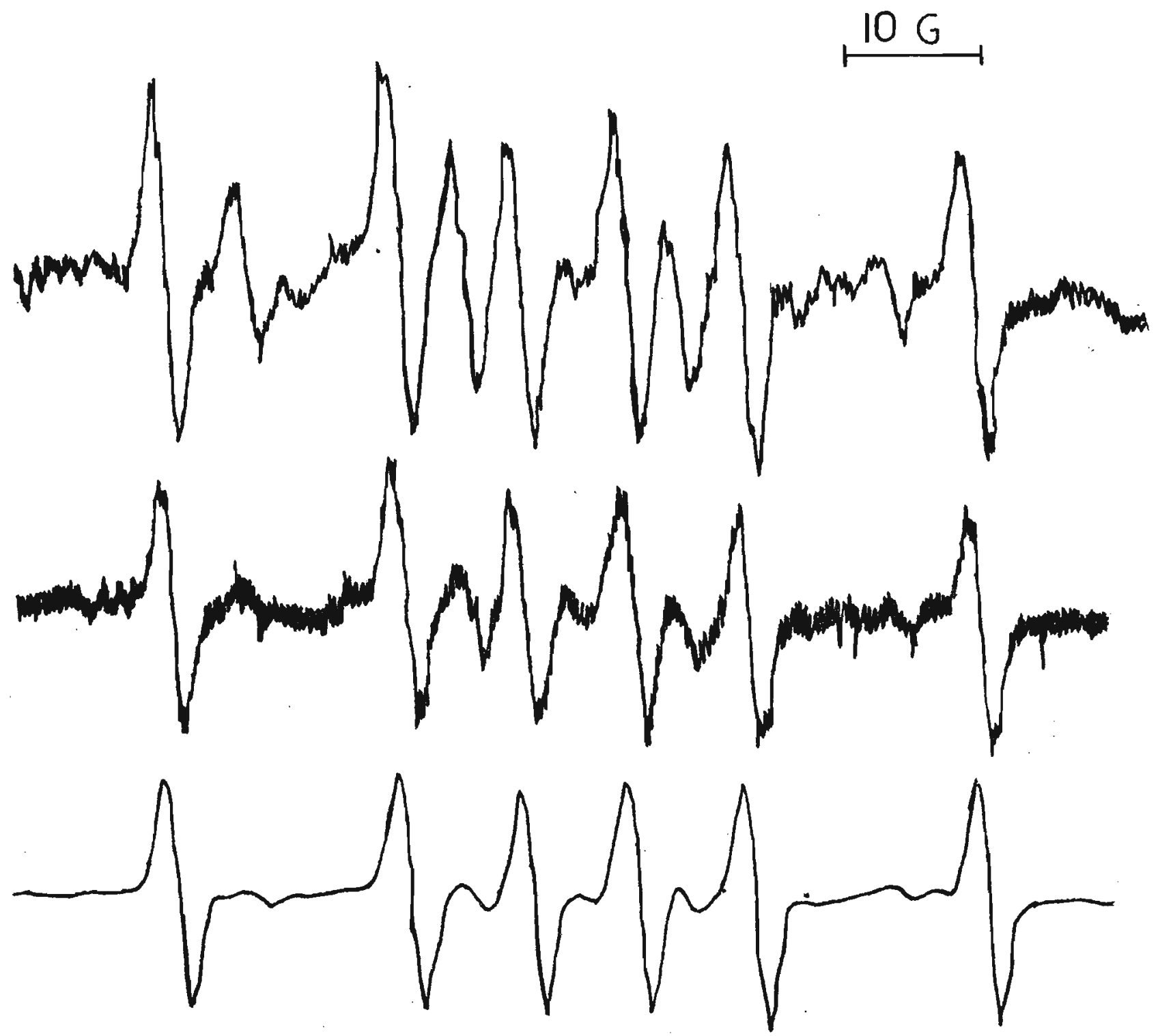

Figura 19. - Espectros de RPE obtidos após incubação de $4 \times 10^{-5}$ M fenilidrazina com $20 \mu M$ monoamino oxidase e $0,1 \mathrm{M}$ DMPO em tampão fosfato $0,05 \mathrm{M}$ contendo 1,0 X $10^{-4}$ M EDTA, $\mathrm{pH} 7.2$ à temperatura ambiente por: (a) 2 min. e (b) 12 min. Ajustes do instrumento: potência $10 \mathrm{~mW}$; amplitude de modulação, 1,0G; constante de tempo $1,0 \mathrm{~s}$; tempo de varredura 0,5 $\mathrm{h}$; intervale de varredura, 200G, ganho, .5 $\mathrm{x} 10^{3}$ para (a) e $6,3 \times 10^{3}$ para (b). 
Tabela 7. - Comparação entre o Nümero de Moles de Substrato Transformado por Nümero de Moles de Enzima Inati vado em Vārios Sistemas.

SISTEMA

$\mathrm{HbO}_{2}+$ Fenilidrazina

cit.P $450+$ Fenelzina $20-24$

$\mathrm{MAO}^{\mathrm{a}}+$ Fenilidrazina

MAO + Fenelzina $20^{\mathrm{b}}$

a MAO (monoamino oxidase)

b valores estimados a partir dos resultados descritos na refe rência 124 


\section{CONCLUSOES GERAIS}

Nossos estudos forneceram novas abordagens experimentais e amplas potencialidades para a compreensão das ba ses moleculares das interações entre xenobióticos e sistemas biológicos. Das várias questões possíveis nessa ārea de pesquisa, o nosso interesse se voltou para o estudo da formação de radicais livres durante o metabolismo de xenobióticos e de seus mecanismos interações com biomoléculas.

A possibilidade de formação de radicais livres em sistemas biológicos tem sido um assunto de pesquisa de evo lução histórica bastante controvertida (46) mas recentemente, inclusive com a aplicação da técnica do captador de spin,ocor reu um avanço considerável na nossa compreensão do papel de radicais livres em processos fisiológicos tanto normais como deletérios $(59,62,126)$.

No contexto geral dos processos de destoxicação e toxicação, a nossa contribuição para a aplicạão judiciosa da técnica do captador de spin durante o metabolismo microsso mal foi muito importante. Na verdade, estudos independentes e concomitantes ao nosso também mostraram que os captadores de spin podiam inibir o metabolismo microssomal (127); contudo, não foram exploradas todas as potencialidades das observações feitas.

o nosso mérito foi tentar e conseguir não só isọ lar, como caracterizar o aduto de spin obtido com o captador que se mostrou mais adequado aos estudos microssomais, o POBN. Mais ainda, ao aplicar a nossa abordagem experimental ao meta 
bolismo de dois compostos estruturalmente distintos, O DDEP e a fenelzina, nós demonstramos que o método pode ser geral e deverá ter um grande impacto na utilização da técnica do cap tador de spin em sistemas microssomais, permitindo estudos me canisticos detalhados.

Os nossos próprios estudọ são um exemplo dessas possibilidades. A nossa abordagem experimental foi ampla e per mitiu que pudessemos de fato avançar na interpretação mecanís tica de fenômenos há muito observados e estudados como a formação de corpúsculos de Heinz e hemólise induzidos por fenel zina $(86,117)$, a inativação do citocromo $\mathrm{P}_{450}$ por derivados de hidrazina $(100,101)$ e a inativação suicida da monoamino oxidą se por alquil e arilidrazina (120-124). Pudemos não só demonstrar o envolvimento de radicais de carbono nesses processos como também, determinar algumas das alterações que eles provocam nas biomolēculas envolvidas, tornando-as fisiologica mente inoperantes.

Consideramos também particularmente importante, a nossa demonstração de que os radicais de carbono podem esca par do sitio ativo e reagir com moléculas circundantes ( Esquema 10). Esse tem sido um aspecto importante nas discussões sobre o envolvimento de radicais livres em processos biológicos, havendo uma tendência em se considerar que somente os ra dicais livres de estabilidade intermediária, nem excessivamen te reativos nem excessivamente inertes, seriam capazes de agir em sitios diferentes dos sitios de formação (128). Essa visão geral, aliada às dificuldades de deteção e identificação dos radicais de carbono, levou a que pouca atenção fosse dada às 
interações entre radicais de carbono e biomoléculas. Nossas observações mostram, contudo, que estudos dessas interações se rão fundamentais para a compreensão de vários processos dele térios. 
Uma nova abordagem experimental para a aplicação da técnica do captador de spin em sistemas biológicos é apresentada. Nós demonstramos que o POBN ( $\alpha-(4-p i r i d ̣ i l-1-o ́ x i$ do) N-tercio-butil nitrona) é o captador de spin mais adequado para radicais de carbono formados no sistema microssomal. Outros captadores, 5,5,-dimetil-1-pirrolidina-N-óxido e $\chi$ fenil-N-tercio-butil nitrona, se mostraram inadequados, o último porque inibe fortemente o citocromo $\mathrm{P}_{450}$. Essa constatação nos possibilitou isolar biologicamente e caracterizar,por espectroscopia de massa, o aduto formado durante o metabolismo microssomal de 3,5-bis-(etoxicarbonil)-4-etil-2,6-dimetil1,4-diidropiridina, como sendo o aduto etil-PoBN. Esse isolamento e caracterização de radicais formados metabolicamente, propiciaram uma firme base estrutural para a técnica do cap tador de spin, tornando-a um instrumento bastante útil para a abordagem mecanistica de reações envolvendo radicais livres.

$$
\text { Como um exemplo dessas novas pótencialidades, nōs }
$$
apresentamos nossos estudos sobre o metabolismo da' " fenelzina (2-feniletilidrazina). Esse composto é um agente antidepres sivo conhecido por vários nomes comerciais como Nardil, Fenel zina, Estinerval,Kalgan, etc. O metabolismo da fenelzina por microssomos hepáticos de ratos leva a formação dos seguintes compostos: 2-fenilacetaldeido, 2-feniletanol e etilbenzeno.Du rante esse processo oxidativo, ocorre a formação de um radical de carbono que reage com o grupo prostético do citocromo $\mathrm{P}_{450}$ inativando-o irreversivelmente. Esse radical foi captado, 
isolado e caracterizado como sendo o radical 2-feniletila. A porfirina derivada do grupo heme, inativado pela fenelzina,foi isolada e caracterizada como sendo a $\mathrm{N}$-(2-feniletil) protopor firina IX.

Assim, 'o metabolismo da fenelzina, uma álquilidra zina, forma um radical de carbono que pode inativar o citocro mo $\mathrm{P}_{450}$, ser convertido num hidrocarboneto, reagir com captadores de spin e provavelmente também, pode reagir com biomolé culas circundantes. Esses resultados, analisados conjuntamente com outros estudos mecanísticos que realizamos sobre trans formações biológicas de derivados de hidrazina, são utilizados para uma discussão geral do possível papel de radicais de car bono na expressão dos efeitos terapêuticos e tóxicos de dro gas. 


\section{SUMMARY}

A new experimental approach to the biological ap plication of the spin-trapping technique is presented.Our stu dies showed that POBN ( $\alpha-(4-$ pyridyl-1-oxide) N-tert-butylnitrone) is the most suitable trap for carbon radicals formed in microsomal systems. Other spin traps, 5,5-dimethyl-1-pyr-. roline-N-oxide and $\alpha$-phenyl-N-tert-butylnitrone were found to be ineffective, the latter because it strongly inhibits cy tochrome $\mathrm{P}_{450}$. POBN suitability enabled us to isolate and cha racterize, by mass spectrometry, the adduct formed during the microsomal metabolism of 3,5-bis (ethoxycarbonyl)-4-ethy 1-2,6 -dimethyl -1,4-dihydropyridine, as a POBN-ethyl adduct. The isolation and characterization of metabolically formed radi cals provided a firm structural basis for the spin-trappingme thodology, rendering it a useful tool for the mechanistic approach to reactions involving radical formation.

As an example of these potencialities, we present our studies on phenelzine (2-phenylethylhydrazine) metabolism. This compound is a tranquilizing arug known under a number of commercial names as Nardil, Fenelzina, Estinerval, Kalgan and others. The transformation of phenelzine by rat liver microsomes yields 2-phenylacetaldehyde, 2-phenylethanol and ethylbenzene. A carbon radical is formed during the oxidative metabolism of phenelzine that reacts with the prosthetic heme group of cytochrome $\mathrm{P}_{450}$ and irreversibly inactivates the enzyme. The radical formed has been spin-trapped; isolated and shown by mass spectrometry to be the 2-phenylethyl radical. 
The metal free porphyrin derived from the prosthetic heme group has been isolated and identified as N-(2-phenylethyl)pro toporphyrin IX.

The metabolism of phenelzine, an alkylhydrazine, thus yields a carbon radical that inactivates cytochrome $\mathrm{P}_{450^{\prime}}$ is converted to a hydrocarbon by hydrogen atom abstraction and reacts with spin traps or, presumably, with alternative celu lar targets. These results, together with other mechanistic studies done by us on biological transformations of hydrazine derivatives, are taken into account in the discussion of the possible role of carbon radicals on drug action and toxicity. 


\section{REFERENCIAS BIBLIOGRÁFICAS}

1. Hodgson, E. e Guthrie, F.E. (1980) em"Introduction to Bio chemical Toxicology" ( Hodgson, E. e Guthrie, F.E., eds), pp 1-9, Elsevier, New York.

2. Jakoby, W.B. (1980) em "Enzymatic Basis of Detoxication", (Jakoby, W.B., ed) Vol. I, pp 1-6,Academic Press, New York.

3. Hodgson, E. e Dauterman, W.C. (1980) em "Introduction to Biochemical Toxicology" (Hodgson, E. e Guthrie, F.G.,eds), pp 67-82, Elsevier, New York.

4. Dauterman, W.C. (1980) em "Introduction to Biochemical T으 xicology" (Hodgson, E. e Guthrie, F.G., eds) pp 83-91, EI sevier, New York.

5. Miller, J.A. (1970) Cancer Research 30,559-576.

6. Hinson, J.A., Pohl, L.R. e Gillette, J.R. (1979) Life Sci. $\underline{24}, 2133-2138$.

7. Miner, D.J. e Kissinger, P.T. (1979) Biochem. Pharmacol. $\underline{28}, 3285-3290$.

8. De Pierre, J.W. e Ernster, L. (1980) em "Microsomes, Drug Oxidations and Chemical Carcinogenesis" (Coon, M.J., Esta brook, R.W., Gelboin, H.V., Gillette, J.R. e O'Brien,P.J., eds) pp 431-443, Academic Press, New York.

9. Estabrook, R.W. (1978) Methods Enzymol. 52,43-47 
10. Strittmatter, P. e Enoch, H.G. (1978) Methods Enzymol. $\underline{52}, 188-193$.

11. Master, B.S. (1980) em "Enzymatic Basis of Detoxication" (W.B. Jakoby, ed) Vol I, pp 183-200, Academic Press, New York.

12. Sato, R. e Mihara, K. (1978) Methods Enzymol. 52, 102-108.

13. Ziegler, D.M. e Poulsen, L.L. (1978) Methods Enzymol. 52, 142-151.

14. Ziegler, D.M. (1980) em "Enzymatic Basis of Detoxication" (W.B. Jakoby, ed) Vol I, pp 201-227. Academic Press, New York.

15. White,R.E. e Coon, M.J. (1980) Ann. Rev. Biochem. 49,315356.

16. Sato,R. e Omura, T. (Editores) (1978) "Cytochrome P450", Academic Press, New York.

17. Estabrook, R.W., Waterman, M.R., Dubois, R.N.', Simpson, E.R. e Werringloer, J. (1981) em "Molecular Basis of Drug Action" (Singer, T. e Ondarza, R., eds) pp 361-386.

18. Coon, M.J., Vermilion, J.C., Vatsis, K.P., French, J.S., Dean, W.L. e Haugen, D.A. (1971) em "Drug Metabolism Con cepts" (Jerina, D.M., ed.) pp 46-71. ACS, Washington,DC.

19. Fujii-Kuriyama, Y., Mizukami, Y.,Kawajiri, K., Sogawa,K. e Muramatsu, M. (1982) Proc. Natl. Acad. Sci. U.S.A. 79, 2793-2797. 
20. Yuan, P-M., Ryan, D.E., Levin, W. e Shively, J.E. (1983) Proc. Natl. Acad. Sci. U.S.A. $80,1169-1173$.

21. Heinemann, F.S. e Ozols, J. (1983). J.Biol. Chem. 258, 4195-4201.

22. Nebert, D.W. Eisen, H.J., Negishi M., Lang, M.A., Hjelme land, L.M. e Okey, A.B. (1981). Ann. Rev. Pharmacol. To$\mathrm{xicol} \cdot \underline{21}, 431-462$

23. Lu, A.Y.H. e West, S.B (1980) Pharmacol. Rev. 31,227-295.

24. Estabrook, R.W., Coon, M.J., Sato, R., Conney, A.H.,Gustadsson, J-A., Omura, T. e Nebert, D.W. (1982) em, "Micro somes, Drug Oxidations and Drug Toxicity" (Sato, R. e Ka to, R. eds) pp 3-11, Japan Scientific Press, Tokyo.

25. Conney, A.A., Lu, A.Y.H., Levin, W., Somogyi, A., West, S., Jacobson, M., Ryan, D. e Kuntzman, R̈. (1973) Drug Met. Disp. $1,199-210$

26. Conney, A.H. (1967). Pharmacol Rev. 19,317-366.

27. Omura, T. (1979) em "The Induction of Drug Metabolism" (Estabrook, R.W. e Lindenlaub, E.,eds) pp 161-175, F.K. Schattauer Verlag, Stuttgart- New York.

28. Parke, D.V. (1979) em "The Induction of Drug Metabolism" (Estabrook, R.W. e Lindenlanb, E. eds) pp 101-111, F. K. Schattauer Verlag, Stuttgart-New York.

29. Estabrook, R.W. (1982) em,"Microsomes, Drug Oxidations 
and Drug Toxicity" (Sato, R. e Kato, R. eds) pp 133-138, Japan Scientific Press, Tokyo.

30. Augusto, O., Beilan, H.S. e Ortiz de Montellano, P.R. (1982) J. Biol. Chem. 257,11288-11295.

31. Cramer, S.P., Dawson, J.H., Hodgson, K.O. e Hager, L.P. (1978) J.Am. Chem. Soc. 100,7282-7290.

32. Sligar, S.G. e Gunsalus, I.C. (1979) Biochemistry 18, 2290-2295.

33. Peisach,J., Mims, W.B., Davis, J.L. (1979) J. Biol.Chem. $12.379-12.389$.

34. White, R.E., Coon, M.J. (1982) J. Biol. Chem. 257, 30733083 .

35. Jefcoate, C.R. (1978) Methods Enzymol. $\frac{52}{2}, 258-279$.

36. Bjorken, I. (1977) Pharmac. Ther. A 1,327-348.

37. Guengerich, F.B., Ballou, D.P. e Coon, M.J. (1976) Biochem. Biophys. Res. Commun. 70,951-956

38. Bonfils, C., Debey, P., Maurel, P. (1979) Biochem. Biophỵs. Res. Commun. 88, 130.1-1307

39. Iyanagi, T., Anan, F.K., Imay, Y., Mason, H.S. (1978) Bio chemistry $17,2224-2230$.

40. Oprian, D.D., Vatsis, K.P., Coon, M.J. (1979) J. Biol. Chem. 254, 8895-8902 
41. Rahimtula, A.D., O'Brien, P.J. (1977) Eur. J. Biochem. 77, 201-208

42. Groves, J.T. e Krupes, Jr., W.J. (1979) J. Am. Chem.Soc. $101,7613-7615$

43. Groves, J.T., McClusky, G.A., White, R.E. e Coon, M.J. (1978) Biochem. Biophys. Res. Commun. 81,154-160

44. Groves, J.T., Akinbote, O.F. e Avaria, G.E. (1980) em"Mi crossomes, Drug Oxidations and Chemical Carcinogenesis" (Coon, M.J., Conney, A.H., Estabrook, R.W., Gelboin, H. V., Gillette, J.R. e O'Brien, P.J., eds) pp 253-261,Academic Press, New York.

45. Ortiz de Montellano, P.R., Kunze, K.L., Beilan, H.S. e Wheeler, C. (1982) Biochemistry 21,1331-1339

46. Pryor, W.A. (1976) em "Free Radicals in Biology" (Pryor, W.A., ed) Vol. 1, pp 1-49, Academic Press, New York.

47. Borg, D.C. (1976) em "Free Radicals in Biology" (Pryor, W.A., ed) Vo1.1, pp69-147, Academic Press, New York.

48. Schaich, K.M. e Borg, D.C. (1980) em "Autoxidation in Food and Biological Systems" (Simic, M.G. e Karel,M.,els) pp 45-70, Plenun Press, New York.

49. Yamazaki, I., Mason, H.S. e Piette, L,H. (1960) J. Biol. Chem. 235, 2444-2449

50. Yamazaki, I. e Piette, L.H, (1961) Biochem. Biophýs.Acta $\underline{50}, 62-69$ 
51. Yamazaki, I. e Piette, L.H. (1963) Biochem. Biophys.Acta $\underline{77}, 47-64$

52. Mason, R.P. e Chignell, C.F. (1982) Pharmacol. Revs. 33 , 189-211.

53. Mason, R.P. (1982) em "Free Radicals in Biology" (Pryor, W.A. ed) Vol. 5, pp 161-222,Academic Press, New York.

54- Chalfont, G.R., Perkins, M.J. e Horsfield,A. (1968) J.Am. Chem. Soc. $90,7141-7142$

55. Forshuls, S., Lagercrantz, C. e Torsell, K. (1969) Acta Chem. Scand. 23, $522-530$.

56. Leaver, I.H. e Ramsay, G.C. (1969) Tetrahedron 25, 56695675 .

57. Terabe, S. e Konaka, R. (1969) J. Am. Chem., Soc. 91, 5655-5657.

58. Janzen, E.G. e Blackburn, B.J. (1968) J.Am. Chem. Soc. $\underline{90}, 5909-5910$

59. Janzen, E.G. (1980) em "Free Radicals in Biology" (Pryor, W.A. ed) Vol. 4 , pp 115-151, Academic Press, New York.

60. Perkins, M.J. (1980) Adv. Phys. Org. Chem. 17,1-64

61. Finkelstein, E., Rosen, M. e Rauckman, E.J. (1980) Arch. Biochem. Biophys. $200,1-16$

62. Kalyanaraman, B. (1982) Revs. Biochem. Toxicol. 4, 73-135. 
63. Janzen, E.G. e Ping-Liu, J. (1973) J.Mag. Res. 9,510-512.

64. Janzen, E.G., Evans, C.A., Dàvis, E.R. (1978) em "Organic Free Radicals" (Pryor, W.A. ed), ACS Symposium Series 69, $433-446$.

65. Rosen, G.M., Finkelstein, E. e Rauckman, E.J. (1982) Arch. Biochem. Biophys. $215,367-378$.

66. Adamic, K., Bowman, D.F., Gillan, T. e Ingold, K.U. (1971) J. Am. Chem. Soc. $\underline{93}, 902-908$.

67. Bowman, D.F., Brokenshire, J.L., Gillan, T. e Ingold, K. U. (1971) J. Am. Chem. Soc. 93,6551-6555.

68. Bowman, D.F., Gillan, T. e Ingold, K.U. (1971) J. Am. Chem. Soc. $\underline{93}, 6555-6561$.

69. Evans, A.C. (1979) Aldrichimica Acta 12,23-29.

70. Rosen, G.M. e Rauckman, E.J. (1977) Biochem. Pharmacol. $\underline{26}, 675-678$.

71. Rosen, G.M., Rauckman, E.J. e Hanck, K.W. (1977) Toxicol. Letters $1,71-74$.

72. Mason, R.P., Kalyanaraman, B., Tainer, B.E. e Eling, T. E. (1980) J. Biol. Chem. 255, 5019-5022.

73. Poyer, J.L., McCay, P.B., Lai, E.K., Janzen, E.G. e Davis, E.R. (1980) Biochem. Biophys. Res. Commun. 94,1154-1160.

74. Buettner, G.R. e Oberley, L.W. (1978) Biochem.Biophys. Res. Commun. $13,69-74$. 
75. Gever, G. e Hayes, K. (1949) J. Org. Chem. 14,813-818

76. Ortiz de Montellano, P.R., Beilan, H.S. e Kunze, K.L. (1981) J. Biol. Chem. 256,6708-6713

77. Salach, J.I (79.79) Arch. Biochem. Biophys. 192,128-137.

78. Estabrook, R.W., Peterson, J., Baron, J. e Hildebrandt, A. (1972) Methods Pharmacol. 2,303-350.

79. Ortiz de Montellano, P.R., Beilan, H.S. e Kunze, K.L. (1981) J. Biol. Chem. 256, 4395-4399.

80. Correia, M.A. e Mannering, G.J. (1973) Mol. Pharmacol.9, $470-485$.

81. Nash, T. (1953) Biochem. J. 55, 416-421.

82. Ortiz de Montellano, P.R. e Kunze, K.L. (1980) J. Biol. Chem. $\underline{255}, 5578-5585$.

83. Ortiz de Montellano, P.R. e Kunze, K.L. (1981) Biochemis $\operatorname{try} \cdot \underline{20}, 7266-7271$

84. Knowles, P.F., Marsh, D. e Rattle, H.W.E. (1976) em "Mag netic Resonance of Biomolecules", John Wiley Sons, London, New York.

85. Augusto, O., Ortiz de Montellano, P.R. e Quintanilha, A. (1981) Biochem. Biophys. Res. Commun. 101,1324-1330

86. Augusto, O., Kunze, K.L. e Ortiz de Montellano, P.R. (1982) J.Biol. Chem. 257,6231-6241 
87. Ortiz de Montellano, P.R., Beilan, H.S., Kunze, K.L. e Augusto, O. (1982) em "Microsomes, Drug Oxidations and Drug Tpxicity" (Sato, R. e Kato, R., eds.), pp 381-388, Japan Scientific Press, Tokyo.

88. Werringloer,J.,Estabrook, R.W. (1975) Arch.Biochem. Biophys. $167,270-286$.

89. Juchan, M.R. e Horita, A. (1972) Drug Metab. Revs. 1,71100 .

90. Goodman, L,S. e Gilman, A. (eds) (1975) The Pharmacologi cal Basis of Therapeutics, Fifth Edition, Mcmillan Publishing Co., New York.

91. Nelson, S.D., Mitchell, J.R., Timbrell, J.A., Snodgrass, W.R. e Corcoran, G.B. (1976) science 193,901-903.

92. Williams, G.M., Mazue, G., McQueen, C.A. e Shimada, T. (1980) Science 210,329-330.

93. Dubroff, L.M. e Reid, R.J. (1980) Science, 208,404-406.

94. Toth, B. (1976) Cancer Res. $36,917-921$.

95. Daneshmend, T.K., Scott, G.L. e Bradfield, J.W.B. (1979) Brit. Med. J. 1,1679-1682.

96. Mitchell, J.R., Nelson, S.D., Thorgeirsson, S.S., McMurtry, R.J., e Dybing, E. (1976) in "Progress in Liver Diseases", Vol. 5 (Popper, H. e Schaffner, F., eds)pp 259279, Grune e Stratton, New York. 
97. Kato, R., Tanaka, A. Shoji, H. (1969) Jap. J. Pharmacol. $19,315-322$.

98. Muakassah, S.F., Bidlack, W.R. e Yang, W.C.T. (1981) Bio chem. Pharmacol. $30,1651-1658$.

99. Hara, S., Satoh, T. e Kitagawa, H. (1982) Res. Commun. Chem. Pathol. Pharmacol. $36,260-272$.

100. Jonen, H.G., Werringloer, J., Prough, R.A. e Estabrook, R.W. (1982) J. Biol, Chem: 257, 4404-4411.

101. Muakkassah, S.F. e Yang, W.C.T. (1981) J. Pharm. Exp.The rap. $219,147-155$

102. Caddy, B., Stead, A.H. e Johnstone, E.C. (1978) Br. J. Clin. Pharmacol. $\underline{6}, 185-188$.

103. Clineschmidt, B.V. e Horita, A. (1969) Biochem. Pharmacol. $18,1021-1028$.

104. Clineschmidt, B.V. e Horita, A. (1969) Biochem. Pharmacol. $18,1011-1020$.

105. Tipton, K.F. e Spires, I.P.C. (1972) Biochem. Pharmacol. $\underline{21}, 268-270$.

106. Tilstone, W.J., Margot, P. e Johnstone, E.C. (1979) Psychopharmacology $60,261-263$.

107. Costa, A.K. e Ivanetich, K.M, (1982) Biochem. Pharmacol. 31, 2093-2102.

108. Walsh, C. (1982) Tetrahedron. 38,871-909. 
109. Kunze, K.L. e Ortiz de Montellano, P.R. (1981) J. Am. Chem. Soc. $103,4225-4230^{\circ}$.

110. Ortiz de Montelitano, , P.R., Beilan, H.S., Kunze, K.L. e MiCo, B.A. (1981) J. Biol. Chem. 256,4395-4399.

111. Castro, C.E., Wade, R.S. e Belser, N.O. (1978) Biochemis $\operatorname{try} 17,225-231$

112. Aebi, H., Dewald, B. e Suter, H. (1965) Helv. Chim. Acta $\underline{48}, 656-674$.

113. Prough, R.A., Wittkop, J.A. e Reed, D.J. (1969) Arch. Biochem. Biophys. $131,369-373$.

114. Prough, R.A., Freeman, P.C. e Hines, R.N. (1981) J. Biol, Chem. 256, 4178-4184.

115. Kosower, E.M. (1958). J. Am. Chem, Soc, $\underline{80}, 3253-3260$.

116. Ito, M e Hata, N. (1955) Bull. Chem, Soc, Japan 28,260263.

117. Ortiz de Montellano, P.R., Kunze, K.L, e Augusto, O. (1982) J. Am. Chem. Soc. 104,3545-3546.

118. Ortiz de Montellano, P.R. e Kunze, K.L. (1981) J. Am, Chem. Soc, 103, 6534-6536.

119. Saito, S. e Itano, H.A. (1981) Proc. Natl. Acad. Sci. U.S.A. 78, $5508-5512$.

120. Singer, T.P. (1979) em "Monoamine Oxidase: Structure Func tion, and Altered Functions" (Singer, T.P.,Von Korff, R. 
W. e Murphy, D.L., eds) pp.7-24, Academic Press, New York.

121. Singer, T.P. e Salach, J.I. (1981) em "Monoamine Oxidase Inhibitors - The State of the Art" (Youdim, M.B.H. e Pay kel, E.S.) pp.17-29, John Wiley \& Sons Ltd, New York.

122. Nagy, J. Kenney, W.C. e Singer, T.P. (1979) J. Biol.Chem. $\underline{254}, 2684-2688$.

123. Kenney, w.C., Naggy, J., Salach, J.I. e Singer, T.P. (1979) em "Monoamine Oxidase: Structure, Function and AI tered Functions" ( Singer, T.P., Von korff, R.W.e Murphy, D.L., eds) pp.25-37, Academic Press, New York.

124. Patek, D.R. e Hellerman, L. (1974) J. Biol. Chem. 249, $2373-2380$.

125. Tsuji, T. e Kosower, E.M. (1971) J. Am: Chem. Soc. 93, 1992-1999.

126. Trush, M.A., Mimnaugh, E.G. e Gram, T. (1982) Biochem. Pharmacol. $31,3335-3346$.

127. Albano, E. Lott, K.A.K., Slater, T.F., Stier, A., Symons, M.C.R. e Tomasi, A. (1982) Biochem. J. 204,593-603.

128. Swartz, H.W. (1982) em "Free Radicals, Lipid Peroxidation and Cancer" (McBrien, D.C.H. e Slater, T.F., eds) pp. 526, Academic Press, New York. 